NBER WORKING PAPER SERIES

\title{
INTERNATIONAL PORTFOLIO DIVERSIFICATION AND MULTILATERAL EFFECTS OF CORRELATIONS
}

\author{
Paul R. Bergin \\ Ju Hyun Pyun \\ Working Paper 17907 \\ http://www.nber.org/papers/w17907
NATIONAL BUREAU OF ECONOMIC RESEARCH
1050 Massachusetts Avenue
Cambridge, MA 02138
March 2012

Previously circulated as "Multilateral Resistance to International Portfolio Diversification." We are grateful to Robert Feenstra for valuable suggestions. We also thank Colin Cameron, Chris Changwha Chung, Jaiho Chung, Kuk Mo Jung, Jinill Kim, Minsik Kim, Yuan Liu, Gabe Mathy, Chris Meissner, Jungbien Moon, Kevin Salyer, Liugang Sheng, Ina Simonovska, Nick Zolas and seminar participants at UC Davis Brown bag, INFINITI conference, KIEP, Korea University, Korea University Business School, UNIST for helpful comments. The views expressed herein are those of the authors and do not necessarily reflect the views of the National Bureau of Economic Research.

NBER working papers are circulated for discussion and comment purposes. They have not been peerreviewed or been subject to the review by the NBER Board of Directors that accompanies official NBER publications.

(C) 2012 by Paul R. Bergin and Ju Hyun Pyun. All rights reserved. Short sections of text, not to exceed two paragraphs, may be quoted without explicit permission provided that full credit, including $\mathbb{C}$ notice, is given to the source. 
International Portfolio Diversification and Multilateral Effects of Correlations

Paul R. Bergin and Ju Hyun Pyun

NBER Working Paper No. 17907

March 2012, Revised December 2014

JEL No. F36,F41,G11,G15

\begin{abstract}
Not only are investors biased toward home assets, but when they do invest abroad, they appear to favor countries with returns more correlated with home assets. Often attributed to a preference for familiarity, this 'correlation puzzle' further reduces effective diversification. However, a multi-country DSGE model of portfolio choice makes clear that the effects of a bilateral stock return correlation must be studied in the context of the full covariance structure. For example, the attractiveness of a foreign country as a hedge depends upon its hedging potential relative to other potential destination countries. This paper develops a new empirical approach based upon a multi-country theoretical model that controls for the full covariance structure in a theoretically rigorous yet tractable manner. Estimation under this approach overturns the correlation puzzle, and finds that international investors do seek the diversification benefits of low cross-country correlations as theory would predict. Since covariances are central to modern theories of portfolio choice, this empirical methodology should be useful also for other applications.
\end{abstract}

\author{
Paul R. Bergin \\ Department of Economics \\ University of California, Davis \\ One Shields Ave. \\ Davis, CA 95616 \\ and NBER \\ prbergin@ucdavis.edu \\ Ju Hyun Pyun \\ Department of Economics \\ University of California, Davis \\ One Shields Ave. \\ Davis, CA 95616 \\ jpyun@ucdavis.edu
}




\section{Introduction}

Home bias in equities is a longstanding puzzle in international finance: investors on average prefer to hold too large a share of their portfolios in domestic assets, given the diversification benefits of assets abroad. ${ }^{1}$ Further, even when investors diversify abroad, evidence suggests that they prefer countries with a high correlation in returns to their home country. ${ }^{2}$ Because a high correlation lowers diversification potential, this behavior compounds investor losses from home bias. Some researchers have explained this second anomaly, termed the 'correlation puzzle,' as a preference for familiarity when investing abroad. ${ }^{3}$

This paper argues that resolving the correlation puzzle requires a multi-country perspective, both theoretically and empirically. General equilibrium asset-pricing models have become widespread in international macro-finance research, with the development of higherorder approximation techniques. ${ }^{4}$ However, these models are generally two-country frameworks which permit analysis of the first anomaly of home bias—-whether to invest abroad—but do not permit analysis of the second anomaly — where to invest abroad. ${ }^{5}$

The main theoretical implication of an N-country general equilibrium framework is that the optimal share of country $i$ 's portfolio in the assets of a foreign country $j$ depends not just on the correlation of returns between countries $i$ and $j$, but also on the broader set of correlations with other countries. Attempts to estimate the effect of the bilateral correlation on portfolio shares must adequately control for the correlations with all other countries. As one example,

\footnotetext{
${ }^{1}$ See French and Poterba (1991); Coeurdacier and Rey (2011).

${ }^{2}$ See Aviat and Coeurdacier (2007); Coeurdacier and Guibaud (2011).

${ }^{3}$ See Huberman (2001); Barberis and Thaler (2004).

${ }^{4}$ See Devereux and Sutherland (2011) and Tille and van Wincoop (2010) for a discussion of methodology, as well as Engel and Matsumoto (2006), and Evans and Hnatkovska (2007) for applications. Stockman and Dellas (1989), Obstfeld and Rogoff (2000), and Coeurdacier (2009) explain portfolio allocation with trade cost and non-tradable goods. Martin and Rey (2004) and Heathcote and Perri (2004) show portfolio choice by invoking a transaction cost or tax on international financial asset trade.

${ }^{5}$ The few papers that model more than two countries in general equilibrium tend to assume the countries are symmetric and have independent returns, such as Baxter, Jermann and King (1998), so these cannot study the choice of investors between alternative destination countries. Okawa and van Wincoop (2012), discussed further below, develop a multi-country model where financial frictions drive portfolio choice among countries. They also consider an extension with a general covariance structure, but their focus is on the role of financial frictions rather than heterogeneous correlations. Further they conclude that an estimable equation can be derived only for the special case of zero cross-country correlations, which clearly precludes study of the "correlation puzzle." The idea of considering heterogeneous correlations across multiple assets or countries is longstanding in classic finance theory such as the Capital Asset Pricing Model (CAPM). However our model differs in key respects. CAPM presumes that investors take a diversified portfolio, so that it only considers correlations of an asset with the diversified market portfolio. In contrast, our model studies the choice among foreign assets in a context that is consistent with overall home bias in the portfolio. Another key difference is that we take a general equilibrium approach in solving the portfolio model.
} 
suppose the stock return correlation between France and Spain were higher than that between New Zealand and Australia. One might predict less asset diversification between France and Spain than between New Zealand and Australia, because the higher return correlation implies a lower diversification benefit. However, it may be that France has even higher correlations with the other countries surrounding it in Europe that would be an alternative to Spain for diversification, so it might make sense for France to purchase assets in Spain because of the relatively lower correlation compared to the alternatives. Hence, we may find a positive relationship between stock return correlation and bilateral asset holdings when we focus on only the bilateral relationship between country $i$ and $j$ without controlling for the correlations with other countries. ${ }^{7}$

We use the N-country general equilibrium model to derive an estimation equation that controls for the overall covariance structure in a theoretically rigorous yet tractable manner. The idea is to extend the use of a second order Taylor approximation, widely used for dealing with the nonlinear Euler equations in portfolio models, to take a second order approximation of the overall portfolio solution as well. We choose for the point around which to construct the approximation a point that exhibits symmetry across countries. It turns out that in this case the proliferation of covariances implied by the covariance matrix in the portfolio solution of an $\mathrm{N}$ country model collapses down to three key average covariances: the covariance between source and destination country, the average covariance between source and other potential destination countries, and the average covariance between the destination and other counties. This means that the aspects of the full covariance matrix relevant to a second order approximation of the portfolio solution can be summarized by adding three new covariance terms to the empirical regression.

Estimates of coefficients in this equation provide a resolution to the correlation puzzle above. In the absence of the recommended controls, where the only covariances included are the bilateral covariances between source and destination, estimation reflects the puzzle by predicting a preference for high correlations. But the sign in the bilateral correlation reverses when including the other covariance terms recommended by our theoretical derivation. In particular, controlling for the covariances with other potential destinations, investors prefer countries which

\footnotetext{
${ }^{7}$ In the international trade literature, an analogous N-country effect was discussed by Anderson and van Wincoop (2003, 2004) with respect to how trade costs affect trade flows.
} 
offer the diversification benefits of low covariance with home equity returns. Our empirical results are robust after controlling for other familiarity factors from previous literature, such as distance, border, common language, etc, as well as controlling for legal restrictions on capital market openness.

Our theoretical model is similar to that of Okawa and van Wincoop (2012), and we agree with their critique of attempts to estimate with an ad hoc and incomplete specification of the covariance structure. However, we go on to propose an empirical methodology that can satisfy this critique and deal with correlations in a theoretically rigorous yet tractable manner. We hope that this methodology also will be useful to other researchers. Covariances are central to modern theories of portfolio choice, and the correlation puzzle we study provides one example where international covariances are essential to the problem, and where an empirical methodology to deal with them clearly is needed.

Coeurdacier and Guibaud (2011) offer an alternative explanation for the correlation puzzle, based upon the endogeneity of correlations. Our results are robust to controlling for endogeneity, and also suggest the two explanations are complementary. ${ }^{8}$

Section 2 introduces the $\mathrm{N}$ country portfolio choice model with full covariance structure and presents simulations of a 3-country version of the model for intuition. It also derives the theoretically-based empirical equation. Section 3 describes data, with empirical results presented in section 4. Concluding remarks follow.

\section{Theory}

\subsection{An $\mathrm{N}$ country, $\mathrm{N}+1$ Asset Model}

The model builds upon the two-country model of Devereux and Sutherland (2011), but expands to an N-country setting, with non-zero covariance structure on incomes. Consider a consumer’s dynamic optimization problem below.

\footnotetext{
${ }^{8}$ While the instrumental variable approach of Coeurdacier and Guibaud (2011) is effective in resolving the puzzle in their results, we find that this explanation is sensitive to the specification of the instrument as non-time varying. An alternative but also conventional specification of the instrument using one-period lags of the correlation does not effectively resolve the puzzle on its own. Further, the instrument used in Coeurdacier and Guibaud, a non-time varying correlation from a period before the sample, resembles the country-pair fixed effects in some of our specifications, which our theoretical derivation shows may also indirectly help control for multilateral effects of correlations.
} 


$$
\begin{gathered}
\max E_{t} \sum_{k=1}^{\infty} \beta^{k} U_{i, t+k} \quad \text { for } i=1, \ldots, N . \\
\text { s.t. } W_{i, t}=\sum_{j=1}^{N} \alpha_{j i, t-1} R_{j, t}+\alpha_{f i t-1} R_{f, t}+Y_{i, t}-C_{i, t} \\
\text { where } U_{i, t+k}=\frac{C_{i, t+k}^{1-\gamma}}{1-\gamma} \text { and } W_{i, t}=\sum_{j=1}^{N} \alpha_{j i, t}+\alpha_{f i t}
\end{gathered}
$$

where $Y_{i, t}$ is the endowment received by country $i, W_{i, t}$ is the total net claims of country $i$ 's agent on all foreign countries at the end of period $t$ (i.e. net foreign assets of country $i$ ), $\alpha_{j i, t}$ is the real holdings of country $j$ 's assets by country $i$, and $R_{j, t}$ is the gross real returns of country $j$ 's assets. We introduce an independent risk-free asset, $R_{f, t}$, as a risk-free bond that is in zero net supply, as this simplifies derivation of an empirical specification later. ${ }^{9}$

A country's output, $Y_{i t}$, follows the process

$$
\log Y_{i, t}=\log \bar{Y}_{i, t}+\varepsilon_{i, t} \text { for } \mathrm{i}=1,2,3, \ldots, N \text {. }
$$

where i.i.d. shocks are correlated across countries:

$$
\left(\begin{array}{c}
\varepsilon_{1, t} \\
\vdots \\
\varepsilon_{N, t}
\end{array}\right) \sim N\left(\left(\begin{array}{c}
0 \\
\vdots \\
0
\end{array}\right), \Omega\right) \text { where } \Omega=\left(\begin{array}{ccc}
\sigma_{11} & \cdots & \sigma_{1 N} \\
\vdots & \ddots & \vdots \\
\sigma_{1 N} & \cdots & \sigma_{N N}
\end{array}\right) \text {. }
$$

The assets are assumed to be one-period equity claims on the home and foreign endowments, with the real payoff to a unit of the equity of country $i$ in period $t$ defined to be $Y_{i, t}$. The real price of a unit of the equity of country $i$ is denoted as $Z_{i, t-1}^{E}$. Thus, the gross real rate of return on the equity of country $i$ is

$$
R_{i, t}=\frac{Y_{i, t}}{Z_{i, t-1}^{E}} \text { for } i=1, \ldots, N .
$$

\footnotetext{
${ }^{9}$ We assume a risk-free bond in the same manner of Okawa and van Wincoop (2012). This assumption can be justified by the existence of nearly risk-free assets such as insured bank deposits or government bonds. Above all, the assumption is useful to derive an empirical specification for equity holdings. Without the risk-free asset as an anchor asset, the optimal equity holdings would depend additively on the expected returns on all equity, thus making it harder to derive a simple form of empirical specification. Note that our real risk-free bond is not related to exchange rate risk. While a bond is used to allow for hedging exchange rate risk in recent studies, Coeurdacier and Gourinchas (2011) argue that equity holdings are not driven by real exchange rate risk, and Engel and Matsumoto (2009) show similar results in a specific model with nominal rigidities.
} 
The price of risk-free bond is denoted as $Z_{t-1}^{f}$, and the real rate of return on the asset $f$,

$$
R_{f, t}=\frac{1}{Z_{t-1}^{f}}
$$

Previous studies such as Kang and Stulz (1997) and van Nieuwerburgh and Veldkamp (2009) emphasized the role of information asymmetry on portfolio choice. We follow Okawa and van Wincoop (2012), and introduce this information friction into risk factor (variance of returns). Domestic agents are more informed than foreigners about idiosyncratic payoff ‘innovations’ on domestic equity claims due to differences in language and financial system. So, from the perspective of agents in country $i$ considering an asset in a foreign country $j, \varepsilon_{i, t}$ has a mean of 0 and variance $\tau_{i j} \sigma_{j j}$ where $\tau_{i j}>1$. Equity home bias in our model arises from this information asymmetry.

Combine FOCs on $N$ assets for country $i$, and write them in terms of the excess return of country j's asset, $\left(R_{j, t}-R_{f, t}\right)$

$$
E\left[C_{i, t+1}^{-\gamma} \cdot\left(R_{j, t+1}-R_{f, t+1}\right)\right]=0 \quad \text { for } j=1,2,3, . . N \text {, }
$$

where a risk-free bond, $f$ is used as a numeraire, so $\left(R_{N, t}-R_{f, t}\right)$ measures the "excess return" on asset $\mathrm{N}$. Assets are assumed to be in zero net supply, so market clearing in the asset market implies

$$
\alpha_{j 1, t}+\alpha_{j 2, t}+\cdots+\alpha_{j N, t}=0 \quad \text { for } j=1,2,3, . ., N .
$$

For the risk-free bond, $f$,

$$
\alpha_{f, t}=0
$$

Equilibrium consumption plans must satisfy the resource constraint,

$$
C_{1, t}+C_{2, t}+\cdots+C_{N, t}=Y_{1, t}+Y_{2, t}+\cdots+Y_{N, t} .
$$

Denote with $(\wedge)$ the $\log$ deviations of the variables from the steady state equilibrium: $\hat{x} \equiv\left(\frac{x-\bar{x}}{\bar{x}}\right)$ where $\bar{x}$ is the value at the equilibrium. To solve for portfolio holdings, we follow the approach of Devereux and Sutherland (2011) and Tille and van Wincoop (2009). A firstorder approximation of the non-portfolio equations (equations (2) for each $\mathrm{N}$ country) and a 
second-order approximation of the Euler equations are needed to express the zero-order component $(\bar{x})$ of equilibrium portfolios. For simplicity, we assume that $\mathrm{N}$ countries' nonstochastic steady state of wealth is equal to zero $(\bar{W}=0)$

$$
\bar{\alpha}_{1, i}+\bar{\alpha}_{2, i}+\cdots+\bar{\alpha}_{N, i}=0 \quad \text { for } i=1, \ldots, N . \quad \text { and } \quad \bar{\alpha}_{f}=0 .
$$

A first-order approximation of a country $i$ ’s budget constraint, equation (2), implies ${ }^{10}$

$$
\hat{W}_{i, t+1}=\sum_{j=1}^{N} \tilde{\alpha}_{j i}\left(\hat{R}_{j, t+1}-\hat{R}_{f, t+1}\right)+\hat{Y}_{i, t+1}-\hat{C}_{i, t+1} .
$$

where $\hat{W}_{i, t}=\left(W_{i, t}-\bar{W}\right) / \bar{C}$ and $\tilde{\alpha}_{j i}=\bar{\alpha}_{j i} /(\bar{\beta} \bar{Y}) \cdot{ }^{11}$

Take a second-order approximation of the country $i$ 's portfolio condition, (6), to yield

$$
E_{t}\left[\hat{R}_{j, t+1}-\hat{R}_{f, t+1}+\frac{1}{2} \hat{R}_{j, t+1}^{2}-\frac{1}{2} \hat{R}_{f, t+1}^{2}\right]=\gamma \cdot E_{t}\left[\hat{C}_{i, t+1}\left(\hat{R}_{j, t+1}-\hat{R}_{f, t+1}\right)\right] \text { for } j=1, \ldots, N .
$$

From $N$ equations of (6') for country $i$, we make pairs between country $i$ and $k$, and derive $N(N-1)$ equations like below

$$
E_{t}\left[\left(\hat{C}_{i, t+1}-\hat{C}_{k, t+1}\right)\left(\hat{R}_{j, t+1}-\hat{R}_{f, t+1}\right)\right]=0 \quad \text { for } j=1, \ldots, N \text {, and } i, k=1, \ldots N, k \neq i .
$$

The first order accurate solution for $\left(\hat{C}_{i, t+1}-\hat{C}_{k, t+1}\right)$ is also straightforward to derive from (2'). Substitute it into (10), and the first-order accurate behavior of $\hat{R}_{j, t+1}-\hat{R}_{f, t+1}$ is particularly simple in this model. First-order approximations of (4) and (5) imply $\hat{R}_{j, t+1}-\hat{R}_{f, t+1}=\hat{Y}_{j, t+1}+O\left(\varepsilon^{2}\right)$ (See Appendix A).

Hence, the distribution of first order components of excess equity returns follows that of first order components of output:

$$
\left(\begin{array}{c}
\hat{R}_{1, t+1}-\hat{R}_{f, t+1} \\
\hat{R}_{2, t+1}-\hat{R}_{f, t+1} \\
\vdots \\
\hat{R}_{N, t+1}-\hat{R}_{f, t+1}
\end{array}\right) \sim N\left(\begin{array}{c}
0 \\
0 \\
\vdots \\
0
\end{array}\right)\left(\begin{array}{cccc}
\sigma_{11} & \sigma_{12} & \cdots & \sigma_{1 N} \\
\sigma_{21} & & & \sigma_{2 N} \\
\vdots & & \ddots & \vdots \\
\sigma_{N 1} & \sigma_{N 2} & \cdots & \sigma_{N N}
\end{array}\right)
$$

${ }^{10}$ Because $\bar{\alpha}_{f}=0$ and $\sum_{j=1}^{N} \tilde{\alpha}_{j i} \hat{R}_{f, t+1}=\hat{R}_{f, t+1} \sum_{j=1}^{N} \tilde{\alpha}_{j i}=0$

${ }^{11}$ The zero-order components of asset returns are imposed as $\bar{R}_{i}=\bar{R}_{f}=\frac{1}{\bar{\beta}}(i=1,2, . . N)$. 
However, perceived variances of asset returns differ among countries due to information asymmetry. For instance, an agent in country 1 faces

$$
\left(\begin{array}{c}
\hat{R}_{1, t+1}-\hat{R}_{f, t+1} \\
\hat{R}_{2, t+1}-\hat{R}_{f, t+1} \\
\vdots \\
\hat{R}_{N, t+1}-\hat{R}_{f, t+1}
\end{array}\right) \sim N\left(\left(\begin{array}{l}
0 \\
0 \\
\vdots \\
0
\end{array}\right), \Omega_{1}\right) \text { where } \Omega_{1} \equiv\left(\begin{array}{cccc}
\sigma_{11} & \sigma_{12} & \cdots & \sigma_{1 N} \\
\sigma_{21} & \tau_{12} \sigma_{22} & & \sigma_{2 N} \\
\vdots & & \ddots & \vdots \\
\sigma_{N 1} & \sigma_{N 2} & \cdots & \tau_{1 \mathrm{~N}} \sigma_{\mathrm{NN}}
\end{array}\right)
$$

Based on equation (10), we construct a matrix system to express the equity holdings (See Appendix B).

$$
\begin{gathered}
\Pi A=B \\
A=\Pi^{-1} B .
\end{gathered}
$$

where $A$ is an $N^{2} \times 1$ vector of equity holdings, $B$ is an $N^{2} \times 1$ vector which consists of the variance and covariance of the excess stock returns, and $\Pi$ is an $N^{2} \times N^{2}$ matrix (see Appendix B for a representation of the $\Pi$ matrix).

While a full analytical solution to this system is not possible, (11) makes clear our main point that portfolio holdings in $(A)$ depend upon the full set of covariances among all countries, contained in the inverse of the full covariance matrix $\left(\Pi^{-1}\right)$, rather than just the bilateral covariance of a given source country and a given destination country. This point will be demonstrated further below.

\subsection{Numerical Simulations}

Given that the system with general covariances is too complex to support analytical solutions, we demonstrate some key properties of the solution using numerical experiments. Consider a three country version of the model $(N=3)$. See Appendix $C$ for an explanation of the full model solution.

The input to the simulation consists of information asymmetry parameter, $\tau_{i}$ and a $3 \times 3$ covariance matrix among capital returns across countries, $\Omega_{3 \times 3}$. For illustration, we assume a uniform unit variance for all assets, and a uniform expected return for all assets, and choose values of the information cost $\tau=1.3$ when $j \neq i, \tau=1$ when $j=i$. The output consists of the $3 \times 3$

transformed equity share matrix, $\tilde{A}_{3 \times 3}$. To help provide economic intuition, define each 
component of matrix $\widetilde{A}_{3 \times 3}$ as the ratio of country $j$ 's equities held by country $i$ to total equities of country $i\left(\frac{\bar{\alpha}_{j i}}{\bar{\beta} \bar{Y}_{i}}=\tilde{\alpha}_{j i}\right)$, where $\bar{\beta} \bar{Y}_{i}$ is the total value of equity of country $i(i=1,2,3)$ in our simulations. We add 1 (endowment itself) to the domestic equity holdings; thus, the sum of equity holdings of each country is equal to 1 .

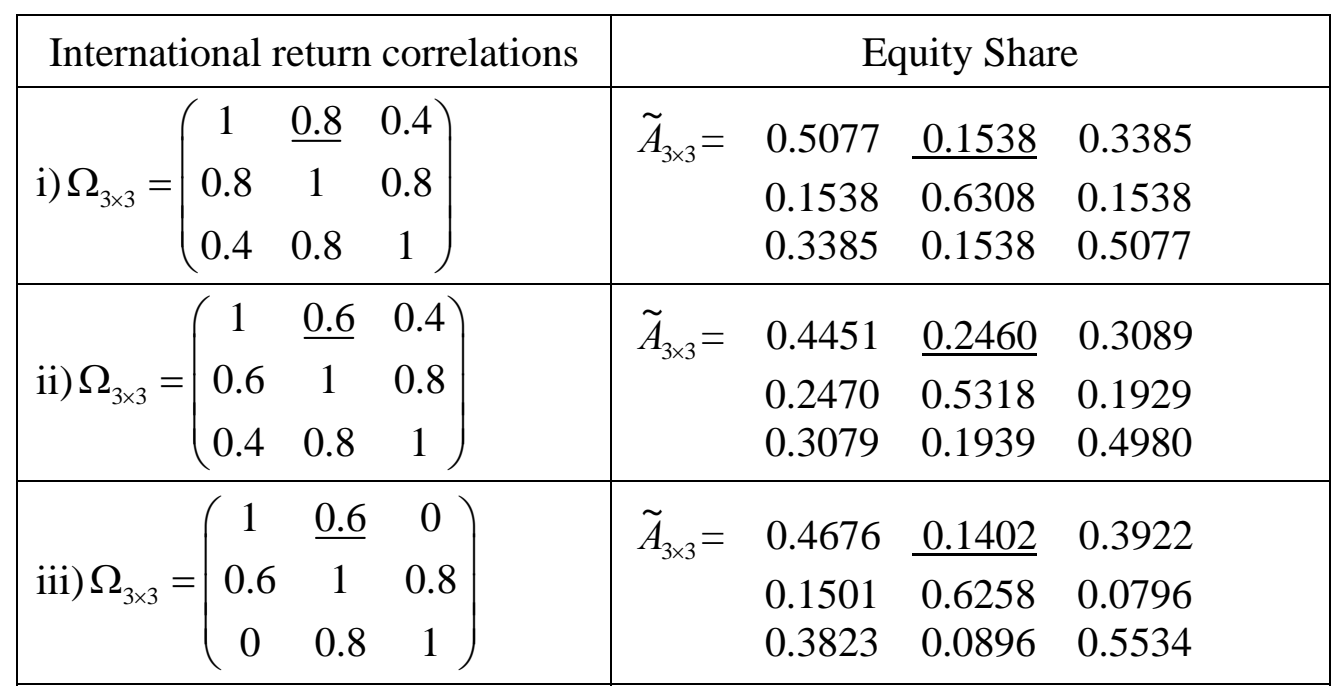

The simulation illustrates three key properties of the portfolio solution. First, the bilateral equity holding between two countries is positively affected by a fall in the bilateral stock return correlation. This property is apparent when comparing cases (i) and (ii) in the table above in regard to the relationship of countries 1 and 2: a fall in the correlation $\sigma_{12}$ from 0.8 to 0.6 raises equity holdings $\tilde{A}_{3 \times 3}(1,2)$ from 0.154 to 0.246 . A second lesson is that a bilateral equity holding between two countries is negatively affected by a fall in the bilateral stock return correlation of one of the countries with a third country. This property is apparent when comparing cases (ii) and (iii) in the table above: a fall in the correlation between countries 1 and 3 from 0.4 to 0 lowers the equity holdings between countries 1 and 2 from 0.246 to 0.14 . Combining these two experiments and comparing case (i) to (iii) illustrates the main claim of the paper, that bilateral asset shares can appear to violate the first lesson above, so that higher correlations sometimes are associated with higher rather than lower asset holdings. But these cases reflect third country effects, and they are still consistent with a portfolio that maximizes hedging benefits. Finally, we 
note that the degree of home bias ${ }^{12}$ (represented in element $\tilde{A}_{3 \times 3}(1,1)$ ) affected the full set of international correlations in this model: an improvement in the opportunities for diversification as represented by a fall in one or more bilateral correlations leads to a fall in the degree of home bias in home equities.

Finally, we summarize a more comprehensive set of simulations of the 3-country model to more broadly characterize the partial derivatives of portfolio share with respect to bilateral and third-country correlations. ${ }^{13}$ Figure 1 reports the derivatives of the portfolio share held by country 1 of country 2 equities with respect to the covariance of bilateral returns between countries 1 and 2 and the third-country covariance between country 1 and 3 . As in the simulations above, we calibrate $\tau=1.3$, but we consider a range of values for the covariance $\sigma_{23}$ do demonstrate robustness. The figure shows that portfolio holdings are everywhere monotonically decreasing in bilateral correlation between source and destination countries $\left(\frac{\partial \tilde{\alpha}_{21}}{\partial \sigma_{12}}<0\right)$, and they are everywhere rising in correlation between source country and a third country $\left(\frac{\partial \tilde{\alpha}_{21}}{\partial \sigma_{13}}>0\right)$.

\subsection{Derivation of Estimation Equation}

The theoretical model makes clear that an empirical equation explaining bilateral equity holdings should account not just for the covariance between source and destination country, but also the broader covariance structure. However, the matrix algebra for portfolios in equation (11) of an $\mathrm{N}$ country model does not produce a linear empirical specification for equity asset holdings. ${ }^{14}$ We derive an estimable equation by taking a second order Taylor approximation. Given that a second order approximation was already employed to derive the Euler equation (6')

\footnotetext{
${ }^{12}$ For present purposes we define the term home bias as the degree to which the share of home assets in the home portfolio exceeds the share of home market capitalization in the world market.

${ }^{13}$ Analytical derivatives are not possible in our N-country general equilibrium setting. In contrast with the model of Coeurdacier and Guibaud (2011), third-country correlations affect also the degree of overall home bias, which complicates the task of assigning a sign to partial derivatives. While we are able to generate analytical expressions for these derivatives with the aid of computer software, the expressions are extremely long and impossible to sign, even in the case of $N=3$.

${ }^{14}$ As shown in Okawa and van Wincoop (2012), a model with a general covariance structure does not imply an estimation equation that is a true gravity equation, in which bilateral asset holdings are the product of country specific variables and a bilateral friction.
} 
used in constructing (11), taking a second order Taylor approximation of the resulting equation (11) is a simple extension of this methodology, and is a logical approach to deriving a reasonable approximation to the theory that both captures the key predictions and is amenable to estimation.

The equity share solution for a source country $i$ in an N-country world is written as follows (see Appendix D for derivation),

$$
A_{(i)}=\Omega_{i}^{-1} H
$$

where

$$
A_{i i}=\left(\begin{array}{c}
\tilde{\alpha}_{1 i} \\
\tilde{\alpha}_{2 i} \\
\vdots \\
\tilde{\alpha}_{N i}
\end{array}\right), H=\left(\begin{array}{c}
E X_{1} \\
E X_{2} \\
\vdots \\
E X_{N}
\end{array}\right)=\left(\begin{array}{c}
\frac{1}{\gamma} E_{t}\left[\hat{R}_{t+1}-\hat{R}_{f t+1}+\frac{1}{2}\left(\hat{R}_{t t+1}^{2}-\hat{R}_{f t+1}^{2}\right)\right] \\
\frac{1}{\gamma} E_{t}\left[\hat{R}_{2 t+1}-\hat{R}_{f t+1}+\frac{1}{2}\left(\hat{R}_{2 t+1}^{2}-\hat{R}_{f t+1}^{2}\right)\right] \\
\vdots \\
\frac{1}{\gamma} E_{t}\left[\hat{R}_{N t+1}-\hat{R}_{f t+1}+\frac{1}{2}\left(\hat{R}_{N t+1}^{2}-\hat{R}_{f t+1}^{2}\right)\right]
\end{array}\right), \Omega_{i}=\left(\begin{array}{cccc}
\tau \sigma_{11} & \sigma_{12} & \cdots & \sigma_{1 N} \\
\sigma_{12} & \tau \sigma_{22} & \cdots & \sigma_{2 N} \\
\vdots & \vdots & \sigma_{i i} & \vdots \\
\sigma_{1 N} & \sigma_{2 N} & \cdots & \tau \sigma_{N N}
\end{array}\right) .
$$

Multiply by $\beta Y_{i}$ to change units from portfolio share to total equity holdings:

$$
\bar{A}_{i}=\beta Y_{i} \cdot \Omega_{i}^{-1} H
$$

where $\bar{\alpha}_{j i}=\tilde{\alpha}_{j i} \bar{\beta} \bar{Y}_{i}$ and $\bar{A}=\left(\begin{array}{c}\bar{\alpha}_{1 i} \\ \bar{\alpha}_{2 i} \\ \vdots \\ \bar{\alpha}_{N i}\end{array}\right)$,

This puts our left hand side variable in the usual units of the dependent variable from previous empirical studies of the correlation puzzle, which will facilitate comparison of our results with the existing literature. Now consider the equity holdings of the source country $i$ in a particular destination country $j$,

$$
\bar{\alpha}_{j i}=\frac{\beta}{\gamma} Y_{i} \sum_{k=1}^{N}\left(\Omega_{i}^{-1}\right)_{(j, k)} E\left[\hat{R}_{k}-\hat{R}_{f}+\frac{1}{2}\left(\hat{R}_{k}^{2}-\hat{R}_{f}^{2}\right)\right]
$$

Next, take a second-order Taylor approximation of (13) with respect to all terms. For the point around which we construct the approximation, we choose a point where all countries are 
symmetric, so that, $\hat{R}_{k}=\overline{\hat{R}}_{f}, \bar{Y}, \bar{\tau}, \sigma_{i i}=\bar{v}, \sigma_{i j}=\bar{\sigma}$ (for $i, j=1, \ldots \mathrm{N}$ ), respectively. As derived in Appendix E, the second order approximation is written:

$$
\begin{array}{r}
\bar{\alpha}_{j i}=\bar{\alpha}+\bar{D} \cdot E_{t}\left(\hat{R}_{i}-\overline{\hat{R}}_{f}\right)+\bar{E} \cdot E_{t}\left(\hat{R}_{j}-\overline{\hat{R}}_{f}\right)+\bar{F} \cdot \sum_{k \neq i, j}^{N} E_{t}\left(\hat{R}_{k}-\overline{\hat{R}}_{f}\right)+\bar{G} \cdot \sigma_{i i}+\bar{I} \cdot \sigma_{j j}+\bar{J} \cdot \sum_{k \neq i, j}^{N} \sigma_{k k} \\
+\bar{K} \cdot \sigma_{i j}+\bar{L} \cdot \sum_{k \neq i, j}^{N} \sigma_{i k}+\bar{P} \cdot \sum_{l \neq i, j}^{N} \sigma_{j l}+\bar{Q} \cdot \sum_{m \neq i, j}^{N} \sum_{n \neq i, j, n \neq m}^{N} \sigma_{m n}+\bar{R} \cdot(\tau-\bar{\tau})+\mathrm{O}\left(\Sigma^{2}\right)
\end{array}
$$

where $\bar{D}, \bar{E}, \bar{F}, \bar{G}, \bar{I}, \bar{J}, \bar{K}, \bar{L}, \bar{P}$ and $\bar{Q}$ are coefficients that are functions of covariances of returns evaluated at the point of approximation (see the specific formula of each coefficient in Appendix E).

Note that the equity holdings indeed depend on the full covariance structure, in that all variances and covariances in the covariance matrix $\Omega_{i}$ appear. A convenient property of constructing the Taylor approximation around a point of symmetry is that the various covariances can be grouped into four categories, each of which is multiplied by the same coefficient in the Taylor approximation. The first is the covariance between source country $i$ and destination $j, \sigma_{i j}$, In the empirical equation (15) below, this regressor will be labeled $E Q C O V_{i j}$, and is of particular interest in our estimation. Appendix E provides a proof that the theoretical model implies the coefficient on this regressor should be negative.

The second set of regressors are the covariances between the source country $i$ and countries other than $j, \sigma_{i k}$. While each of these $\mathrm{N}-2$ covariances can differ from each other, the fact we evaluate the Taylor approximation coefficient at a point of symmetry means that each of these covariances is multiplied by the same coefficient, which we label as $\bar{L}$ in equation (14). See appendix E for a proof of this claim, as well as the analogous claims for the other groups of regressors. This means we can sum up these covariances and factor out the common coefficient. In our estimation equation (15) below, this summation of covariances becomes a regressor we label as $M T_{i j}$, representing “multilateral effects” of covariances in alternative destinations. A large value for $M T_{i j}$ indicates that there is a high correlation of returns between country $i$ and all other countries other than $j$. So, it is expected that this $M T$ term is positively associated with bilateral financial asset holdings between countries $i$ and $j$. Appendix E provides a proof that the theoretical model implies the coefficient on this regressor should be positive. 
The third group of regressors are the covariances between the destination country $j$ and countries other than $i, \sigma_{j l}$. Appendix E again shows that even while these individual covariances will differ from each other, they take the same coefficient in the Taylor approximation and therefore can be summed up to form a regressor with a common coefficient. This regressor we label $D T_{i j}$, representing “destination” effects. As shown in Appendix E, the theoretical model implies an ambiguous sign for this regressor.

Fourth are covariances between countries other than $i$ and $j$. Again these $(N-2)^{2}$ covariances will differ from each other in value, but they can be summed together as a single regressor, which while label as $O T_{i j}$, representing “other” country effects. As shown in Appendix E, the theoretical model implies an ambiguous sign for this regressor.

To summarize, we rewrite the equity holdings solution (14) to form the estimation equation:

$$
\begin{aligned}
\text { Equity }_{i j}=\alpha+\beta_{1} E_{\text {QCOV }}+\beta_{2} \text { Var }_{i}+\beta_{3} \text { Var }_{j}+\beta_{4} M T_{i j}+\beta_{5} D T_{i j} & +\beta_{6} O T_{i j} \\
& +\beta_{7} E R_{i}+\beta_{8} E R_{j}+T_{i j} \cdot \gamma+\varepsilon_{i j}
\end{aligned}
$$

Each term in this estimation equation corresponds to a term in the theoretical equation (14) above. In addition to the composite covariance regressors discussed above, the regressors $\operatorname{Var}_{i}$ and $\operatorname{Var}_{j}$ are the names we assign to the variances of returns terms $\sigma_{i i}$ and $\sigma_{i j}$ in (14). The regressors $E R_{i}$ and $E R_{j}$ are the names we assign to the expected excess returns terms $E_{t}\left(\hat{R}_{i}-\overline{\hat{R}}_{f}\right)$ and $E_{t}\left(\hat{R}_{j}-\overline{\hat{R}}_{f}\right)$ in (14). The dependent variable, Equity ${ }_{i j}$, is the log of equity holdings. ${ }^{15}$

Lastly, we note that if one sums the four composite regressors, it becomes the sum of all elements in the covariance matrix. This will be the same for all country pairs, and implies a colinearity problem. If the values of 3 variables out of the 4 variables, $E Q C O V_{i j}, M T_{i j}, D T_{i j}$, and $O T_{i j}$, are known, the value of any fourth variable is determined and the information on the fourth variable is redundant. Thus, in the regression analysis, we need to control for any 3 variables among the 4 variables, and we therefore will drop $O T_{i j}$. This also applies to $\operatorname{Var}_{i}, \operatorname{Var}_{j}$ and the

\footnotetext{
${ }^{15}$ We take a log of equity holdings for scaling, which also makes our depending variable directly comparable to that usually used in the related empirical literature. This is easily incorporated in the Taylor approximation by writing the dependent variable as $\exp \left(\log \left(\bar{\alpha}_{j i}\right)\right)$ before taking derivatives. This simply introduces a constant factor of

$1 / \bar{\alpha}$ which is included in each of the constants $\bar{D}, \bar{E}, \bar{F}, \bar{G}, \bar{I}, \overline{\mathrm{J}}, \overline{\mathrm{K}}, \overline{\mathrm{L}}, \bar{P}$, and, $\bar{Q}$ in the equation (14).
} 
sum of variances of third countries $\left(\sum_{k \neq i, j}^{N} \sigma_{k k}\right.$ ) because the sum of $\operatorname{Var}_{i}, \operatorname{Var}_{j}$ and $\sum_{k \neq i, j}^{N} \sigma_{k k}$ (the sum of variances of all countries) are the same for all country pairs. Hence, we include $\operatorname{Var}_{i}$ and $\operatorname{Var}_{j}$, not $\sum_{k \neq i, j}^{N} \sigma_{k k}$ in all specifications. ${ }^{16}$ In this line, we control for only $E R_{i}$ and $E R_{j}$ which are equity returns of a host and destination countries $i$ and $j$ respectively, not the sum of equity returns for third countries. In addition, we proxy for the information frictions $(\tau)$ in equation (14) with a vector $T$ of common regressors, including distance, border, common language, etc.

\section{Data and Measurement}

This section discusses how data are used to measure the regressors in the estimation equation (15) above.

\subsection{Main Variables}

Data for the bilateral portfolio equity holdings, the dependent variable, come from the Coordinated Portfolio Investment Survey (CPIS) published by the International Monetary Fund (IMF). The survey has been conducted annually since 2001 (and for the first time in 1997). The first CPIS involved 29 source economies, while the CPIS has expanded participation up to 73 source economies in 2006, including several offshore and financial centers. In each case, the bilateral positions of the source countries in 218 destination countries/territories are reported.

The CPIS provides a breakdown of a country’s stock of portfolio investment assets by country of residence of issuer. Lee (2008) and Lane and Milesi-Ferretti (2008) point out the shortcomings of survey methods and under-reporting of assets by participating countries (See the details in Lane and Milesi-Ferretti 2008). Nevertheless, the survey presents a unique opportunity to examine foreign equity and debt holdings of many participating countries. We choose bilateral equity holdings for 2006 and take a log. ${ }^{17}$

\footnotetext{
${ }^{16}$ The results with the sum of third country’s variances $\left(\sum_{k \neq i, j}^{N} \sigma_{k k}\right)$ do not change our main message. The results are available from the authors upon request.

${ }^{17}$ Equity holdings are reported in terms of millions of U.S. dollars. A unit is converted from millions to thousands. All values are real: we convert nominal value into real term using US GDP deflator (2005=100).
} 
We introduce equity return and stock market capitalization variables. The stock market capitalization variable is constructed by taking a log of product of source and destination countries' market capitalization divided by world market capitalization. Domestic stock market capitalization data is available from the Global Financial Database. The measure for equity return variance-covariance (or correlation) of 49 countries (21 advanced countries and 28 emerging and developing countries: see Appendix F for the list of countries) is constructed using stock price indices collected from the DataStream. We compute annual equity return variancecovariance over preceding 4-years from 2006, for each country pair, using bilateral monthly return data. $^{18}$

To demonstrate robustness, we use the alternative measures, equity return correlation $(E Q S Y N C)$ and output co-movement $(S Y N C)^{19}$ (see Portes and Rey, 2005, and Lane and MilesiFerretti, 2008, which also utilize both equity return correlation and output correlation). Either measure is consistent with our theoretical endowment economy model where the distribution of first order components of excess equity returns follows that of output. We also construct the multilateral correlation term using both measures: for each country pair $i$ and $j$, we sum the (EQ)SYNC measure between the source country $i$ and countries other than $j$ : $M T_{i j}^{(E Q) S Y N C} \equiv \sum_{k \neq i, j}^{N}(E Q) S Y N C_{i k}$ and also obtain $D T_{i j}^{(E Q) S Y N C} \equiv \sum_{l \neq i, j}^{N}(E Q) S Y N C_{j l}$.

\subsection{Other Controls}

We include other important determinants $(T)$ of bilateral equity asset holdings identified by previous literature, including specific geographical, political and cultural factors. To control for explicit barriers to international equity investment, we consider a country’s equity market liberalization index based on Bekaert and Harvey (2004) and Bekaert, Harvey, and Lundblad (2005). Official equity market liberalization indicator is coded as 1 when a country's equity market is officially liberalized-foreign investors officially have the opportunity to invest in domestic equity securities-and zero otherwise. We construct bilateral equity market

\footnotetext{
${ }^{18}$ The reason why using the preceding 4 years data (48 monthly observations, 2003-2006) for equity covariance is to make avoid extraordinary crisis events that may result in abnormal equity correlation or equity flow patterns, such as Latin America economic crisis in the early 2000s (2001-2002) and Asian Financial crisis in the late 1990s (19971998). In addition, previous study such as Longin and Solnik (1995) presented equity return correlation computed using a 4 year rolling window.

${ }^{19}$ EQSYNC is also computed over preceding 4-years with bilateral monthly return data and SYNC is using preceding 10 -years real GDP data from Penn World Table.
} 
liberalization indicator by multiplying each equity market indicator in a country pair. ${ }^{20}$ However, in our sample of 2006, equity markets of most developed and emerging economies are categorized as 'officially liberalized' and the measure has not much cross-sectional variation in 2006 (The mean of the measure is about 0.9). Thus, for the robustness of the results, we introduce the alternative measures of capital account openness proposed by Quinn (1997) and Quinn and Toyoda (2008) and Chinn and Ito (2006) respectively and construct bilateral measure by multiplication. ${ }^{21}$

To measure geographical proximity, we use two variables from Rose and Spiegel (2004): (i) the log of bilateral distance between countries and (ii) a binary variable indicating a shared border. To control for cultural and historical affinities between countries that can affect crossborder asset holdings, we add binary variables for common language, for country pairs with a history of colonization, and for common colonizer. Common language may lower information costs between countries, so investors can more easily access each other's financial market. The same colonial experience may predict more familiar financial institutions in another country.

We include indicators for currency unions as they may decrease transaction costs and also remove risk from exchange rate volatility (Coeurdacier and Martin, 2009). Previous studies introduce a time zone difference dummy to proxy for communication difficulties when the overlap between office hours is limited (Portes and Rey, 2005 and Lane and Milesi-Ferretti 2008). We include the difference in longitude between countries to measure time difference, where the data is from the CIA World Fact book.

Lane and Milesi-Ferretti (2008) find that OECD countries and emerging market countries differed in the factors determining the pattern of equity investments. So we add an OECD dummy variable coded as 1 if two countries in a pair are both OECD members. This variable also control for income level and development of financial institution of a country pair. A

\footnotetext{
${ }^{20}$ We include not only bilateral equity market liberalization but also each country's equity market liberalization separately in our regression. Both ways of controls do not affect our main results.

${ }^{21}$ The results with Quinn's measure and Chinn and Ito's measure are consistent with our main results and are available from the authors upon request. Quinn (1997) constructs a measure by taking into account severity of restrictions balancing across all categories of financial transaction from AREAER, IMF. The measure is scored 0-4, in half integer units and the maximum value of 4 represents an economy fully open to capital flows. The data are available for 95 countries for 1940-2004. Chinn and Ito (2006) also creates a measure based on three financial current binary indicators in the AREAER. Their measure takes the value of 2.44 if countries are "most financially open" while it takes score of -1.86 for the "least financial open" countries. So when we make bilateral measure, we add 2 before multiplying by countries' measures in a country pair. The data are available for 1970-2011 for 182 countries.
} 
variable of common legal origin indicates if both source and destination countries have a legal system from the same origin; English (Common), French, German or Scandinavian law. Common legal origin is likely to lead to similar institutions, regulation and custom for financial transaction between countries. The information on legal origins is from the Rose and Spiegel dataset. We also follow Lane and Milesi-Ferretti (2008) and Coeurdacier and Guibaud (2011) in including an indicator variable if the source and destination countries have a tax treaty enacted prior to 2001 and in force until 2006. ${ }^{22}$

Lastly, we include a log of bilateral trade (sum of imports and exports between countries) divided by the sum of GDPs between two countries in line with Aviat and Coeurdacier (2007) and Lane and Milesi-Ferretti (2008). ${ }^{23}$ We report summary statistics and correlation of variables in Appendix G.

\section{Empirical Results}

\subsection{Main Results}

The coefficient estimates reported in the first three columns of Table 1 convey our main message. Column (1) shows that we reproduce the basic puzzle identified in past research: the estimated coefficient on international equity returns covariance (EQCOV) is significantly positive at the $10 \%$ critical level. Despite the theoretical benefits of diversifying the composition of the foreign portfolio, investors seem to prefer countries with fluctuations in returns that are similar to their home country. However, the result is completely transformed once we control for the full covariance structure by including the multilateral effects (MT) term and the destination effect term $(D T)$ of returns covariance, which captures returns covariance with the multilateral partners. Column (2) shows that the estimated coefficient of EQCOV becomes significantly negative at the $5 \%$ critical level. Thus, we confirm that a higher return covariance lowers bilateral equity asset holdings once we adequately take into consideration covariances with third countries. Furthermore, the estimated coefficient of $M T$ term is significantly positive, as our theory would predict.

\footnotetext{
${ }^{22}$ This control varies by country pair. The data are available from the IBFD Tax Treaty Database (http://www.ibfd.org).

${ }^{23}$ Our trade intensity measure reflects trade relationships between countries that are not induced by countries sizes. Moreover, using other trade measures such as log of bilateral trade or log of trade over product of GDP does not affect our main results.
} 
Column (3) includes more variables that represent frictions across countries in terms of geography, language, culture, and also countries’ real economic linkage such as trade in goods and services that previous studies considered. Also we control for legal barriers to equity market investment (equity market liberalization index). Column (3) shows that the estimated coefficient of EQCOV is still positive and of similar magnitude as in column (1) but statistically insignificant. Column (4) supports our main message. Further addition of our MT and DT controls in column (4) makes the estimated coefficient of EQCOV become negative and statistically significant at the $1 \%$ critical level as well as larger in magnitude. Hence, controlling for the full covariance structure in the regression contributes to resolving the correlation puzzle. Throughout columns (1)-(4) in Table 1, other standard explanatory variables have the expected signs. Countries' stock market capitalizations have a positive effect on bilateral equity holdings. Higher asset holdings are associated with higher equity returns in both countries, as are common language, colonial relationship, tax treaty and currency union. Distance has a negative effect. Bilateral asset holding is found to be positively influenced by bilateral trade intensity.

Column (5) shows that our results on EQCOV are preserved if we expand the sample by defining the dependent variable as $\ln ($ equity +1$)$, to prevent observations from dropping when taking a log of zeroes. ${ }^{24}$ We implement tobit estimation to consider left censored observations of the dependent variable, including $M T$ and $D T$ terms. The estimated coefficient of EQCOV is significantly negative at the $1 \%$ critical level. Also most of the estimated coefficients remain as the same as those of column (4) but the effect of equity liberalization index turns out to be significantly positive. $^{25}$

\subsection{An Instrumental Variable Approach}

The empirical investigation of the effects of equity returns covariance on equity asset holdings may encounter an endogeneity problem, as discussed in Coeurdacier and Guibaud (2011). The causality can run in the opposite direction: financial asset holdings between countries (financial integration) may have either a negative or a positive effect on equity returns correlation. Hence, the former estimates of equity returns covariance on bilateral asset holdings might be biased. As a robustness check, this section implements an instrument variable (IV)

\footnotetext{
${ }^{24}$ Our equity holdings are measured in thousands of US dollars. So, 1 means a thousand US dollar.

${ }^{25}$ To check the robustness of the result, we implement the same analysis with alternative samples for 2001-2005. The results are qualitatively similar to those in Table 1. See the additional Appendix.
} 
approach, using past information on equity return correlation as an instrument, as suggested by Lane and Milesi-Ferretti (2008) and Coeurdacier and Guibaud (2011).

Panel B of Table 2 presents the first stage regression of IV. We instrument EQCOV on its lagged information. The estimated coefficient of our instruments on current returns covariance (EQCOV) is reported in Panel B. F-test statistics on the first stage regression all exceed the critical values at $10 \%$ maximal IV size which is 22.4 for weak instruments as reported by Stock and Yogo (2002). Thus, we can reject the null hypothesis that the IV equation is weakly identified and confirm that the instrument variables are statistically powerful. We also find no evidence of an over-identification problem. The joint-null hypothesis for the over-identification test—which implies that instruments are uncorrelated with the error term-cannot be rejected. The p-values of Hansen J-statistics in both IV regressions of Table 2 support the exogeneity hypothesis of our instruments.

Panel A of Table 2 reports estimates from the second stage instrumental variable regressions, beginning with a specification drawn from column (2) of Table 1. Results confirm the conclusions from previous tables. Comparing columns (1) and (2) shows that once again including our control for $M T$ and $D T$ terms confers statistical significance (at the $1 \%$ level) to the negative relationship between equity holdings and equity returns covariance (EQCOV). And once again, we show that our results with full covariance terms are robust to controlling for endogeneity.

\subsection{Measure for Returns Correlation: Equity Return and Output Co-movement ${ }^{26}$}

To reinforce the robustness of the results, we repeated our estimation while replacing equity return covariance (EQCOV) with the alternative measures, equity return correlation (EQSYNC) and output co-movement (SYNC). Previous studies consider equity return correlation as a determinant of bilateral asset holdings, so we report the results with equity return correlation for a comparative purpose. We also use output correlation instead of equity return correlation as another alternative measure. An advantage of the output measure is that it is available for a much

\footnotetext{
${ }^{26}$ More robustness checks considering country pair and time panel structure are reported in Bergin and Pyun (2012).
} 
wider set of countries, doubling the sample size (see Appendix F for the list of countries in the sample). ${ }^{27}$

Table 3 shows the estimation results which correspond to the results of Tables 1 and 2 . In column (1), we reproduce the correlation puzzle again without considering full covariance structure. However further addition of our $M T^{E Q S Y N C}$ and $D T^{E Q S Y N C}$ controls in columns (3) and (4) confers statistical significance (at the $1 \%$ level) to the negative relationship between equity holdings and equity returns correlations (EQSYNC). Moreover, IV regressions in columns (5) and (6) of Table 3 again supports our main message. The estimated coefficient of EQSYNC starts as positive in column (1) despite controlling for endogeneity and becomes significantly negative once we control for multilateral effects of returns correlation $\left(M T^{\text {EQSYNC }}\right)$ and the correlations among destination countries $\left(D T^{E Q S Y N C}\right)$ in column (6). Note that our IV regressions pass the tests for weak instruments and over-identification. ${ }^{28}$

Table 4 shows that the results with SYNC are consistent overall with our baseline results with EQSYNC. Hence, we confirm that a higher return correlation indeed lowers bilateral equity asset holdings once we adequately control for return correlations with multilateral partners.

\section{Concluding Remarks}

This paper studies how asset diversification between a pair of countries is affected by correlations with third countries. Our N-country theoretical framework offers one explanation for why recent empirical work has found that higher return correlations are sometimes associated with higher portfolio holdings, which is contrary to the pursuit of risk hedging. Because bilateral asset holdings depend not only upon bilateral stock return correlation with the destination country but on the full covariance structure, the attractiveness of a foreign country as a hedge

\footnotetext{
${ }^{27}$ The finance literature has established the empirical relationship between stock returns and production growth rates (Fama, 1990, and Schwert, 1990, for the U.S., and Choi, Hauser, and, Kopecky, 1999, for G-7 countries). For instance, the model of simple discounted cash flow valuation maintains that stock prices reflect investors' expectations about the future real economic variables such as corporate earnings, or its aggregate proxy, industrial production. If these expectations are correct on average, lagged stock returns should be correlated with the contemporaneous growth rate of industrial production. So, another benefit of using output growth correlation is that we avoid a simultaneity problem between stock return correlation and bilateral stock holdings because output comovement is highly correlated with the lagged stock return correlation.

${ }^{28}$ Instruments are a year lagged EQSYNC, 4 year lagged EQSYNC, and a year lagged EQSYNC growth. F-test statistics on the first stage regressions of columns (5) and (6) are above the critical values at $10 \%$ maximal IV size for weak instruments as reported by Stock and Yogo (2002). This implies that our first stage has good power and instruments are not weak. We also find no evidence of an over-identification problem. The p-values of Hansen $\mathrm{J}$ statistics in both IV regressions support the exogeneity hypothesis of our instruments.
} 
depends upon its hedging potential relative to other potential destination countries. The model suggests a means for controlling for third-country effects, and empirical specifications implementing these controls reverse this finding of preceding literature. This issue illustrates an advantage of taking a multi-country perspective in modeling bilateral asset holdings. 


\section{References}

[1] Anderson, J. and E. van Wincoop, 2003. Gravity with Gravitas: A Solution to the Border Puzzle. American Economic Review 93, 170-192.

[2] Anderson, J. and E. van Wincoop, 2004. Trade Costs. Journal of Economic Literature 42, 691-751.

[3] Aviat, A., and N. Coeurdacier, 2007. The geography of trade in goods and asset holdings. Journal of International Economics 71, 22-51.

[4] Barberis, N., and R. Thaler, 2004. A Survey of Behavioral Finance, in G. Constantinides. M. Harris, and R.M. Stulz, eds.: Handbook of the Economics of Finance (Elsevier North-Holland).

[5] Bekaert, G., and C. R. Harvey. 2004. Chronology of Economic and Political Events in Emerging Markets. (http://www.duke.edu/ charvey/Country_risk/couindex.htm)

[6] Bekaert, G., Harvey, C. R., and Lundblad, C. 2005. Does financial liberalization spur growth?. Journal of Financial economics, 77(1), 3-55.

[7] Bergin, P.R. and J.H. Pyun, 2012.Multilateral Resistance to International Portfolio Diversification, NBER working paper.

[8] Chinn, Menzie D. and Hiro Ito, 2006. What Matters for Financial Development? Capital Controls, Institutions, and Interactions, Journal of Development Economics, 81(1), 163-192.

[9] Choi, J.-J., Hauser, S., Kopecky, K.J., 1999. Does the stock market predict real activity? Time series evidence from the G-7 countries. Journal of Banking and Finance 23, 1771-1792.

[10] Coeurdacier, N., 2009. Do Trade costs in Goods Markets Lead to Home Bias in Equities. Journal of International Economics 77, 86-100.

[11] Coeurdacier, N. and Martin, Philippe, 2009. The Geography of Asset Trade and the Euro: Insiders and Outsiders. Journal of the Japanese and International Economies, 23, 90-113.

[12] Coeurdacier, N., and P.-O. Gourinchas. 2011. When Bonds Matter: Home Bias in Goods and Assets. Working Paper, University of California, Berkeley.

[13] Coeurdacier, N. and Helene Rey, 2010. Home bias in Open Economy Financial Macroeconomics. working papers, Sciences Po.

[14] Coeurdacier, N. and Stéphane Guibaud, 2011. International Portfolio Diversification Is Better Than You Think. Journal of International Money and Finance, 30, 289-308.

[15] Devereux, M. B., and A. Sutherland, 2010. Country Portfolios in Open Economy Macro Models. Journal of the European Economic Association, forthcoming.

[16] Engel, C. and Akito Matsumoto, 2009. The International Diversification Puzzle When Prices are Sticky: It's Really about Exchange-Rate Hedging not Equity Portfolios. American Economic Journal: Macroeconomics 1, 155-188.

[17] Evans, M., and V. Hnatkovska, 2007. Solving General Equilibrium Models with Incomplete Markets and Many Financial Assets, working paper, Georgetown University.

[18] Fama, E.F., 1990. Stock returns, expected returns, and real activity. Journal of Finance 45, 1089-1108. 
[19] French, Kenneth R., and James M. Poterba, 1991. Investor Diversification and International Equity Markets. American Economic Review 81, 222-26.

[20] Heathcote, J. and F. Perri, 2004. Financial globalization and real regionalization. Journal of Economic Theory 119, 207-243

[21] Huberman, G. 2001. Familiarity breeds investment. Review of Financial Studies 14, 659-80.

[22] Kang, J.K., Stulz, R.M., 1997. Why is there a home bias? An analysis of foreign portfolio equity ownership in Japan. Journal of Financial Economics 46 (1), 3-28.

[23] Lane, P. and G.M. Milesi-Ferretti, 2008. International Investment Patterns. Review of Economics and Statistics 90, 538-549.

[24] Lee, J.-W., 2008. Patterns and Determinants of Cross-border Financial Asset Holdings in East Asia. Asian Development working paper.

[25] Longin, F., and Solnik, B. 1995. Is the correlation in international equity returns constant: 1960-1990?. Journal of international money and finance, 14(1), 3-26.

[26] Martin, P. and H. Rey, 2004. Financial Super-Markets: Size Matters for Asset Trade. Journal of International Economics 64, 335-361.

[27] Obstfeld, M., and K. Rogoff, 2000. The six major puzzles in international macroeconomics: Is there a common cause? NBER Macroeconomics Annual, 339-390.

[28] Okawa, Y. and E. van Wincoop, 2012. Gravity in International Finance. Journal of International Economics 87, 205-215.

[29] Quinn, D., 1997. The correlates of changes in international financial regulation. American Political Science Review 91, 531-551.

[30] Quinn, D. P., \& Toyoda, A. M. (2008). Does capital account liberalization lead to growth?. Review of Financial Studies, 21(3), 1403-1449.

[31] Portes, R. and H, Rey, 2005. The Determinants of Cross-border Equity Flows. Journal of International Economics 65, 269-296.

[32] Rose, A.K. and M. Spiegel, 2004. A Gravity Model of Sovereign Lending: Trade, Default and Credit. IMF Staff Papers 51, 64-74.

[33] Schwert, G.W., 1990. Stock returns and real economic activity: A century of evidence. Journal of Finance 45, 1237-1257.

[34] Stock, James H. and Motohiro Yogo, 2002. Testing for Weak Instruments in Linear IV Regressions. NBER Technical Working Paper 284

[35] Stockman, A. and H. Dellas, 1989. International portfolio non diversification and exchange rate variability. Journal of International Economics 26, 271-90.

[36] Tille, C., and E. van Wincoop, 2010. International Capital Flows. Journal of International Economics 80, 157-175.

[37] van Nieuwerburgh, S., Veldkamp, L., 2009. Information immobility and the home bias puzzle. Journal of Finance 64 (3), 1187-1215. 
Table 1. The Determinants of Bilateral Equity Holdings

\begin{tabular}{|c|c|c|c|c|c|}
\hline \multirow{3}{*}{$\begin{array}{l}\text { Dependent variable } \\
\text { Method }\end{array}$} & \multicolumn{4}{|c|}{ In(equity holdings $\left.s_{i j}\right)$} & \multirow{3}{*}{$\begin{array}{c}\ln (e q+1) \\
\text { Tobit } \\
\text { w/ MT, DT }\end{array}$} \\
\hline & \multicolumn{4}{|c|}{ OLS } & \\
\hline & $\begin{array}{l}\text { Correlation } \\
\text { puzzle }\end{array}$ & w/ MT, DT & $\begin{array}{l}\text { Correlation } \\
\text { puzzle }\end{array}$ & w/ MT, DT & \\
\hline & (1) & (2) & (3) & (4) & (5) \\
\hline$E Q C O V_{i j}$ & $\begin{array}{l}4.522 * \\
{[2.735]}\end{array}$ & $\begin{array}{c}-5.292 * * \\
{[2.407]}\end{array}$ & $\begin{array}{c}4.249 \\
{[2.995]}\end{array}$ & $\begin{array}{c}-12.41 * * * \\
{[3.978]}\end{array}$ & $\begin{array}{c}-28.40 * * * \\
{[7.263]}\end{array}$ \\
\hline $\operatorname{Var}_{i}$ & $\begin{array}{c}-2.907 * * * \\
{[0.490]}\end{array}$ & $\begin{array}{c}-2.921^{* * *} \\
{[0.466]}\end{array}$ & $\begin{array}{c}-1.679 * * * \\
{[0.530]}\end{array}$ & $\begin{array}{c}-1.432 * * * \\
{[0.501]}\end{array}$ & $\begin{array}{c}-4.303 * * * \\
{[0.798]}\end{array}$ \\
\hline $\operatorname{Var}_{j}$ & $\begin{array}{c}-0.574 * * * \\
{[0.199]}\end{array}$ & $\begin{array}{c}-1.184^{* * *} \\
{[0.241]}\end{array}$ & $\begin{array}{c}0.05 \\
{[0.190]}\end{array}$ & $\begin{array}{c}-0.466 * * \\
{[0.231]}\end{array}$ & $\begin{array}{c}-1.908 * * * \\
{[0.446]}\end{array}$ \\
\hline $\begin{array}{l}\text { Multilateral Effects } \\
\left(M T_{i j}\right)\end{array}$ & & $\begin{array}{c}1.026 * * * \\
{[0.191]}\end{array}$ & & $\begin{array}{c}1.337 * * * \\
{[0.176]}\end{array}$ & $\begin{array}{c}3.007 * * * \\
{[0.301]}\end{array}$ \\
\hline $\begin{array}{l}\text { Destination Effects } \\
\left(D T_{i j}\right)\end{array}$ & & $\begin{array}{c}1.149 * * * \\
{[0.206]}\end{array}$ & & $\begin{array}{c}1.173^{* * *} \\
{[0.212]}\end{array}$ & $\begin{array}{c}3.228^{* * *} \\
{[0.393]}\end{array}$ \\
\hline Equity Return (i) & $\begin{array}{l}7.957 * * \\
{[3.222]}\end{array}$ & $\begin{array}{l}6.163^{*} \\
{[3.213]}\end{array}$ & $\begin{array}{c}10.726 * * * \\
{[2.933]}\end{array}$ & $\begin{array}{c}9.300 * * * \\
{[2.904]}\end{array}$ & $\begin{array}{c}13.965^{* * * *} \\
{[4.852]}\end{array}$ \\
\hline Equity Return (j) & $\begin{array}{c}5.350 * * * \\
{[1.627]}\end{array}$ & $\begin{array}{c}9.036 * * * \\
{[1.763]}\end{array}$ & $\begin{array}{c}4.547 * * * \\
{[1.499]}\end{array}$ & $\begin{array}{c}7.672 * * * \\
{[1.561]}\end{array}$ & $\begin{array}{c}19.485 * * * \\
{[3.176]}\end{array}$ \\
\hline $\begin{array}{l}\text { Stock market cap. } \\
(\log )\left(\mathrm{cap}_{\mathrm{i}}{ }^{*} \mathrm{cap}_{\mathrm{j}} / \text { world) }\right.\end{array}$ & $\begin{array}{c}0.932 * * * \\
{[0.033]}\end{array}$ & $\begin{array}{c}0.870 * * * \\
{[0.035]}\end{array}$ & $\begin{array}{c}0.944 * * * \\
{[0.040]}\end{array}$ & $\begin{array}{c}0.890 * * * \\
{[0.040]}\end{array}$ & $\begin{array}{c}1.264 * * * \\
{[0.078]}\end{array}$ \\
\hline $\begin{array}{l}\text { Equity Market } \\
\text { Liberalization }\end{array}$ & & & $\begin{array}{c}0.082 \\
{[0.244]}\end{array}$ & $\begin{array}{c}-0.222 \\
{[0.253]}\end{array}$ & $\begin{array}{c}2.150 * * * \\
{[0.586]}\end{array}$ \\
\hline Border & & & $\begin{array}{c}0.011 \\
{[0.256]}\end{array}$ & $\begin{array}{c}0.068 \\
{[0.251]}\end{array}$ & $\begin{array}{l}-0.216 \\
{[0.507]}\end{array}$ \\
\hline (log) Distance & & & $\begin{array}{c}-0.692 * * * \\
{[0.137]}\end{array}$ & $\begin{array}{c}-0.649 * * * \\
{[0.137]}\end{array}$ & $\begin{array}{c}-1.330 * * * \\
{[0.266]}\end{array}$ \\
\hline Common language & & & $\begin{array}{c}1.145^{* * *} \\
{[0.218]}\end{array}$ & $\begin{array}{c}0.995^{* * *} \\
{[0.210]}\end{array}$ & $\begin{array}{c}1.070 * * * \\
{[0.333]}\end{array}$ \\
\hline Colony dummy & & & $\begin{array}{c}0.645 \\
{[0.404]}\end{array}$ & $\begin{array}{l}0.972 * * \\
{[0.412]}\end{array}$ & $\begin{array}{c}2.055^{* * *} \\
{[0.612]}\end{array}$ \\
\hline Common colonizers & & & $\begin{array}{c}0.421 \\
{[0.841]}\end{array}$ & $\begin{array}{c}0.438 \\
{[0.876]}\end{array}$ & $\begin{array}{l}2.934 * * \\
{[1.421]}\end{array}$ \\
\hline Currency Union & & & $\begin{array}{c}0.807 * * * \\
{[0.199]}\end{array}$ & $\begin{array}{c}0.709 * * * \\
{[0.191]}\end{array}$ & $\begin{array}{c}0.266 \\
{[0.257]}\end{array}$ \\
\hline Longitude difference & & & $\begin{array}{c}0.001 \\
{[0.002]}\end{array}$ & $\begin{array}{l}0.00001 \\
{[0.002]}\end{array}$ & $\begin{array}{c}-0.001 \\
{[0.004]}\end{array}$ \\
\hline Both OECD countries & & & $\begin{array}{c}1.134 * * * \\
{[0.172]}\end{array}$ & $\begin{array}{c}1.105^{* * *} \\
{[0.168]}\end{array}$ & $\begin{array}{c}0.876 * * * \\
{[0.312]}\end{array}$ \\
\hline Common legal origin & & & $\begin{array}{l}-0.175 \\
{[0.142]}\end{array}$ & $\begin{array}{l}-0.122 \\
{[0.138]}\end{array}$ & $\begin{array}{c}0.201 \\
{[0.242]}\end{array}$ \\
\hline Tax treaty & & & $\begin{array}{c}0.402 * * * \\
{[0.137]}\end{array}$ & $\begin{array}{c}0.348^{* * *} \\
{[0.131]}\end{array}$ & $\begin{array}{c}1.290 * * * \\
{[0.248]}\end{array}$ \\
\hline $\begin{array}{l}\text { (log) Bilateral trade } \\
\text { over sum of GDP }\end{array}$ & & & $\begin{array}{c}0.201 * * * \\
{[0.067]}\end{array}$ & $\begin{array}{c}0.248 * * * \\
{[0.067]}\end{array}$ & $\begin{array}{l}0.270 * * \\
{[0.136]}\end{array}$ \\
\hline Constant & $\begin{array}{c}-2.230 * * * \\
{[0.584]} \\
\end{array}$ & $\begin{array}{c}-2.291^{* * *} \\
{[0.586]} \\
\end{array}$ & $\begin{array}{c}3.025^{* * *} \\
{[0.937]} \\
\end{array}$ & $\begin{array}{c}3.148 * * * \\
{[0.907]} \\
\end{array}$ & $\begin{array}{c}-2.077 \\
{[1.825]}\end{array}$ \\
\hline Observations & 1,113 & 1,113 & 1,040 & 1,040 & 1,262 \\
\hline R-squared & 0.453 & 0.471 & 0.644 & 0.667 & \\
\hline
\end{tabular}

Note: Robust standard errors are reported in brackets. $*, * *$,and $* * *$ are respectively significance level at $10 \%, 5 \%$ and $1 \%$. 
Table 2. Robustness Check I: Instrument Variable Estimation

\begin{tabular}{|c|c|c|}
\hline & (1) & (2) \\
\hline \multicolumn{3}{|c|}{ Panel A: Second stage IV estimates: Dependent variable is Equity Asset Holdings } \\
\hline$E Q C O V_{i j}$ & $\begin{array}{c}-8.112 \\
{[9.326]}\end{array}$ & $\begin{array}{c}-36.308 * * * \\
{[13.526]}\end{array}$ \\
\hline $\operatorname{Var}_{i}$ & $\begin{array}{l}-1.075^{*} \\
{[0.608]}\end{array}$ & $\begin{array}{l}-0.519 \\
{[0.759]}\end{array}$ \\
\hline $\operatorname{Var}_{j}$ & $\begin{array}{c}0.332 \\
{[0.294]}\end{array}$ & $\begin{array}{l}-0.420^{*} \\
{[0.246]}\end{array}$ \\
\hline Multilateral Effects $\left(M T_{i j}\right)$ & & $\begin{array}{c}1.841^{* * *} \\
{[0.322]}\end{array}$ \\
\hline Destination Effects $\left(D T_{i j}\right)$ & & $\begin{array}{c}1.819^{* * *} \\
{[0.419]}\end{array}$ \\
\hline Equity Return (i) & $\begin{array}{c}12.173 * * * \\
{[2.842]}\end{array}$ & $\begin{array}{c}10.552 * * * \\
{[2.901]}\end{array}$ \\
\hline Equity Return $(j)$ & $\begin{array}{c}2.649 \\
{[1.925]}\end{array}$ & $\begin{array}{c}7.211^{* * *} \\
{[1.588]}\end{array}$ \\
\hline $\begin{array}{l}\text { Stock market cap. } \\
\text { (log) ( } \text { cap }_{\mathrm{i}}{ }^{*} \mathrm{cap}_{\mathrm{j}} / \text { world) }\end{array}$ & $\begin{array}{c}0.924 * * * \\
{[0.043]}\end{array}$ & $\begin{array}{c}0.835^{* * *} \\
{[0.050]}\end{array}$ \\
\hline Equity Market Liberalization & $\begin{array}{c}0.291 \\
{[0.247]}\end{array}$ & $\begin{array}{l}-0.106 \\
{[0.220]}\end{array}$ \\
\hline Border & $\begin{array}{c}0.039 \\
{[0.259]}\end{array}$ & $\begin{array}{c}0.119 \\
{[0.265]}\end{array}$ \\
\hline (log) Distance & $\begin{array}{c}-0.731 * * * \\
{[0.134]}\end{array}$ & $\begin{array}{c}-0.681^{* * *} \\
{[0.135]}\end{array}$ \\
\hline Common language & $\begin{array}{c}1.178^{* * *} \\
{[0.218]}\end{array}$ & $\begin{array}{c}0.983 * * * \\
{[0.209]}\end{array}$ \\
\hline Colony dummy & $\begin{array}{c}0.583 \\
{[0.398]}\end{array}$ & $\begin{array}{l}1.004^{* *} \\
{[0.409]}\end{array}$ \\
\hline Common colonizers & $\begin{array}{c}0.328 \\
{[0.854]}\end{array}$ & $\begin{array}{c}0.337 \\
{[0.912]}\end{array}$ \\
\hline Currency Union & $\begin{array}{c}0.820 * * * \\
{[0.204]}\end{array}$ & $\begin{array}{c}0.675^{* * *} \\
{[0.188]}\end{array}$ \\
\hline Longitude difference & $\begin{array}{c}0.002 \\
{[0.002]}\end{array}$ & $\begin{array}{c}0.001 \\
{[0.002]}\end{array}$ \\
\hline Both OECD countries & $\begin{array}{c}1.081^{* * *} \\
{[0.159]}\end{array}$ & $\begin{array}{c}1.036^{* * *} \\
{[0.158]}\end{array}$ \\
\hline Common legal origin & $\begin{array}{l}-0.189 \\
{[0.141]}\end{array}$ & $\begin{array}{l}-0.099 \\
{[0.138]}\end{array}$ \\
\hline Tax treaty & $\begin{array}{c}0.399 * * * \\
{[0.135]}\end{array}$ & $\begin{array}{l}0.314^{* *} \\
{[0.132]}\end{array}$ \\
\hline (log) Bilateral trade over sum of GDP & $\begin{array}{c}0.221^{* * *} \\
{[0.065]}\end{array}$ & $\begin{array}{c}0.293^{* * *} \\
{[0.070]}\end{array}$ \\
\hline \multicolumn{3}{|c|}{ Panel B: $1^{\text {st }}$ stage IV estimates \& Diagnostics: Dependent variable is $E Q C O V^{b}$} \\
\hline $\begin{array}{l}E Q C O V_{i j(t-1)} \\
\text { (a year lagged EQCOV) }\end{array}$ & $\begin{array}{c}0.041 * * * \\
{[0.009]}\end{array}$ & $\begin{array}{c}0.026^{* * *} \\
{[0.007]}\end{array}$ \\
\hline$E Q C O V_{i j(t-4)}$ & $\begin{array}{c}0.014^{* * *} \\
{[0.005]}\end{array}$ & $\begin{array}{l}0.008^{* *} \\
{[0.004]}\end{array}$ \\
\hline lagged growth EQCOV & $\begin{array}{l}-0.00001 \\
{[0.00002]}\end{array}$ & $\begin{array}{c}-0.0001 * * * \\
{[0.00001]}\end{array}$ \\
\hline F- test on IV & 12.8 & 16.42 \\
\hline Hansen J stats.(p-val.) & $4.54(0.1)$ & $2.38(0.3)$ \\
\hline Observations & 1,040 & 1,040 \\
\hline R-squared & 0.637 & 0.652 \\
\hline
\end{tabular}

Note: Robust standard errors are reported respectively in brackets. ${ }^{*}, * *$,and $* * *$ are respectively significance level at $10 \%$, $5 \%$ and $1 \%$. Constant is included but not reported. We report only the estimation results of IVs and omit other variables of the first stage regression in Panel B. 
Table 3. Robustness Check II: Equity Correlation Measures

\begin{tabular}{|c|c|c|c|c|c|c|}
\hline Dependent variable & & equity hold & $\left.g s_{i j}\right)$ & $\ln (e q+1)$ & & eq) \\
\hline Method & & OLS & & Tobit & & $\mathrm{V}$ \\
\hline & $\begin{array}{l}\text { Correlation } \\
\text { Puzzle }\end{array}$ & $\begin{array}{c}\text { w/ more } \\
\text { variables }\end{array}$ & $\mathrm{w} / \mathrm{MT}, \mathrm{DT}$ & w/ MT, DT & $\begin{array}{l}\text { Correlation } \\
\text { puzzle }\end{array}$ & w/ MT, DT \\
\hline & $(1)$ & $(2)$ & (3) & (4) & (5) & (6) \\
\hline$E Q S Y N C_{i j}$ & $\begin{array}{c}3.862 * * * \\
{[0.384]}\end{array}$ & $\begin{array}{c}-0.203 \\
{[0.391]}\end{array}$ & $\begin{array}{c}-2.146 * * * \\
{[0.454]}\end{array}$ & $\begin{array}{c}-4.267 * * * \\
{[0.841]}\end{array}$ & $\begin{array}{l}1.039 * * \\
{[0.522]}\end{array}$ & $\begin{array}{c}-1.370 * * \\
{[0.638]}\end{array}$ \\
\hline $\begin{array}{l}\text { Multilateral Effects } \\
\left(M T^{E Q S Y N C}\right)\end{array}$ & & & $\begin{array}{c}0.179 * * * \\
{[0.018]}\end{array}$ & $\begin{array}{c}0.399 * * * \\
{[0.034]}\end{array}$ & & $\begin{array}{c}0.166^{* * *} \\
{[0.019]}\end{array}$ \\
\hline $\begin{array}{l}\text { Destination Effects } \\
\left(D T^{E Q S Y N C}\right)\end{array}$ & & & $\begin{array}{c}0.114 * * * \\
{[0.024]}\end{array}$ & $\begin{array}{c}0.514 * * * \\
{[0.046]}\end{array}$ & & $\begin{array}{c}0.098 * * * \\
{[0.026]}\end{array}$ \\
\hline Equity Return (i) & $\begin{array}{c}12.614 * * * \\
{[2.892]}\end{array}$ & $\begin{array}{c}15.195^{* * *} \\
{[2.642]}\end{array}$ & $\begin{array}{c}11.197 * * * \\
{[2.558]}\end{array}$ & $\begin{array}{c}26.078^{* * * *} \\
{[4.511]}\end{array}$ & $\begin{array}{c}14.165^{* * *} \\
{[2.666]}\end{array}$ & $\begin{array}{c}10.501 * * * \\
{[2.607]}\end{array}$ \\
\hline Equity Return $(j)$ & $\begin{array}{c}5.785 * * * \\
{[1.454]}\end{array}$ & $\begin{array}{c}4.487 * * * \\
{[1.341]}\end{array}$ & $\begin{array}{c}5.467 * * * \\
{[1.240]}\end{array}$ & $\begin{array}{c}16.619 * * * \\
{[2.499]}\end{array}$ & $\begin{array}{c}5.045^{* * *} \\
{[1.348]}\end{array}$ & $\begin{array}{c}5.571 * * * \\
{[1.241]}\end{array}$ \\
\hline $\begin{array}{l}\text { Stock market cap. } \\
(\log )\left(\text { cap }^{*}{ }^{*} \text { cap }_{j} / \text { world }\right)\end{array}$ & $\begin{array}{c}0.845^{* * *} \\
{[0.036]}\end{array}$ & $\begin{array}{c}0.959 * * * \\
{[0.037]}\end{array}$ & $\begin{array}{c}0.779 * * * \\
{[0.041]}\end{array}$ & $\begin{array}{c}0.883 * * * \\
{[0.080]}\end{array}$ & $\begin{array}{c}0.939 * * * \\
{[0.038]}\end{array}$ & $\begin{array}{c}0.787 * * * \\
{[0.041]}\end{array}$ \\
\hline Equity Market Liberalization & & $\begin{array}{c}0.185 \\
{[0.221]}\end{array}$ & $\begin{array}{c}0.153 \\
{[0.225]}\end{array}$ & $\begin{array}{l}1.098^{* *} \\
{[0.503]}\end{array}$ & $\begin{array}{l}-0.0003 \\
{[0.222]}\end{array}$ & $\begin{array}{c}0.049 \\
{[0.227]}\end{array}$ \\
\hline Border & & $\begin{array}{c}0.048 \\
{[0.250]}\end{array}$ & $\begin{array}{l}0.490^{*} \\
{[0.253]}\end{array}$ & $\begin{array}{c}0.874 \\
{[0.565]}\end{array}$ & $\begin{array}{c}-0.004 \\
{[0.251]}\end{array}$ & $\begin{array}{l}0.455^{*} \\
{[0.251]}\end{array}$ \\
\hline (log) Distance & & $\begin{array}{c}-0.746 * * * \\
{[0.134]}\end{array}$ & $\begin{array}{c}-0.618 * * * \\
{[0.134]}\end{array}$ & $\begin{array}{c}-1.309 * * * \\
{[0.262]}\end{array}$ & $\begin{array}{c}-0.717 * * * \\
{[0.134]}\end{array}$ & $\begin{array}{c}-0.594 * * * \\
{[0.134]}\end{array}$ \\
\hline Common language & & $\begin{array}{c}1.090^{* * *} \\
{[0.212]}\end{array}$ & $\begin{array}{c}1.073 * * * \\
{[0.206]}\end{array}$ & $\begin{array}{c}0.942 * * * \\
{[0.342]}\end{array}$ & $\begin{array}{c}1.087 * * * \\
{[0.213]}\end{array}$ & $\begin{array}{c}1.081^{* * *} \\
{[0.209]}\end{array}$ \\
\hline Colony dummy & & $\begin{array}{c}0.634 \\
{[0.389]}\end{array}$ & $\begin{array}{l}0.646^{*} \\
{[0.365]}\end{array}$ & $\begin{array}{c}1.425 * * * \\
{[0.551]}\end{array}$ & $\begin{array}{l}0.721^{*} \\
{[0.402]}\end{array}$ & $\begin{array}{l}0.653^{*} \\
{[0.383]}\end{array}$ \\
\hline Common colonizers & & $\begin{array}{c}0.539 \\
{[0.861]}\end{array}$ & $\begin{array}{c}1.074 \\
{[0.952]}\end{array}$ & $\begin{array}{c}5.019 * * * \\
{[1.444]}\end{array}$ & $\begin{array}{c}0.567 \\
{[0.817]}\end{array}$ & $\begin{array}{c}1.024 \\
{[0.909]}\end{array}$ \\
\hline Currency Union & & $\begin{array}{c}0.873^{* * *} \\
{[0.201]}\end{array}$ & $\begin{array}{c}0.729 * * * \\
{[0.198]}\end{array}$ & $\begin{array}{l}-0.032 \\
{[0.294]}\end{array}$ & $\begin{array}{c}0.708^{* * *} \\
{[0.204]}\end{array}$ & $\begin{array}{c}0.681^{* * *} \\
{[0.198]}\end{array}$ \\
\hline Longitude difference & & $\begin{array}{c}0.002 \\
{[0.002]}\end{array}$ & $\begin{array}{c}0.002 \\
{[0.002]}\end{array}$ & $\begin{array}{c}0.005 \\
{[0.004]}\end{array}$ & $\begin{array}{c}0.001 \\
{[0.002]}\end{array}$ & $\begin{array}{c}0.001 \\
{[0.002]}\end{array}$ \\
\hline Both OECD countries & & $\begin{array}{c}1.125^{* * *} \\
{[0.160]}\end{array}$ & $\begin{array}{c}1.010^{* * *} \\
{[0.172]}\end{array}$ & $\begin{array}{c}0.163 \\
{[0.344]}\end{array}$ & $\begin{array}{c}1.013^{* * *} \\
{[0.162]}\end{array}$ & $\begin{array}{c}1.007^{* * *} \\
{[0.171]}\end{array}$ \\
\hline Common legal origin & & $\begin{array}{l}-0.161 \\
{[0.141]}\end{array}$ & $\begin{array}{l}-0.143 \\
{[0.135]}\end{array}$ & $\begin{array}{c}0.142 \\
{[0.250]}\end{array}$ & $\begin{array}{l}-0.168 \\
{[0.141]}\end{array}$ & $\begin{array}{l}-0.162 \\
{[0.134]}\end{array}$ \\
\hline Tax treaty & & $\begin{array}{c}0.419 * * * \\
{[0.137]}\end{array}$ & $\begin{array}{l}0.276^{* *} \\
{[0.127]}\end{array}$ & $\begin{array}{c}1.238 * * * \\
{[0.241]}\end{array}$ & $\begin{array}{c}0.436 * * * \\
{[0.138]}\end{array}$ & $\begin{array}{l}0.294^{* *} \\
{[0.129]}\end{array}$ \\
\hline $\begin{array}{l}\text { (log) Bilateral trade over } \\
\text { sum of GDP }\end{array}$ & & $\begin{array}{c}0.181^{* * *} \\
{[0.064]}\end{array}$ & $\begin{array}{c}0.201^{* * *} \\
{[0.064]}\end{array}$ & $\begin{array}{c}0.133 \\
{[0.131]}\end{array}$ & $\begin{array}{c}0.175^{* * *} \\
{[0.065]}\end{array}$ & $\begin{array}{c}0.194^{* * *} \\
{[0.065]}\end{array}$ \\
\hline Constant & $\begin{array}{c}-2.627 * * * \\
{[0.510]}\end{array}$ & $\begin{array}{c}3.028 * * * \\
{[0.925]}\end{array}$ & $\begin{array}{l}2.085^{* *} \\
{[0.939]}\end{array}$ & $\begin{array}{c}-4.588 * * \\
{[1.892]} \\
\end{array}$ & $\begin{array}{c}2.834 * * * \\
{[0.937]}\end{array}$ & $\begin{array}{l}1.935^{* *} \\
{[0.947]}\end{array}$ \\
\hline F-test on IV & & & & & 435.42 & 278.67 \\
\hline Hansen J stats.(p-val.) & & & & & $2.46(0.29)$ & $3.04(0.22)$ \\
\hline Observations & 1,137 & 1,064 & 1,064 & 1,289 & 1,040 & 1,040 \\
\hline R-squared & 0.471 & 0.633 & 0.677 & & 0.633 & 0.676 \\
\hline
\end{tabular}


Note: Robust standard errors are reported in brackets. *,**,and $* * *$ are respectively significance level at $10 \%, 5 \%$ and $1 \%$. Instrument variables are a year lagged EQSYNC, 4 year lagged EQSYNC, and a year lagged EQSYNC growth. We omit the first stage regression and the results are available upon request. 
Table 4. Robustness Check III: Other Measure for Return Correlation, SYNC

\begin{tabular}{|c|c|c|c|c|c|}
\hline \multirow[t]{2}{*}{ Dependent variables } & \multicolumn{5}{|c|}{$\ln \left(\right.$ equity holdings $\left.s_{i j}\right)$} \\
\hline & & & & \multicolumn{2}{|r|}{ IV } \\
\hline & $\begin{array}{l}\text { Correlation } \\
\text { Puzzle }\end{array}$ & $\begin{array}{l}\text { w/ more } \\
\text { variables }\end{array}$ & w/ MT, DT & $\begin{array}{l}\text { Correlation } \\
\text { Puzzle }\end{array}$ & w/ MT, DT \\
\hline & $(1)$ & $(2)$ & (3) & (4) & (5) \\
\hline \multirow{2}{*}{$S Y N C_{i j}$} & $1.934 * * *$ & 0.479 & $-1.222 * * *$ & 0.541 & $-1.520 * * *$ \\
\hline & {$[0.474]$} & [0.313] & {$[0.367]$} & {$[0.347]$} & {$[0.396]$} \\
\hline \multirow{2}{*}{ Multilateral Effects $\left(M T^{S Y N C}\right)$} & & & $0.082^{* * *}$ & & $0.083 * * *$ \\
\hline & & & {$[0.003]$} & & {$[0.003]$} \\
\hline \multirow{2}{*}{ Destination Effects $\left(D T^{S Y N C}\right)$} & & & $0.111^{* * *}$ & & $0.112 * * *$ \\
\hline & & & {$[0.006]$} & & {$[0.006]$} \\
\hline \multirow{2}{*}{$\begin{array}{l}\text { Stock market capitalization } \\
(\log )\left(\text { cap }_{i}^{*}{ }^{*}{ }^{2} p_{j} / \text { world }\right)\end{array}$} & $0.627 * * *$ & $0.548 * * *$ & $0.204 * * *$ & $0.548 * * *$ & $0.203^{* * *}$ \\
\hline & {$[0.023]$} & {$[0.033]$} & {$[0.030]$} & {$[0.033]$} & {$[0.030]$} \\
\hline \multirow{2}{*}{ Equity Market Liberalization } & & $0.614^{* * *}$ & $0.296 * *$ & $0.613^{* * *}$ & $0.298^{* *}$ \\
\hline & & {$[0.168]$} & {$[0.141]$} & {$[0.168]$} & {$[0.141]$} \\
\hline \multirow{2}{*}{ Border } & & 0.236 & $0.397^{*}$ & 0.239 & $0.386^{*}$ \\
\hline & & {$[0.242]$} & {$[0.211]$} & {$[0.241]$} & {$[0.211]$} \\
\hline \multirow{2}{*}{ (log) Distance } & & $-0.859 * * *$ & $-0.620 * * *$ & $-0.857 * * *$ & $-0.628 * * *$ \\
\hline & & {$[0.121]$} & {$[0.107]$} & {$[0.121]$} & [0.107] \\
\hline \multirow{2}{*}{ Common language } & & $0.784 * * *$ & $0.983 * * *$ & $0.785^{* * *}$ & $0.980 * * *$ \\
\hline & & {$[0.163]$} & {$[0.147]$} & {$[0.163]$} & {$[0.147]$} \\
\hline \multirow{2}{*}{ Colony dummy } & & $0.701^{* *}$ & 0.336 & $0.700^{* *}$ & 0.339 \\
\hline & & {$[0.316]$} & {$[0.258]$} & {$[0.315]$} & {$[0.256]$} \\
\hline \multirow{2}{*}{ Common colonizers } & & $0.906^{* *}$ & $1.253^{* * *}$ & $0.904^{* *}$ & $1.267 * * *$ \\
\hline & & {$[0.438]$} & {$[0.354]$} & {$[0.436]$} & {$[0.355]$} \\
\hline \multirow{2}{*}{ Currency Union } & & $1.448 * * *$ & $0.850 * * *$ & $1.447 * * *$ & $0.850 * * *$ \\
\hline & & {$[0.201]$} & {$[0.162]$} & {$[0.200]$} & [0.162] \\
\hline \multirow{2}{*}{ Longitude difference } & & $0.005^{* * *}$ & $0.006^{* * *}$ & $0.005^{* * *}$ & $0.006^{* * *}$ \\
\hline & & {$[0.002]$} & {$[0.002]$} & {$[0.002]$} & {$[0.002]$} \\
\hline \multirow{2}{*}{ Both OECD countries } & & $1.161^{* * *}$ & $0.571^{* * *}$ & $1.161^{* * *}$ & $0.566^{* * *}$ \\
\hline & & {$[0.155]$} & {$[0.132]$} & {$[0.155]$} & {$[0.132]$} \\
\hline \multirow{2}{*}{ Tax treaty } & & $0.256 * *$ & 0.01 & $0.255^{* *}$ & 0.012 \\
\hline & & {$[0.118]$} & {$[0.096]$} & {$[0.118]$} & {$[0.096]$} \\
\hline \multirow{2}{*}{$\begin{array}{l}\text { (log) Bilateral trade over sum } \\
\text { of GDP }\end{array}$} & & $-0.088^{*}$ & $0.124^{* * *}$ & $-0.088^{*}$ & $0.125^{* * *}$ \\
\hline & & {$[0.050]$} & {$[0.043]$} & {$[0.050]$} & {$[0.043]$} \\
\hline \multirow{2}{*}{ Constant } & $1.264^{* *}$ & $8.204^{* * *}$ & $7.314 * * *$ & $8.137 * * *$ & $7.622 * * *$ \\
\hline & {$[0.515]$} & {$[0.921]$} & {$[0.821]$} & {$[0.932]$} & {$[0.830]$} \\
\hline F- test on IV & & & & 742.66 & 723.58 \\
\hline Hansen J stats.(p-val.) & & & & -- & -- \\
\hline Observations & 1,916 & 1,882 & 1,882 & 1,882 & 1,882 \\
\hline R-squared & 0.309 & 0.466 & 0.64 & 0.466 & 0.64 \\
\hline
\end{tabular}

Note: Robust standard errors are reported respectively in brackets. ${ }^{*}, * *$,and $* * *$ are respectively significance level at $10 \%, 5 \%$ and $1 \%$. A single instrument, a year lagged SYNC, is used so the model is exactly identified. 
Fig. 1: Numerical Solutions of Partial Derivatives in a 3 Country Model

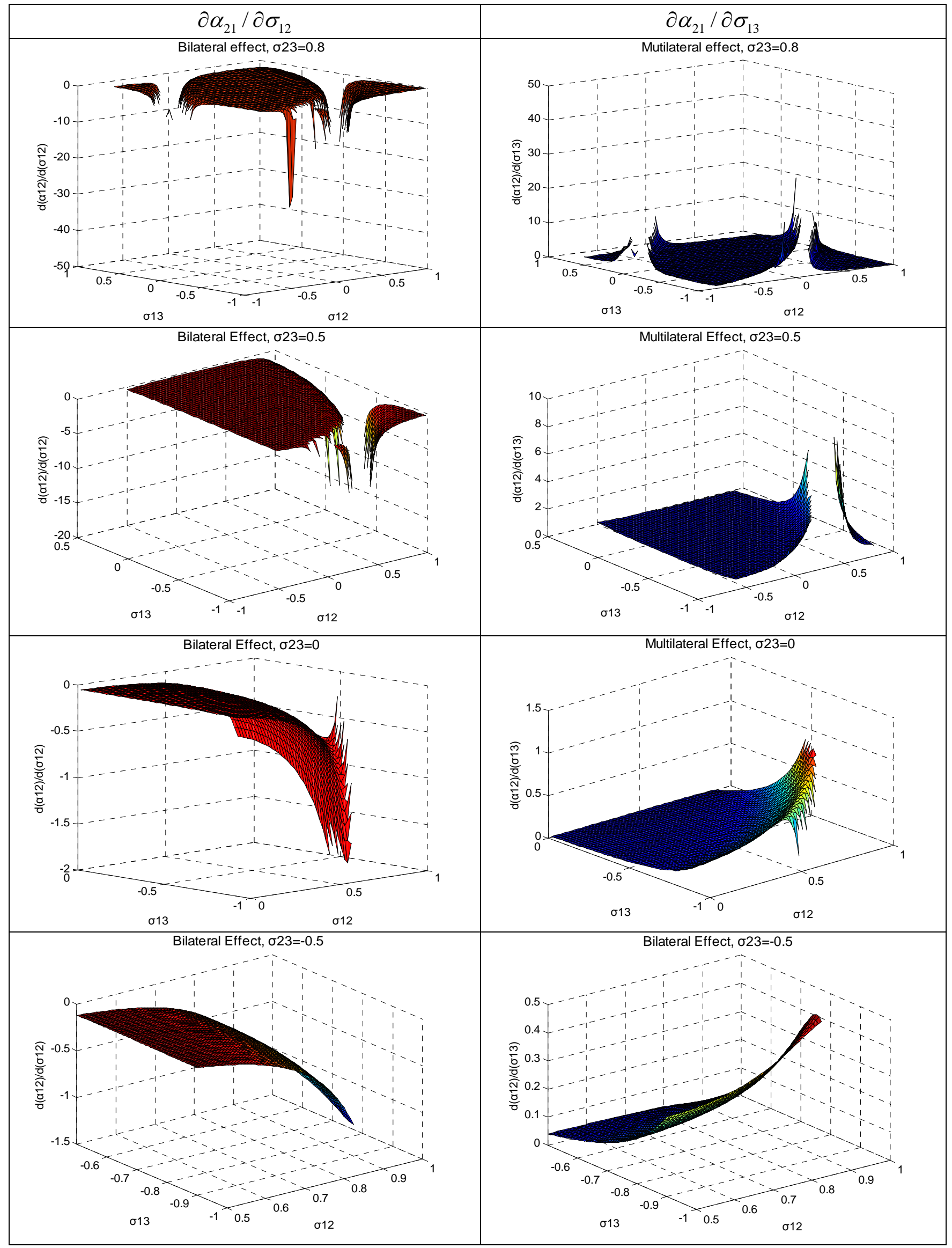




\section{Appendix}

\section{A. The first-order accurate behavior of $\left(\hat{R}_{j, t+1}-\hat{R}_{f, t+1}\right)$}

$$
\hat{R}_{j, t+1}-\hat{R}_{f, t+1}=\hat{Y}_{j, t+1}-\hat{Z}_{j, t}^{E}-\hat{Z}_{j, t}^{B}+O\left(\varepsilon^{2}\right) .
$$

where $O\left(\varepsilon^{2}\right)$ is a residual which contains all terms of order higher than one, so

$$
E_{t}\left(\hat{R}_{j, t+1}-\hat{R}_{f, t+1}\right)=E_{t}\left(\hat{Y}_{j, t+1}\right)-\hat{Z}_{j, t}^{E}-\hat{Z}_{j, t}^{B}+O\left(\varepsilon^{2}\right) .
$$

The return on equities must equal to each other, up to a first-order approximation. Moreover, first components of the equity return and bond return are assumed to be equal,

$$
\begin{gathered}
E_{t}\left(\hat{R}_{i, t+1}-\hat{R}_{f, t+1}\right)=0 \text {, so } \\
\hat{Z}_{j, t}^{E}-\hat{Z}_{j, t}^{B}=E_{t}\left(\hat{Y}_{j, t+1}\right)+O\left(\varepsilon^{2}\right) \text { where } E_{t}\left(\hat{Y}_{j, t+1}\right)=0 .
\end{gathered}
$$

Therefore, $\hat{R}_{j, t+1}-\hat{R}_{f, t+1}=\hat{Y}_{j, t+1}+O\left(\varepsilon^{2}\right)$

\section{B. Solving for the portfolio holdings, equations (10) and (11)}

(10) $E_{t}\left[\left(\hat{C}_{i, t+1}-\hat{C}_{k, t+1}\right)\left(\hat{R}_{j, t+1}-\hat{R}_{f, t+1}\right)\right]=0 \quad$ for $\mathrm{i}, \mathrm{j}=1, \ldots \mathrm{N}$, and $\mathrm{k}=2, \ldots, \mathrm{N}, \mathrm{k} \neq \mathrm{i}$

$=E_{t}\left[\left\{\tilde{\alpha}_{1 i}\left(\hat{R}_{1, t+1}-\hat{R}_{f, t+1}\right)+\cdots+\tilde{\alpha}_{N i}\left(\hat{R}_{N, t+1}-\hat{R}_{f, t+1}\right)-\tilde{\alpha}_{1 k}\left(\hat{R}_{1, t+1}-\hat{R}_{f, t+1}\right)-\cdots-\tilde{\alpha}_{N k}\left(\hat{R}_{N, t+1}-\hat{R}_{f, t+1}\right)\right.\right.$

$\left.\left.+\left(\hat{Y}_{i, t+1}-\hat{Y}_{k, t+1}\right)-\left(\hat{W}_{i, t+1}-\hat{W}_{k, t+1}\right)\right\} \times\left(\hat{R}_{j, t+1}-\hat{R}_{f, t+1}\right)\right]=0$

where, $E_{t}\left[\left\{\left(\hat{W}_{i, t+1}-\hat{W}_{k, t+1}\right) \times\left(\hat{R}_{j, t+1}-\hat{R}_{f, t+1}\right)\right]=0\right.$

$\left(\tilde{\alpha}_{1 i}-\tilde{\alpha}_{1 k}\right) \operatorname{cov}\left(X R_{1 t+1}, X R_{j t+1}\right)+\left(\tilde{\alpha}_{2 i}-\tilde{\alpha}_{2 k}\right) \operatorname{cov}\left(X R_{2 t+1}, X R_{j t+1}\right)+\cdots+\left(\tilde{\alpha}_{N i}-\tilde{\alpha}_{N k}\right) \operatorname{cov}\left(X R_{N t+1,}, X R_{j t+1}\right)$

$+\operatorname{cov}\left(X R_{i t+1}, X R_{j t+1}\right)-\operatorname{cov}\left(X R_{k t+1,} X R_{j t+1}\right)=0$

where $X R_{i, t+1}=\hat{R}_{i, t+1}-\hat{R}_{f, t+1}$

For instance, country 1 and country 2 have,

$$
\begin{aligned}
& \text { (10’) } E_{t}\left[\left(\hat{C}_{1, t+1}-\hat{C}_{2, t+1}\right)\left(\hat{R}_{j, t+1}-\hat{R}_{f, t+1}\right)\right]=0 \text { for } \mathrm{j}=1, \ldots, \mathrm{N} \\
& =E_{t}\left[\left\{\tilde{\alpha}_{11}\left(\hat{R}_{1, t+1}-\hat{R}_{f, t+1}\right)+\cdots+\tilde{\alpha}_{N 1}\left(\hat{R}_{N, t+1}-\hat{R}_{f, t+1}\right)-\tilde{\alpha}_{12}\left(\hat{R}_{1, t+1}-\hat{R}_{f, t+1}\right)-\cdots-\tilde{\alpha}_{N 2}\left(\hat{R}_{N, t+1}-\hat{R}_{f, t+1}\right)\right.\right. \\
& \left.\left.\quad+\left(\hat{Y}_{1, t+1}-\hat{Y}_{2, t+1}\right)-\left(\hat{W}_{1, t+1}-\hat{W}_{2, t+1}\right)\right\} \times\left(\hat{R}_{j, t+1}-\hat{R}_{f, t+1}\right)\right]=0 \\
& \quad \text { where } E_{t}\left[\left\{\left(\hat{W}_{1, t+1}-\hat{W}_{2, t+1}\right) \times\left(\hat{R}_{j, t+1}-\hat{R}_{f, t+1}\right)\right]=0\right.
\end{aligned}
$$




$$
\begin{aligned}
= & \tilde{\alpha}_{11} \operatorname{cov}\left(X R_{1 t+1}, X R_{j t+1}\right)+\cdots+\tilde{\alpha}_{N 1} \operatorname{cov}\left(X R_{N t+1}, X R_{j t+1}\right)-\tilde{\alpha}_{12} \operatorname{cov}\left(X R_{1 t+1}, X R_{j t+1}\right)-\cdots \\
& -\tilde{\alpha}_{N 2} \operatorname{cov}\left(X R_{N t+1,} X R_{j t+1}\right)+\operatorname{cov}\left(X R_{1 t+1}, X R_{j t+1}\right)-\operatorname{cov}\left(X R_{2 t+1}, X R_{j t+1}\right)=0
\end{aligned}
$$

where $X R_{i, t+1}=\hat{R}_{i, t+1}-\hat{R}_{f, t+1}$

Thus, based on the above, we have $N(N-1)$ equations of country $i$ and $k$.

In equation (11), $A=\Pi^{-1} B$

$$
\boldsymbol{A}^{\prime}=\left(\begin{array}{llllllllllllll}
\tilde{\alpha}_{11} & \tilde{\alpha}_{21} & \ldots & \tilde{\alpha}_{N 1} & \tilde{\alpha}_{12} & \ldots & \tilde{\alpha}_{N 2} & \tilde{\alpha}_{13} & \ldots & \tilde{\alpha}_{N 3} & \ldots & \tilde{\alpha}_{1 N} & \ldots & \tilde{\alpha}_{N N}
\end{array}\right) .
$$

$\boldsymbol{A}^{\prime}$ is a solution for equity holdings and it is $N^{2} \times 1$.

$\boldsymbol{B}=$

$$
\left(\begin{array}{c}
0 \\
\vdots \\
0 \\
\hline-\operatorname{cov}\left(X R_{1 t+1}, X R_{1 t+1}\right)+\operatorname{cov}\left(X R_{2 t+1,} X R_{1 t+1}\right) \\
-\operatorname{cov}\left(X R_{1 t+1}, X R_{2 t+1}\right)+\operatorname{cov}\left(X R_{2 t+1,}, X R_{2 t+1}\right) \\
\vdots \\
-\operatorname{cov}\left(X R_{1 t+1}, X R_{N t+1}\right)+\operatorname{cov}\left(X R_{2 t+1,} X R_{N t+1}\right) \\
\hline-\operatorname{cov}\left(X R_{1 t+1}, X R_{1 t+1}\right)+\operatorname{cov}\left(X R_{3 t+1,} X R_{1 t+1}\right) \\
-\operatorname{cov}\left(X R_{1 t+1}, X R_{2 t+1}\right)+\operatorname{cov}\left(X R_{3 t+1,} X R_{2 t+1}\right) \\
\vdots \\
-\operatorname{cov}\left(X R_{1 t+1}, X R_{N t+1}\right)+\operatorname{cov}\left(X R_{3 t+1,} X R_{N t+1}\right) \\
\vdots \\
\vdots \\
\hline-\operatorname{cov}\left(X R_{1 t+1}, X R_{1 t+1}\right)+\operatorname{cov}\left(X R_{N t+1,}, X R_{1 t+1}\right) \\
-\operatorname{cov}\left(X R_{1 t+1}, X R_{2 t+1}\right)+\operatorname{cov}\left(X R_{N t+1,}, X R_{2 t+1}\right) \\
\vdots \\
-\operatorname{cov}\left(X R_{1 t+1}, X R_{N t+1}\right)+\operatorname{cov}\left(X R_{N t+1,} X R_{N t+1}\right)
\end{array}\right)
$$

$B$ is an $N^{2} \times 1$ matrix which consists of variance of excess stock returns (or covariance of stock returns between two countries). We generate special variance-covariance matrix of excess stock return between countries, $\Pi$, like below. 


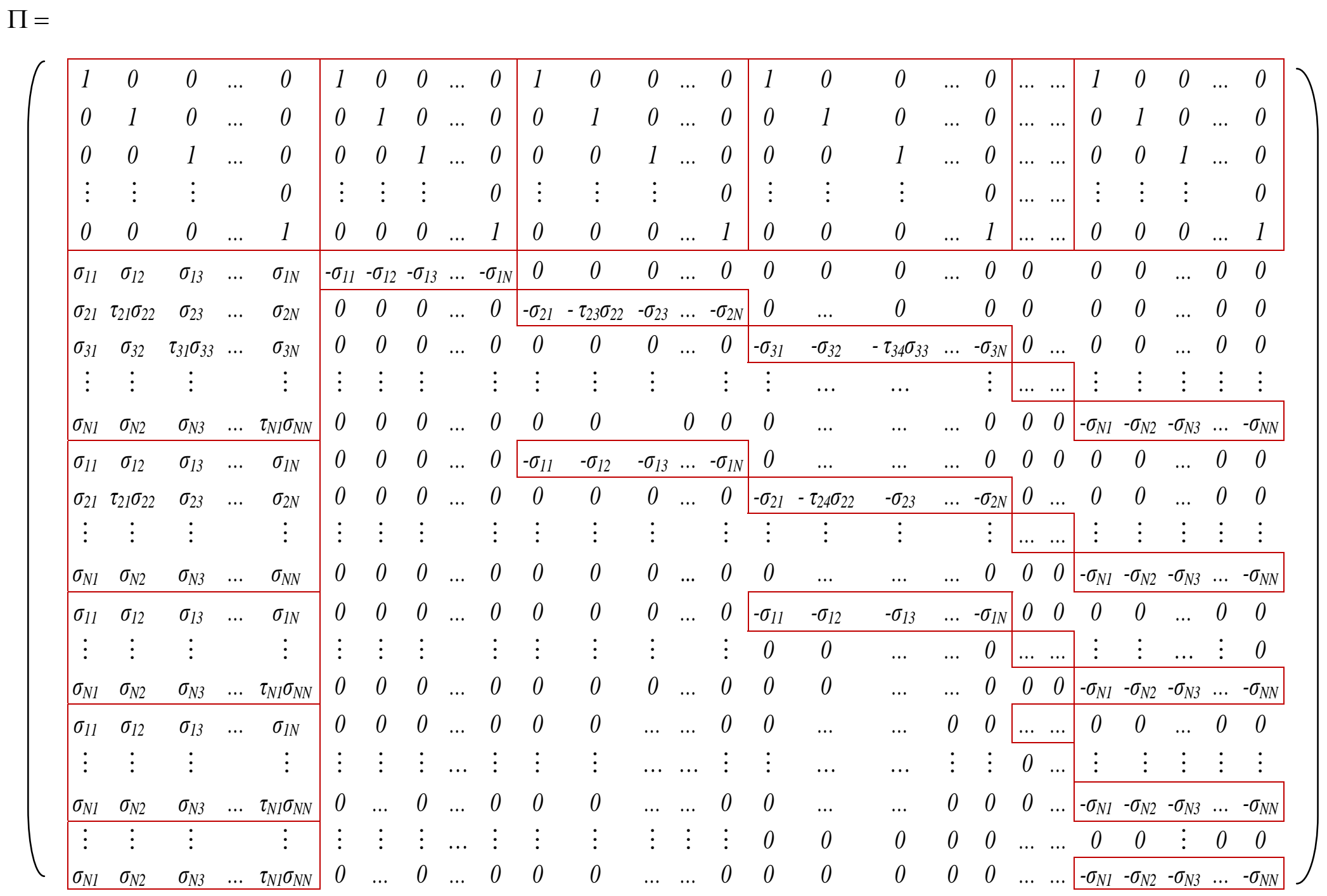

where $\Pi$ is an $N^{2} \times N^{2}$ matrix. Variance and covariance of excess stock returns are inside the red-line box, otherwise zero. 


\section{Solving For Equilibrium Portfolio Shares in a 3 Country Case}

Combining FOCs and taking a second-order approximation, we derive the 6 equations below:

(i) $E_{t}\left[\left(\hat{C}_{1, t+1}-\hat{C}_{2, t+1}\right)\left(\hat{R}_{i, t+1}-\hat{R}_{f, t+1}\right)\right]=0$ for $\mathrm{i}=1,2,3$

$$
\begin{aligned}
& =E_{t}\left[\left\{\tilde{\alpha}_{11}\left(\hat{R}_{1, t+1}-\hat{R}_{f, t+1}\right)+\tilde{\alpha}_{21}\left(\hat{R}_{2, t+1}-\hat{R}_{f, t+1}\right)+\tilde{\alpha}_{31}\left(\hat{R}_{3, t+1}-\hat{R}_{f, t+1}\right)-\tilde{\alpha}_{12}\left(\hat{R}_{1, t+1}-\hat{R}_{f, t+1}\right)\right.\right. \\
& \left.\left.-\tilde{\alpha}_{22}\left(\hat{R}_{2, t+1}-\hat{R}_{f, t+1}\right)-\tilde{\alpha}_{32}\left(\hat{R}_{3, t+1}-\hat{R}_{f, t+1}\right)+\left(\hat{Y}_{1, t+1}-\hat{Y}_{2, t+1}\right)-\left(\hat{W}_{1, t+1}-\hat{W}_{2, t+1}\right)\right\} \times\left(\hat{R}_{i, t+1}-\hat{R}_{f, t+1}\right)\right]
\end{aligned}
$$

where $E_{t}\left[\left\{\left(\hat{W}_{1, t+1}-\hat{W}_{2, t+1}\right)\right\} \times\left(\hat{R}_{1, t+1}-\hat{R}_{f, t+1}\right)\right]=0$

for $i=1,=\tilde{\alpha}_{11} \sigma_{11}+\tilde{\alpha}_{21} \sigma_{12}+\tilde{\alpha}_{31} \sigma_{13}-\tilde{\alpha}_{12} \tau_{12} \sigma_{11}-\tilde{\alpha}_{22} \sigma_{12}-\tilde{\alpha}_{32} \sigma_{13}+\left(\sigma_{11}-\sigma_{12}\right)=0$

for $i=2,=\tilde{\alpha}_{11} \sigma_{12}+\tilde{\alpha}_{21} \boldsymbol{\tau}_{21} \sigma_{22}+\tilde{\alpha}_{31} \sigma_{23}-\tilde{\alpha}_{12} \sigma_{12}-\tilde{\alpha}_{22} \sigma_{22}-\tilde{\alpha}_{32} \sigma_{23}+\left(\sigma_{12}-\sigma_{22}\right)=0$

for $i=3,=\tilde{\alpha}_{11} \sigma_{13}+\tilde{\alpha}_{21} \sigma_{23}+\tilde{\alpha}_{31} \tau_{31} \sigma_{33}-\tilde{\alpha}_{12} \sigma_{13}-\tilde{\alpha}_{22} \sigma_{23}-\tilde{\alpha}_{32} \tau_{32} \sigma_{33}+\left(\sigma_{13}-\sigma_{23}\right)=0$

(ii) $E_{t}\left[\left(\hat{C}_{1, t+1}-\hat{C}_{3, t+1}\right)\left(\hat{R}_{i, t+1}-\hat{R}_{f, t+1}\right)\right]=0$ for $\mathrm{i}=1,2,3$

$$
\begin{aligned}
& =E_{t}\left[\left\{\tilde{\alpha}_{11}\left(\hat{R}_{1, t+1}-\hat{R}_{f, t+1}\right)+\tilde{\alpha}_{21}\left(\hat{R}_{2, t+1}-\hat{R}_{f, t+1}\right)+\tilde{\alpha}_{31}\left(\hat{R}_{3, t+1}-\hat{R}_{f, t+1}\right)-\tilde{\alpha}_{13}\left(\hat{R}_{1, t+1}-\hat{R}_{f, t+1}\right)\right.\right. \\
& \left.\left.-\tilde{\alpha}_{23}\left(\hat{R}_{2, t+1}-\hat{R}_{f, t+1}\right)-\tilde{\alpha}_{33}\left(\hat{R}_{3, t+1}-\hat{R}_{f, t+1}\right)+\left(\hat{Y}_{1, t+1}-\hat{Y}_{3, t+1}\right)-\left(\hat{W}_{1, t+1}-\hat{W}_{3, t+1}\right)\right\} \times\left(\hat{R}_{i, t+1}-\hat{R}_{f, t+1}\right)\right]
\end{aligned}
$$

where $E_{t}\left[\left\{\left(\hat{W}_{1, t+1}-\hat{W}_{3, t+1}\right)\right\} \times\left(\hat{R}_{i, t+1}-\hat{R}_{f, t+1}\right)\right]=0$

for $i=1,=\tilde{\alpha}_{11} \sigma_{11}+\tilde{\alpha}_{21} \sigma_{12}+\tilde{\alpha}_{31} \sigma_{13}-\tilde{\alpha}_{13} \tau_{13} \sigma_{11}-\tilde{\alpha}_{23} \sigma_{12}-\tilde{\alpha}_{33} \sigma_{13}+\left(\sigma_{11}-\sigma_{13}\right)=0$

for $i=2,=\tilde{\alpha}_{11} \sigma_{12}+\tilde{\alpha}_{21} \boldsymbol{\tau}_{21} \sigma_{22}+\tilde{\alpha}_{31} \sigma_{23}-\tilde{\alpha}_{13} \sigma_{12}-\tilde{\alpha}_{23} \tau_{23} \sigma_{22}-\tilde{\alpha}_{33} \sigma_{23}+\left(\sigma_{12}-\sigma_{23}\right)=0$

for $i=3,=\tilde{\alpha}_{11} \sigma_{13}+\tilde{\alpha}_{21} \sigma_{23}+\tilde{\alpha}_{31} \tau_{31} \sigma_{33}-\tilde{\alpha}_{13} \sigma_{13}-\tilde{\alpha}_{23} \sigma_{23}-\tilde{\alpha}_{33} \sigma_{33}+\left(\sigma_{13}-\sigma_{33}\right)=0$

We solve the system of equations (i),(ii) (6 equations) with asset market clearing conditions and the steady state assumption of wealth $(\bar{W}=0)$ (3 equations).

$$
\begin{aligned}
& \tilde{\alpha}_{11}+\tilde{\alpha}_{21}+\tilde{\alpha}_{31}=0 \\
& \tilde{\alpha}_{21}+\tilde{\alpha}_{31}-\tilde{\alpha}_{12}-\tilde{\alpha}_{13}=0 \\
& \tilde{\alpha}_{13}+\tilde{\alpha}_{23}-\tilde{\alpha}_{31}-\tilde{\alpha}_{32}=0
\end{aligned}
$$

which are derived from $\tilde{\alpha}_{1 i}+\tilde{\alpha}_{2 i}+\tilde{\alpha}_{3 i}=0 \& \tilde{\alpha}_{i 1}+\tilde{\alpha}_{i 2}+\tilde{\alpha}_{i 3}=0$ 


\section{Derivation of (12)}

To solve for the holdings by country $i$ of country $j$ assets, combine the equation (6')

$E_{t}\left[\hat{R}_{j, t+1}-\hat{R}_{f, t+1}+\frac{1}{2} \hat{R}_{j, t+1}^{2}-\frac{1}{2} \hat{R}_{f, t+1}^{2}\right]=\gamma \cdot E_{t}\left[\hat{C}_{i, t+1}\left(\hat{R}_{j, t+1}-\hat{R}_{f, t+1}\right)\right]$ for $j=1,2, \ldots, \mathrm{N}$ with

equation (2'), the log linearization of the budget constraint evaluated for country $i$,

$\hat{W}_{i, t+1}=\sum_{k=1}^{N} \tilde{\alpha}_{k 1}\left(\hat{R}_{k, t+1}-\hat{R}_{f, t+1}\right)+\hat{Y}_{i, t+1}-\hat{C}_{i, t+1}$

Substitute (2') into (6') and examine the conditions in terms of country specific assets $(j=1,2, \ldots, N)$, then we obtain equations (6'”) below

$E_{t}\left[\hat{R}_{j, t+1}-\hat{R}_{f, t+1}+\frac{1}{2} \hat{R}_{j, t+1}^{2}-\frac{1}{2} \hat{R}_{f, t+1}^{2}\right]=\gamma \cdot E_{t}\left[\left(\sum_{k=1}^{N} \tilde{\alpha}_{k i}\left(\hat{R}_{k, t+1}-\hat{R}_{f, t+1}\right)+\hat{Y}_{i, t+1}-\hat{W}_{i, t+1}\right)\left(\hat{R}_{j, t+1}-\hat{R}_{f, t+1}\right)\right]$

for $j=1, \ldots, \mathrm{N}$

Therefore,

$E_{t}\left[\hat{R}_{j, t+1}-\hat{R}_{f, t+1}+\frac{1}{2} \hat{R}_{j, t+1}^{2}-\frac{1}{2} \hat{R}_{f, t+1}^{2}\right]=\gamma \cdot E_{t}\left[\sum_{k=1}^{N} \tilde{\alpha}_{k i}\left(\hat{R}_{k, t+1}-\hat{R}_{f, t+1}\right)\left(\hat{R}_{j, t+1}-\hat{R}_{f, t+1}\right)+\hat{Y}_{i, t+1}\left(\hat{R}_{j, t+1}-\hat{R}_{f, t+1}\right)\right]$

for $j=1, \ldots, \mathrm{N}$, where, $E_{t}\left[\hat{W}_{i, t+1}\left(\hat{R}_{j, t+1}-\hat{R}_{f, t+1}\right)\right]=0$

Hence, we have $\mathrm{N}$ equations as follows;

$$
\begin{aligned}
& \text { for } j=1, \quad E_{t}\left[\hat{R}_{1 t+1}-\hat{R}_{f t+1}+\frac{1}{2}\left(\hat{R}_{1 t+1}^{2}-\hat{R}_{f t+1}^{2}\right)\right] \\
& =\gamma \cdot E_{t}\left[\left(\tilde{\alpha}_{1 i}\left(\hat{R}_{1 t+1}-\hat{R}_{f t+1}\right)^{2}+\tilde{\alpha}_{2 i}\left(\hat{R}_{2 t+1}-\hat{R}_{f t+1}\right)\left(\hat{R}_{1 t+1}-\hat{R}_{f t+1}\right)+\ldots+\tilde{\alpha}_{N i}\left(\hat{R}_{N t+1}-\hat{R}_{f t+1}\right)\left(\hat{R}_{1 t+1}-\hat{R}_{f t+1}\right)+\hat{Y}_{i t+1}\left(\hat{R}_{1 t+1}-\hat{R}_{f t+1}\right)\right]\right.
\end{aligned}
$$

for $j=\mathrm{N}, \quad E_{t}\left[\hat{R}_{N t+1}-\hat{R}_{f t+1}+\frac{1}{2}\left(\hat{R}_{N t+1}^{2}-\hat{R}_{f t+1}^{2}\right)\right]$

$$
=\gamma \cdot E_{t}\left[\left(\tilde{\alpha}_{1 i}\left(\hat{R}_{\mathrm{It}+1}-\hat{R}_{f t+1}\right)\left(\hat{R}_{N t+1}-\hat{R}_{f t+1}\right)+\tilde{\alpha}_{2 i}\left(\hat{R}_{2 t+1}-\hat{R}_{f t+1}\right)\left(\hat{R}_{N t+1}-\hat{R}_{f t+1}\right)+\ldots+\tilde{\alpha}_{N i}\left(\hat{R}_{N t+1}-\hat{R}_{f t+1}\right)^{2}+\hat{Y}_{i t+1}\left(\hat{R}_{N t+1}-\hat{R}_{f t+1}\right)\right]\right.
$$

Solve the expectation terms of the right hand sides,

$$
\begin{aligned}
& \text { for } j=1, \frac{1}{\gamma} E_{t}\left[\hat{R}_{1 t+1}-\hat{R}_{f t+1}+\frac{1}{2}\left(\hat{R}_{1 t+1}^{2}-\hat{R}_{f t+1}^{2}\right)\right]=\tilde{\alpha}_{1 i} \tau_{1 i} \sigma_{11}+\tilde{\alpha}_{2 i} \sigma_{12}+\ldots+\underbrace{\left(1+\tilde{\alpha}_{i i}\right.}_{\tilde{\tilde{\alpha}}_{i i}}) \sigma_{1 i}+\ldots+\tilde{\alpha}_{N i} \sigma_{1 N} \\
& \text { for } j=2, \frac{1}{\gamma} E_{t}\left[\hat{R}_{2 t+1}-\hat{R}_{f t+1}+\frac{1}{2}\left(\hat{R}_{2 t+1}^{2}-\hat{R}_{f t+1}^{2}\right)\right]=\tilde{\alpha}_{1 i} \sigma_{12}+\tilde{\alpha}_{2 i} \tau_{2 i} \sigma_{22}+\ldots+\underbrace{\left(1+\tilde{\alpha}_{i i}\right.}_{\tilde{\tilde{\alpha}}_{i i}}) \sigma_{2 i}+\ldots+\tilde{\alpha}_{N i} \sigma_{2 N}
\end{aligned}
$$


for $j=i, \frac{1}{\gamma} E_{t}\left[\hat{R}_{i t+1}-\hat{R}_{f t+1}+\frac{1}{2}\left(\hat{R}_{i t+1}^{2}-\hat{R}_{f t+1}^{2}\right)\right]=\tilde{\alpha}_{1 i} \sigma_{1 i}+\tilde{\alpha}_{2 i} \sigma_{2 i}+\ldots+\underbrace{\left(1+\tilde{\alpha}_{i i}\right.}_{\tilde{\alpha}_{i i}}) \sigma_{i i}+\ldots+\tilde{\alpha}_{N i} \sigma_{i N}$

for $j=\mathrm{N}$,

$$
\frac{1}{\gamma} E_{t}\left[\hat{R}_{N t+1}-\hat{R}_{f t+1}+\frac{1}{2}\left(\hat{R}_{N t+1}^{2}-\hat{R}_{f t+1}^{2}\right)\right]=\tilde{\alpha}_{1 i} \sigma_{1 N}+\tilde{\alpha}_{2 i} \sigma_{2 N}+\ldots+\underbrace{\left(1+\tilde{\alpha}_{i i}\right.}_{\tilde{\tilde{\alpha}}_{i i}}) \sigma_{N i}+\ldots+\tilde{\alpha}_{N i} \tau_{N i} \sigma_{N N}
$$

Then, obtain matrix equation as follows,

$$
\Omega_{i} \cdot A_{(i)}=H .
$$

where

$$
A_{i i}=\left(\begin{array}{c}
\tilde{\alpha}_{1 i} \\
\tilde{\alpha}_{2 i} \\
\vdots \\
\tilde{\alpha}_{i i} \\
\vdots \\
\tilde{\alpha}_{N i}
\end{array}\right), H=\left(\begin{array}{c}
E X_{1} \\
E X_{2} \\
\vdots \\
E X_{N}
\end{array}\right)=\left(\begin{array}{c}
\frac{1}{\gamma} E_{t}\left[\hat{R}_{1 t+1}-\hat{R}_{f t+1}+\frac{1}{2}\left(\hat{R}_{1 t+1}^{2}-\hat{R}_{f t+1}^{2}\right)\right] \\
\frac{1}{\gamma} E_{t}\left[\hat{R}_{2 t+1}-\hat{R}_{f t+1}+\frac{1}{2}\left(\hat{R}_{2 t+1}^{2}-\hat{R}_{f t+1}^{2}\right)\right] \\
\vdots \\
\frac{1}{\gamma} E_{t}\left[\hat{R}_{N t+1}-\hat{R}_{f t+1}+\frac{1}{2}\left(\hat{R}_{N t+1}^{2}-\hat{R}_{f t+1}^{2}\right)\right]
\end{array}\right), \Omega_{i}=\left(\begin{array}{cccc}
\tau \sigma_{11} & \sigma_{12} & \cdots & \sigma_{1 N} \\
\sigma_{12} & \tau \sigma_{22} & \cdots & \sigma_{2 N} \\
\vdots & \vdots & \sigma_{i i} & \vdots \\
\sigma_{1 N} & \sigma_{2 N} & \cdots & \tau \sigma_{N N}
\end{array}\right)
$$

\section{E. Second order Approximation of (13)}

We examine the case for source country $i=1$ and destination country $j=2$.

$$
\begin{aligned}
& \bar{\alpha}_{21}=\left.\bar{\alpha}_{21}\right|_{\left(\hat{R}_{k}=\overline{\hat{R}}_{f}, \bar{Y}, \bar{\tau}, \bar{v}, \bar{\sigma}\right)}+\left.\frac{\partial \bar{\alpha}_{21}}{\partial \hat{R}_{1}}\right|_{\left(\overline{\hat{R}}_{f}, \bar{\tau}, \bar{v}, \bar{\sigma}\right)} E_{t}\left(\hat{R}_{1}-\overline{\hat{R}}_{f}\right)+\left.\frac{\partial \bar{\alpha}_{21}}{\partial \hat{R}_{2}}\right|_{\left(\hat{\hat{R}}_{f}, \bar{\tau}, \bar{v}, \bar{\sigma}\right)} E_{t}\left(\hat{R}_{2}-\overline{\hat{R}}_{f}\right)+\left.\sum_{k=3}^{N} \frac{\partial \bar{\alpha}_{21}}{\partial \hat{R}_{k}}\right|_{\left(\hat{R}_{f}, \bar{\tau}, \bar{v}, \bar{\sigma}\right)} E_{t}\left(\hat{R}_{k}-\overline{\hat{R}}_{f}\right) \\
& +\left.\frac{1}{2} \frac{\partial^{2} \bar{\alpha}_{21}}{\partial \hat{R}_{1} \partial \hat{R}_{1}}\right|_{\left(\hat{R}_{f}, \bar{\tau}, \bar{v}, \bar{\sigma}\right)} E_{t}\left(\hat{R}_{1}-\overline{\hat{R}}_{f}\right)^{2}+\left.\frac{1}{2} \frac{\partial^{2} \bar{\alpha}_{21}}{\partial \hat{R}_{2} \partial \hat{R}_{2}}\right|_{\left(\hat{R}_{f}, \bar{\tau}, \bar{v}, \bar{\sigma}\right)} E_{t}\left(\hat{R}_{2}-\overline{\hat{R}}_{f}\right)^{2}+\left.\frac{1}{2} \sum_{k=3}^{N} \frac{\partial^{2} \bar{\alpha}_{21}}{\partial \hat{R}_{k} \partial \hat{R}_{k}}\right|_{\left(\hat{R}_{f}, \bar{\tau}, \bar{v}, \bar{\sigma}\right)} E_{t}\left(\hat{R}_{k}-\overline{\hat{R}}_{f}\right)^{2} \\
& +\left.\frac{1}{2} \frac{\partial^{2} \bar{\alpha}_{21}}{\partial \hat{R}_{1} \partial \hat{R}_{2}}\right|_{\left(\hat{R}_{f}, \bar{\tau}, \bar{v}, \bar{\sigma}\right)} E_{t}\left(\hat{R}_{1}-\overline{\hat{R}}_{f}\right)\left(\hat{R}_{2}-\overline{\hat{R}}_{f}\right) \\
& +\left.\frac{1}{2} \frac{\partial^{2} \bar{\alpha}_{21}}{\partial \hat{R}_{1} \partial \hat{R}_{3}}\right|_{\left(\hat{\hat{R}}_{f}, \bar{\tau}, \bar{v}, \bar{\sigma}\right)} E_{t}\left(\hat{R}_{1}-\overline{\hat{R}}_{f}\right)\left(\hat{R}_{3}-\overline{\hat{R}}_{f}\right)+\ldots+\left.\frac{1}{2} \frac{\partial^{2} \bar{\alpha}_{21}}{\partial \hat{R}_{1} \partial \hat{R}_{j, j \neq 1,2}}\right|_{\left(\overline{\hat{R}}_{f}, \bar{\tau}, \bar{v}, \bar{\sigma}\right)} E_{t}\left(\hat{R}_{1}-\overline{\hat{R}}_{f}\right)\left(\hat{R}_{j}-\overline{\hat{R}}_{f}\right)
\end{aligned}
$$




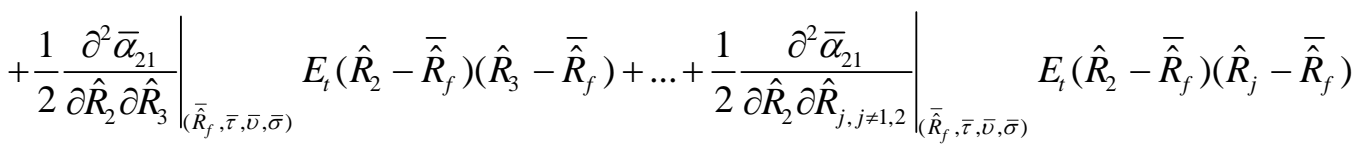

$$
\begin{aligned}
& +\left.\frac{1}{2} \sum_{i \neq 1,2}^{N} \sum_{j \neq 1,2}^{N} \frac{\partial^{2} \bar{\alpha}_{21}}{\partial \hat{R}_{i} \partial \hat{R}_{j}}\right|_{\left(\overline{\hat{R}}_{f}, \bar{\tau}, \bar{\nu}, \bar{\sigma}\right)} E_{t}\left(\hat{R}_{i}-\overline{\hat{R}}_{f}\right)\left(\hat{R}_{j}-\overline{\hat{R}}_{f}\right)+\left.\frac{\partial \bar{\alpha}_{21}}{\partial \tau}\right|_{\left(\hat{R}_{k}=\overline{\hat{R}}_{f}, \overline{\mathbf{Y}}, \overline{\bar{\nu}}, \bar{\sigma}\right)} E_{t}(\tilde{\tau}-\bar{\tau})+\mathrm{O}\left(\Sigma^{2}\right) \\
& \text { where }\left.\frac{\partial \bar{\alpha}_{21}}{\partial Y_{1}}\right|_{\left(\hat{R}_{k}=\overline{\hat{R}}_{f}, \bar{\tau}, \bar{b}, \bar{\sigma}\right)}=0
\end{aligned}
$$

Rearrange the above approximation equation as follows;

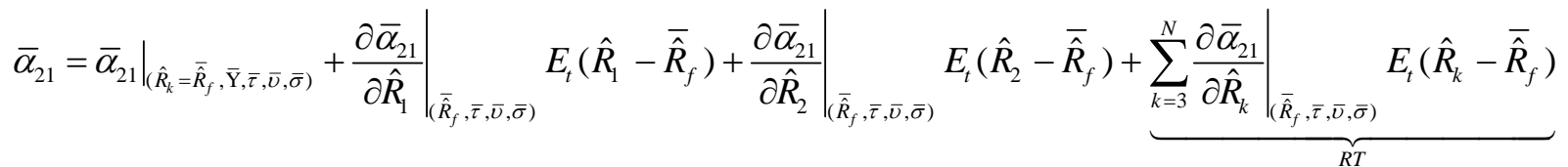

$$
\begin{aligned}
& +\left.\frac{1}{2} \frac{\partial^{2} \bar{\alpha}_{21}}{\partial \hat{R}_{1}^{2}}\right|_{\left.\overline{\hat{R}}_{f}, \bar{\tau}, \overline{,}, \bar{\sigma}\right)} \tilde{\sigma}_{11}+\left.\frac{1}{2} \frac{\partial^{2} \bar{\alpha}_{21}}{\partial \hat{R}_{2}^{2}}\right|_{\left.\overline{\hat{R}}_{f}, \bar{\tau}, \overline{,}, \bar{\sigma}\right)} \tilde{\sigma}_{22}+\underbrace{\left.\frac{1}{2} \sum_{k=3}^{N} \frac{\partial^{2} \bar{\alpha}_{21}}{\partial \hat{R}_{k}^{2}}\right|_{\left(\bar{R}_{f}, \bar{\tau}, \bar{\nu}, \bar{\sigma}\right)} \tilde{\sigma}_{k k}}_{V T} \\
& +\left.\frac{1}{2} \frac{\partial^{2} \bar{\alpha}_{21}}{\partial \hat{R}_{1} \partial \hat{R}_{2}}\right|_{\left(\bar{R}_{f}, \bar{\tau}, \bar{v}, \bar{\sigma}\right)} \tilde{\sigma}_{12}+\underbrace{\left.\frac{1}{2} \frac{\partial^{2} \bar{\alpha}_{21}}{\partial \hat{R}_{1} \partial \hat{R}_{3}}\right|_{\left.\hat{R}_{\hat{R},}, \bar{\tau}, \bar{v}, \bar{\sigma}\right)} \tilde{\sigma}_{13}+\ldots+\left.\frac{1}{2} \frac{\partial^{2} \bar{\alpha}_{21}}{\partial \hat{R}_{1} \partial \hat{R}_{j, j \neq 1,2}}\right|_{\left(\bar{R}_{f}, \bar{\tau}, \overline{\bar{v}}, \bar{\sigma}\right)} \tilde{\sigma}_{1 j}}_{M T} \\
& \underbrace{+\left.\frac{1}{2} \frac{\partial^{2} \bar{\alpha}_{21}}{\partial \hat{R}_{2} \partial \hat{R}_{3}}\right|_{\left(\bar{R}_{f}, \bar{t}, \overline{,}, \bar{\sigma}\right)} \tilde{\sigma}_{23}+\ldots+\left.\frac{1}{2} \frac{\partial^{2} \bar{\alpha}_{21}}{\partial \hat{R}_{2} \partial \hat{R}_{j, j \neq 1,2}}\right|_{\left(\bar{R}_{f}, \bar{z}, \bar{v}, \bar{\sigma}\right)} \tilde{\sigma}_{2 j}}_{D T}+\underbrace{\left.\frac{1}{2} \sum_{i \neq 1,2}^{N} \sum_{j \neq 1,2}^{N} \frac{\partial^{2} \bar{\alpha}_{21}}{\partial \hat{R}_{i} \partial \hat{R}_{j}}\right|_{\left(\bar{R}_{f}, \bar{\tau}, \overline{,}, \bar{\sigma}\right)} \tilde{\sigma}_{i j}}_{O T} \\
& +\left.\frac{\partial \bar{\alpha}_{21}}{\partial \tau}\right|_{\left.\hat{R}_{k}=\overline{\hat{R}}_{f}, \overline{\bar{y}}, \bar{v}, \bar{\sigma}\right)}(\tilde{\tau}-\bar{\tau})+\mathrm{O}\left(\Sigma^{2}\right)
\end{aligned}
$$

\section{Because}

$$
\begin{aligned}
& \text { i) }\left.\frac{\partial \bar{\alpha}_{21}}{\partial \hat{R}_{3}}\right|_{\left(\bar{R}_{f}, \bar{\tau}, \bar{\nu}, \bar{\sigma}\right)}=\ldots=\left.\frac{\partial \bar{\alpha}_{21}}{\partial \hat{R}_{N}}\right|_{\left(\overline{\hat{R}}_{f}, \bar{\tau}, \bar{\nu}, \bar{\sigma}\right)} \\
& \text { ii) }\left.\frac{\partial^{2} \bar{\alpha}_{21}}{\partial \hat{R}_{3}^{2}}\right|_{\bar{R}_{\left.\hat{R}_{f}, \bar{\tau}, \bar{\sigma}, \bar{\sigma}\right)}}=\ldots=\left.\frac{\partial^{2} \bar{\alpha}_{21}}{\partial \hat{R}_{N}^{2}}\right|_{\left(\bar{R}_{f}, \bar{\tau}, \bar{\sigma}, \bar{\sigma}\right)} \text {, iii) }\left.\frac{\partial^{2} \bar{\alpha}_{21}}{\partial \hat{R}_{1} \partial \hat{R}_{3}}\right|_{\left(\bar{R}_{f}, \bar{\tau}, \bar{\nu}, \bar{\sigma}\right)}=\ldots=\left.\frac{\partial^{2} \bar{\alpha}_{21}}{\partial \hat{R}_{1} \partial \hat{R}_{N}}\right|_{\left(\bar{R}_{f}, \bar{\tau}, \bar{v}, \bar{\sigma}\right)} \text {, } \\
& \text { iv) }\left.\frac{\partial^{2} \bar{\alpha}_{21}}{\partial \hat{R}_{2} \partial \hat{R}_{3}}\right|_{\left(\bar{R}_{f}, \bar{\tau}, \bar{v}, \bar{\sigma}\right)}=\ldots=\left.\frac{\partial^{2} \bar{\alpha}_{21}}{\partial \hat{R}_{2} \partial \hat{R}_{\mathrm{N}}}\right|_{\left(\bar{R}_{f}, \overline{,}, \overline{,}, \bar{\sigma}\right)}
\end{aligned}
$$


and v) $\left.\frac{\partial^{2} \bar{\alpha}_{21}}{\partial \hat{R}_{m} \partial \hat{R}_{n}}\right|_{\left(\bar{R}_{R}, \bar{\tau}, \bar{v}, \bar{\sigma}\right)}=\ldots=\left.\frac{\partial^{2} \bar{\alpha}_{21}}{\partial \hat{R}_{N} \partial \hat{R}_{N-1}}\right|_{\left.\bar{R}_{R}, \bar{\tau}, \bar{v}, \bar{\sigma}\right)} \quad$ (for $\mathrm{m}, \mathrm{n} \neq 1,2$ and $\mathrm{m} \neq \mathrm{n}$ )

Hence, rewrite the approximation equation as follows;

$$
\begin{gathered}
\bar{\alpha}_{21}=\bar{\alpha}+\bar{D} \cdot E_{t}\left(\hat{R}_{1}-\overline{\hat{R}}_{f}\right)+\bar{E} \cdot E_{t}\left(\hat{R}_{2}-\overline{\hat{R}}_{f}\right)+\bar{F} \cdot \sum_{k=3}^{N} E_{t}\left(\hat{R}_{k}-\overline{\hat{R}}_{f}\right)+\bar{G} \cdot \sigma_{11}+\bar{I} \cdot \sigma_{22}+\bar{J} \cdot \sum_{k=3}^{N} \sigma_{k k} \\
+\bar{K} \cdot \sigma_{12}+\bar{L} \cdot \sum_{k \neq 1,2}^{N} \sigma_{1 k}+\bar{P} \cdot \sum_{l \neq 1,2}^{N} \sigma_{2 l}+\bar{Q} \cdot \sum_{i \neq 1,2}^{N} \sum_{j \neq 1,2, j \neq i}^{N} \sigma_{i j}+\bar{R} \cdot(\tau-\bar{\tau})+\mathrm{O}\left(\Sigma^{2}\right)
\end{gathered}
$$

See the following proofs;

$\underline{\text { Proof }} \mathbf{i})\left.\frac{\partial \bar{\alpha}_{21}}{\partial \hat{R}_{3}}\right|_{\left.\bar{R}_{R}, \overline{\bar{t}}, \overline{\bar{\nu}}, \bar{\sigma}\right)}=\ldots=\left.\frac{\partial \bar{\alpha}_{21}}{\partial \hat{R}_{\mathrm{N}}}\right|_{\left(\overline{\hat{R}}_{f}, \overline{\bar{\tau}}, \bar{\nu}, \bar{\sigma}\right)}=\bar{F}$

From equation (13), $\frac{\partial \bar{\alpha}_{21}}{\partial \hat{R}_{m}}=\frac{\beta}{\gamma} Y_{1} \Omega_{1(2, m)}^{-1}\left(1+\hat{R}_{m}\right)+\frac{\beta}{\gamma} Y_{1} \sum_{k=1}^{N} \frac{\partial\left(\Omega_{1}^{-1}\right)_{(2, k)}}{\partial \hat{R}_{m}} E\left[\hat{R}_{k}-\hat{R}_{f}+\frac{1}{2}\left(\hat{R}_{k}^{2}-\hat{R}_{f}^{2}\right)\right]$ Because $\left.\sum_{k=1}^{N} \frac{\partial\left(\Omega_{1}^{-1}\right)_{(2, k)}}{\partial \hat{R}_{m}}\right|_{\left(\bar{R}_{t}, \bar{\tau}, \bar{\sigma}, \bar{\sigma}\right)}=0$ for $\mathrm{m}=1, \ldots \mathrm{N}$ (The inverse of the omega matrix includes second order terms only, so partial derivative with respect to equity return evaluated at the point, $\overline{\hat{R}}_{f}$, is zero), $\frac{\partial \bar{\alpha}_{21}}{\partial \hat{R}_{m}}=\frac{\beta}{\gamma} Y_{1} \Omega_{1(2, m)}^{-1}\left(1+\hat{R}_{m}\right)$

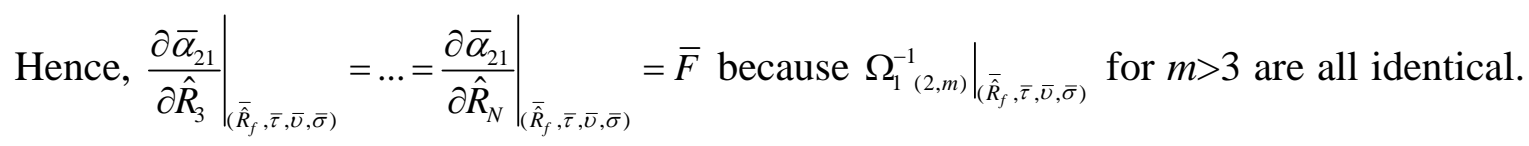

Proof ii) $\left.\frac{\partial^{2} \bar{\alpha}_{21}}{\partial \hat{R}_{3}^{2}}\right|_{\left(\bar{R}_{f}, \bar{\tau}, \bar{v}, \bar{\sigma}\right)}=\ldots=\left.\frac{\partial^{2} \bar{\alpha}_{21}}{\partial \hat{R}_{N}^{2}}\right|_{\left(\bar{R}_{f}, \bar{\tau}, \bar{\nu}, \bar{\sigma}\right)}=\bar{J}$

From equation (13), $\frac{\partial \bar{\alpha}_{21}}{\partial \hat{R}_{m}}=\frac{\beta}{\gamma} \bar{Y} \Omega_{1(2, m)}^{-1}\left(1+\hat{R}_{m}\right)+\frac{\beta}{\gamma} \bar{Y} \sum_{k=1}^{N} \frac{\partial\left(\Omega_{1}^{-1}\right)_{(2, k)}}{\partial \hat{R}_{m}} E\left[\hat{R}_{k}-\hat{R}_{f}+\frac{1}{2}\left(\hat{R}_{k}^{2}-\hat{R}_{f}^{2}\right)\right]$ $\frac{\partial^{2} \bar{\alpha}_{21}}{\partial \hat{R}_{m} \partial \hat{R}_{m}}=\frac{\beta}{\gamma} \bar{Y}\left(\left(\Omega_{1}^{-1}\right)_{(2, m)}+2 \frac{\partial\left(\Omega_{1}^{-1}\right)_{(2, m)}}{\partial \hat{R}_{m}}\left(1+\hat{R}_{m}\right)+\sum_{k=1}^{N} \frac{\partial^{2}\left(\Omega_{1}^{-1}\right)_{(2, k)}}{\partial \hat{R}_{m} \partial \hat{R}_{m}} E\left[\hat{R}_{k}-\hat{R}_{f}+\frac{1}{2}\left(\hat{R}_{k}^{2}-\hat{R}_{f}^{2}\right)\right]\right)$

for $\mathrm{m}=3, \ldots, \mathrm{N}$ 
Note) Differentiation of the inverse of the matrix

$$
\Omega_{1}^{-1} \Omega_{1}=I
$$

Differentiate with respect to equity return i

$$
\frac{\partial \Omega_{1}^{-1}}{\partial \hat{R}_{i}} \Omega_{1}+\Omega_{1}^{-1} \frac{\partial \Omega_{1}}{\partial \hat{R}_{i}}=0 \quad \therefore \frac{\partial \Omega_{1}^{-1}}{\partial \hat{R}_{i}}=-\Omega_{1}^{-1} \frac{\partial \Omega_{1}}{\partial \hat{R}_{i}} \Omega_{1}^{-1}
$$

Differentiate with respect to equity return $\mathrm{j}$ again,

$$
\begin{gathered}
\frac{\partial^{2} \Omega_{1}^{-1}}{\partial \hat{R}_{i} \partial \hat{R}_{j}} \Omega_{1}+\frac{\partial \Omega_{1}^{-1}}{\partial \hat{R}_{i}} \frac{\partial \Omega_{1}}{\partial \hat{R}_{j}}+\frac{\partial \Omega_{1}^{-1}}{\partial \hat{R}_{j}} \frac{\partial \Omega_{1}}{\partial \hat{R}_{i}}+\Omega_{1}^{-1} \frac{\partial^{2} \Omega_{1}}{\partial \hat{R}_{i} \partial \hat{R}_{j}}=0 \\
\text { So, } \frac{\partial^{2} \Omega_{1}^{-1}}{\partial \hat{R}_{i} \partial \hat{R}_{j}}=-\left(\frac{\partial \Omega_{1}^{-1}}{\partial \hat{R}_{i}} \frac{\partial \Omega_{1}}{\partial \hat{R}_{j}}+\frac{\partial \Omega_{1}^{-1}}{\partial \hat{R}_{j}} \frac{\partial \Omega_{1}}{\partial \hat{R}_{i}}+\Omega_{1}^{-1} \frac{\partial^{2} \Omega_{1}}{\partial \hat{R}_{i} \partial \hat{R}_{j}}\right) \Omega_{1}^{-1}
\end{gathered}
$$

By $(*)$, the derivative of matrix inverse,

$$
\frac{\partial^{2} \Omega_{1}^{-1}}{\partial \hat{R}_{i} \partial \hat{R}_{j}}=-\left(-\Omega_{1}^{-1} \frac{\partial \Omega_{1}}{\partial \hat{R}_{i}} \Omega_{1}^{-1} \frac{\partial \Omega_{1}}{\partial \hat{R}_{j}}-\Omega_{1}^{-1} \frac{\partial \Omega_{1}}{\partial \hat{R}_{j}} \Omega_{1}^{-1} \frac{\partial \Omega_{1}}{\partial \hat{R}_{i}}+\Omega_{1}^{-1} \frac{\partial^{2} \Omega_{1}}{\partial \hat{R}_{i} \partial \hat{R}_{j}}\right) \Omega_{1}^{-1}
$$

$\Omega_{1}$ is a symmetric matrix and the inverse of $\Omega_{1}$ is also symmetric.

$\left.\Omega_{1}\right|_{\left(\overline{\hat{R}}_{f}, \bar{\tau}, \bar{\sigma}, \bar{\sigma}\right)}=\left(\begin{array}{cccc}\bar{v} & \bar{\sigma} & \ldots & \bar{\sigma} \\ \bar{\sigma} & \overline{\boldsymbol{\tau}} \times \overline{\boldsymbol{v}} & & \bar{\sigma} \\ \vdots & & \ddots & \\ \bar{\sigma} & \bar{\sigma} & \ldots & \overline{\boldsymbol{\tau}} \times \overline{\boldsymbol{v}}\end{array}\right)$, Because of multiplication of tau, the inverse covariance matrix is denoted as $\left.\Omega_{1}^{-1}\right|_{\left(\bar{R}_{f}, \bar{\tau}, \bar{v}, \bar{\sigma}\right)}=\left(\begin{array}{cccc}a & b & \cdots & b \\ b & c & & d \\ \vdots & & \ddots & \\ b & d & \cdots & c\end{array}\right)$ where $a>c>0$ and $b \leq d \leq 0$, and its leading principal minors are all positive; $a c-b^{2}>0, b d-b c>0, c^{2}-d^{2}>0$ and $b^{2}-b d>0$.

For instance,

a) $\left.\frac{\partial^{2} \bar{\alpha}_{21}}{\partial \hat{R}_{3} \partial \hat{R}_{3}}\right|_{\left(\overline{\hat{R}}_{f}, \bar{\tau}, \bar{v}, \bar{\sigma}\right)}=\left.\frac{\beta}{\gamma} \bar{Y}\left(\Omega_{1}^{-1}\right)_{(2,3)}\right|_{\left(\bar{R}_{f}, \bar{\tau}, \bar{v}, \bar{\sigma}\right)}+\left.\frac{\beta}{\gamma} \bar{Y} \sum_{k=1}^{N} \frac{\partial^{2}\left(\Omega_{1}^{-1}\right)_{(2, k)}}{\partial \hat{R}_{3} \partial \hat{R}_{3}} E\left[\hat{R}_{k}-\hat{R}_{f}+\frac{1}{2}\left(\hat{R}_{k}^{2}-\hat{R}_{f}^{2}\right)\right]\right|_{\left(\bar{R}_{f}, \bar{\tau}, \bar{\nu}, \bar{\sigma}\right)}$

Based on the differentiation rule of inverse matrix, 


$$
\begin{aligned}
& \left.\frac{\partial^{2} \Omega_{1}^{-1}}{\partial \hat{R}_{3} \partial \hat{R}_{3}}\right|_{\left(\bar{R}_{f}, \bar{\tau}, \bar{\nu}, \bar{\sigma}\right)}=-\left.\left(-\Omega_{1}^{-1} \frac{\partial \Omega_{1}}{\partial \hat{R}_{3}} \Omega_{1}^{-1} \frac{\partial \Omega_{1}}{\partial \hat{R}_{3}}-\Omega_{1}^{-1} \frac{\partial \Omega_{1}}{\partial \hat{R}_{3}} \Omega_{1}^{-1} \frac{\partial \Omega_{1}}{\partial \hat{R}_{3}}+\Omega_{1}^{-1} \frac{\partial^{2} \Omega_{1}}{\partial \hat{R}_{3} \partial \hat{R}_{3}}\right) \Omega_{1}^{-1}\right|_{\left(\bar{R}_{f}, \bar{\tau}, \bar{\nu}, \bar{\sigma}\right)}=-\left.\Omega_{1}^{-1} \frac{\partial^{2} \Omega_{1}}{\partial \hat{R}_{3} \partial \hat{R}_{3}} \Omega_{1}^{-1}\right|_{\left(\bar{R}_{f}, \bar{\tau}, \bar{\nu}, \bar{\sigma}\right)} \\
& \text { where }\left.\frac{\partial^{2} \Omega_{1}}{\partial \hat{R}_{3} \partial \hat{R}_{3}}\right|_{\left(\bar{R}_{f}, \bar{\tau}, \bar{v}, \bar{\sigma}\right)}=\left(\begin{array}{ccccc}
0 & 0 & 0 & \cdots & 0 \\
0 & 0 & 0 & \cdots & 0 \\
0 & 0 & \bar{\tau} & & 0 \\
\vdots & \vdots & & \ddots & \vdots \\
0 & 0 & & \cdots & 0
\end{array}\right),\left.\frac{\partial \Omega_{1}}{\partial \hat{R}_{3}}\right|_{\left(\bar{R}_{f}, \bar{\tau}, \bar{\nu}, \bar{\sigma}\right)}=\left(\begin{array}{ccccc}
0 & 0 & 0 & \cdots & 0 \\
0 & 0 & 0 & \cdots & 0 \\
0 & 0 & 0 & & 0 \\
\vdots & \vdots & & \ddots & \vdots \\
0 & 0 & & \cdots & 0
\end{array}\right)
\end{aligned}
$$

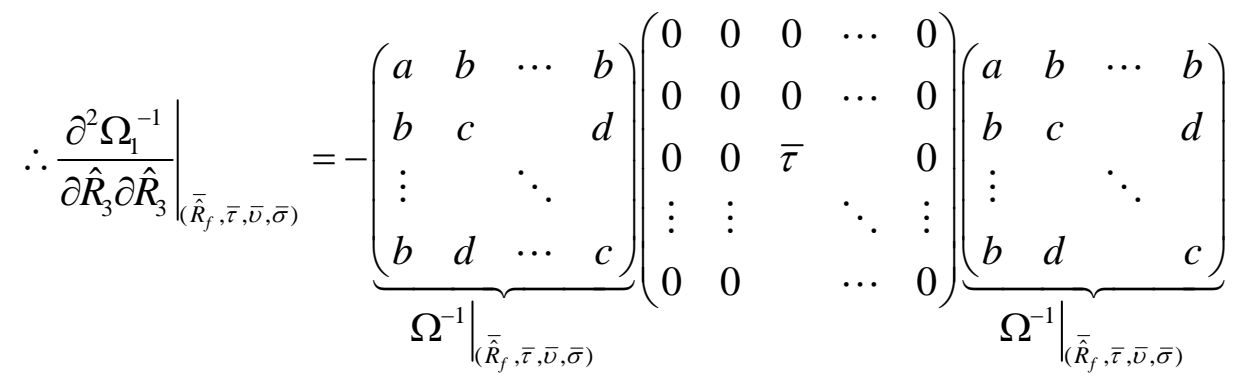

$$
\begin{aligned}
& =-\left(\begin{array}{cccc}
0 & 0 & b \bar{\tau} & 0 \\
0 & 0 & d \bar{\tau} & 0 \\
0 & 0 & c \bar{\tau} & 0 \\
\vdots & 0 & d \bar{\tau} & 0 \\
0 & 0 & d \bar{\tau} & 0
\end{array}\right) \underbrace{\left(\begin{array}{llll}
a & b & \cdots & b \\
b & c & & d \\
\vdots & & \ddots & \\
b & d & & c
\end{array}\right)}_{\left.\Omega^{-1}\right|_{\left.\bar{R}_{R}, \bar{\tau}, \bar{v}, \bar{\sigma}\right)}}
\end{aligned}
$$

Hence,

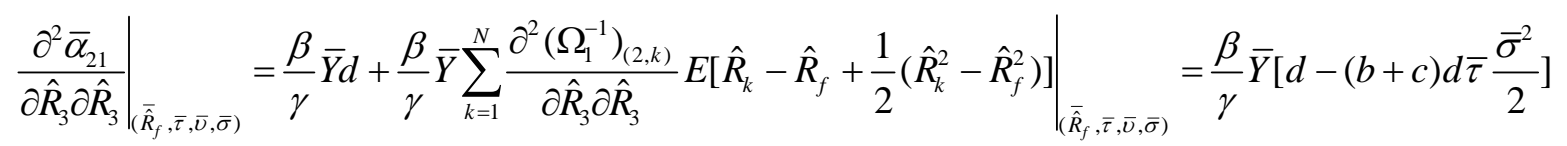$$
\text { where } \frac{\partial^{2}\left(\Omega_{1}^{-1}\right)_{(2,1)}}{\partial \hat{R}_{3} \partial \hat{R}_{3}}=-b d \bar{\tau}, \frac{\partial^{2}\left(\Omega_{1}^{-1}\right)_{(2,3)}}{\partial \hat{R}_{3} \partial \hat{R}_{3}}=-c d \bar{\tau} \text {; }
$$$$
E\left[\hat{R}_{1}-\hat{R}_{f}+\frac{1}{2}\left(\hat{R}_{1}^{2}-\hat{R}_{f}^{2}\right)\right]=\frac{\bar{\sigma}^{2}}{2} \text { and } E\left[\hat{R}_{3}-\hat{R}_{f}+\frac{1}{2}\left(\hat{R}_{3}^{2}-\hat{R}_{f}^{2}\right)\right]=\frac{\bar{\sigma}^{2}}{2} \text { but } E\left[\hat{R}_{k}-\hat{R}_{f}+\frac{1}{2}\left(\hat{R}_{k}^{2}-\hat{R}_{f}^{2}\right)\right]=0
$$

for $\mathrm{k}=2,4 \ldots, \mathrm{N}, \mathrm{k} \neq 1,3$, because $\hat{R}_{1}$ (a source country's return) and $\hat{R}_{3}$ are only variables and other return terms are considered as the constant.

Furthermore, 


$$
\begin{aligned}
& \left.\frac{\partial^{2} \bar{\alpha}_{21}}{\partial \hat{R}_{m} \partial \hat{R}_{m}}\right|_{\left(\bar{R}_{f}, \bar{\tau}, \bar{v}, \bar{\sigma}\right)}=\left.\frac{\beta}{\gamma} \bar{Y}\left(\Omega_{1}^{-1}\right)_{(2, m)}\right|_{\left(\bar{R}_{f}, \bar{\tau}, \bar{v}, \bar{\sigma}\right)}+\frac{\beta}{\gamma} \bar{Y} \sum_{k=1}^{N} \frac{\partial^{2}\left(\Omega_{1}^{-1}\right)_{(2, k)}}{\partial \hat{R}_{m} \partial \hat{R}_{m}} E\left[\hat{R}_{k}-\hat{R}_{f}+\left.\frac{1}{2}\left(\hat{R}_{k}^{2}-\hat{R}_{f}^{2}\right)\right|_{\left(\bar{R}_{f}, \bar{\tau}, \bar{v}, \bar{\sigma}\right)}\right. \\
& =\frac{\beta}{\gamma} \bar{Y} d+\left.\frac{\beta}{\gamma} \bar{Y} \sum_{k=1}^{N} \frac{\partial^{2}\left(\Omega_{1}^{-1}\right)_{(2, k)}}{\partial \hat{R}_{m} \partial \hat{R}_{m}} E\left[\hat{R}_{k}-\hat{R}_{f}+\frac{1}{2}\left(\hat{R}_{k}^{2}-\hat{R}_{f}^{2}\right)\right]\right|_{\left(\overline{\hat{R}}_{,}, \bar{\tau}, \bar{v}, \bar{\sigma}\right)}=\frac{\beta}{\gamma} \bar{Y}\left[d-(b+c) d \bar{\tau} \frac{\bar{\sigma}^{2}}{2}\right] \text { for } \mathrm{m}=3, . ., \mathrm{N}
\end{aligned}
$$

where $\frac{\partial^{2}\left(\Omega_{1}^{-1}\right)_{(2,1)}}{\partial \hat{R}_{m} \partial \hat{R}_{m}}=-b d \bar{\tau}, \frac{\partial^{2}\left(\Omega_{1}^{-1}\right)_{(2, m)}}{\partial \hat{R}_{m} \partial \hat{R}_{m}}=-c d \bar{\tau}$;

$$
E\left[\hat{R}_{1}-\hat{R}_{f}+\frac{1}{2}\left(\hat{R}_{1}^{2}-\hat{R}_{f}^{2}\right)\right]=\frac{\bar{\sigma}^{2}}{2} ; E\left[\hat{R}_{m}-\hat{R}_{f}+\frac{1}{2}\left(\hat{R}_{m}^{2}-\hat{R}_{f}^{2}\right)\right]=\frac{\bar{\sigma}^{2}}{2} \text { and } E\left[\hat{R}_{k}-\hat{R}_{f}+\frac{1}{2}\left(\hat{R}_{k}^{2}-\hat{R}_{f}^{2}\right)\right]=0
$$

for $\mathrm{k}=2, \ldots, \mathrm{N}, \mathrm{k} \neq 1, \mathrm{~m}$,

Hence, $\left.\frac{\partial^{2} \bar{\alpha}_{21}}{\partial \hat{R}_{3} \partial \hat{R}_{3}}\right|_{\left(\bar{R}_{f}, \bar{\tau}, \bar{v}, \bar{\sigma}\right)}=\left.\frac{\partial^{2} \bar{\alpha}_{21}}{\partial \hat{R}_{4} \partial \hat{R}_{4}}\right|_{\left(\bar{R}_{R}, \bar{\tau}, \bar{v}, \bar{\sigma}\right)}=\ldots=\left.\frac{\partial^{2} \bar{\alpha}_{21}}{\partial \hat{R}_{N} \partial \hat{R}_{N}}\right|_{\left(\bar{R}_{r}, \bar{\tau}, \bar{v}, \bar{\sigma}\right)}=\bar{J}$.

(Q.E.D)

$\left.\underline{\text { Proof iii) }} \frac{\partial^{2} \bar{\alpha}_{21}}{\partial \hat{R}_{1} \partial \hat{R}_{2}}\right|_{\left(\bar{R}_{r}, \bar{\tau}, \bar{v}, \bar{\sigma}\right)}=\bar{K}<0$

From equation (13),

$$
\begin{aligned}
& \frac{\partial^{2} \bar{\alpha}_{21}}{\partial \hat{R}_{1} \partial \hat{R}_{2}}=\frac{\beta}{\gamma} \bar{Y} \frac{\partial\left(\Omega_{1}^{-1}\right)_{(2,1)}}{\partial \hat{R}_{2}}\left(1+\hat{R}_{1}\right)+\frac{\beta}{\gamma} \bar{Y} \sum_{k=1}^{N} \frac{\partial^{2}\left(\Omega_{1}^{-1}\right)_{(2, k)}}{\partial \hat{R}_{1} \partial \hat{R}_{2}} E\left[\hat{R}_{k}-\hat{R}_{f}+\frac{1}{2}\left(\hat{R}_{k}^{2}-\hat{R}_{f}^{2}\right)\right]+\frac{\beta}{\gamma} \bar{Y} \frac{\partial\left(\Omega_{1}^{-1}\right)_{(2,2)}}{\partial \hat{R}_{1}}\left(1+\hat{R}_{2}\right) \\
& \left.\frac{\partial^{2} \bar{\alpha}_{21}}{\partial \hat{R}_{1} \partial \hat{R}_{2}}\right|_{\left(\overline{\hat{R}}_{f}, \bar{\tau}, \bar{v}, \bar{\sigma}\right)}=\left.\frac{\beta}{\gamma} Y_{1} \sum_{k=1}^{N} \frac{\partial^{2}\left(\Omega_{1}^{-1}\right)_{(2, k)}}{\partial \hat{R}_{1} \partial \hat{R}_{2}} E\left[\hat{R}_{k}-\hat{R}_{f}+\frac{1}{2}\left(\hat{R}_{k}^{2}-\hat{R}_{f}^{2}\right)\right]\right|_{\left(\overline{\hat{R}}_{f}, \bar{\tau}, \bar{\nu}, \bar{\sigma}\right)} \text { because } \\
& \left.\frac{\partial \Omega_{1}}{\partial \hat{R}_{2}}\right|_{\left(\overline{\hat{R}}_{f}, \bar{\tau}, \bar{v}, \bar{\sigma}\right)}=\left(\begin{array}{ccccc}
0 & 0 & 0 & \cdots & 0 \\
0 & 0 & 0 & \cdots & 0 \\
0 & 0 & 0 & & 0 \\
\vdots & \vdots & & \ddots & \vdots \\
0 & 0 & \cdots & 0
\end{array}\right)
\end{aligned}
$$




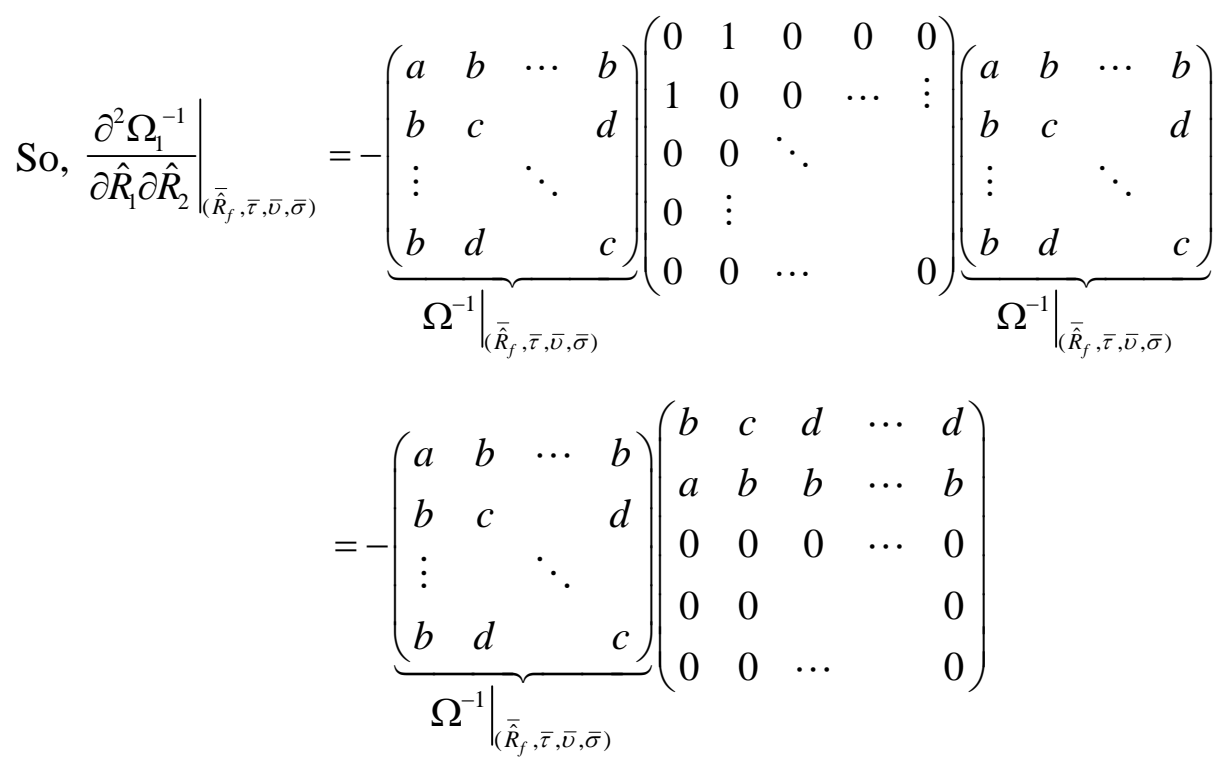

Hence,

$\left.\frac{\partial^{2} \bar{\alpha}_{21}}{\partial \hat{R}_{1} \partial \hat{R}_{2}}\right|_{\left(\bar{R}_{f}, \bar{\tau}, \bar{v}, \bar{\sigma}\right)}=\left.\frac{\beta}{\gamma} Y_{1} \sum_{k=1}^{N} \frac{\partial^{2}\left(\Omega^{-1}\right)_{(2, k)}}{\partial \hat{R}_{1} \partial \hat{R}_{2}} E\left[\hat{R}_{k}-\hat{R}_{f}+\frac{1}{2}\left(\hat{R}_{k}^{2}-\hat{R}_{f}^{2}\right)\right]\right|_{\left(\overline{\hat{R}}_{f}, \bar{\tau}, \bar{v}, \bar{\sigma}\right)}=-\frac{\beta \bar{\sigma}^{2}}{2 \gamma} \bar{Y}\left(b^{2}+a c+2 b c\right)$

where $\left.\frac{\partial^{2}\left(\Omega^{-1}\right)_{(2,1)}}{\partial \hat{R}_{1} \partial \hat{R}_{2}}\right|_{\left(\hat{R}_{f}, \bar{\tau}, \bar{v}, \bar{\sigma}\right)}=-b^{2}-a c,\left.\frac{\partial^{2}\left(\Omega^{-1}\right)_{(2,2)}}{\partial \hat{R}_{1} \partial \hat{R}_{2}}\right|_{\left.\overline{\hat{R}}_{f}, \bar{\tau}, \bar{v}, \bar{\sigma}\right)}=-2 b c$

$E\left[\hat{R}_{k}-\hat{R}_{f}+\frac{1}{2}\left(\hat{R}_{k}^{2}-\hat{R}_{f}^{2}\right)\right]=\frac{\bar{\sigma}^{2}}{2}$ for $\mathrm{k}=1,2$, and $E\left[\hat{R}_{k}-\hat{R}_{f}+\frac{1}{2}\left(\hat{R}_{k}^{2}-\hat{R}_{f}^{2}\right)\right]=0$ for

$\mathrm{k}=3, \ldots, \mathrm{N}$, because $\hat{R}_{1}$ and $\hat{R}_{2}$ are only variables and other return terms are considered as the constant.

The sign of $\left.\frac{\partial^{2} \bar{\alpha}_{21}}{\partial \hat{R}_{1} \partial \hat{R}_{2}}\right|_{\left(\hat{R}_{f}, \bar{\tau}, \bar{v}, \bar{\sigma}\right)}<0$

$\left.\frac{\partial^{2} \bar{\alpha}_{21}}{\partial \hat{R}_{1} \partial \hat{R}_{2}}\right|_{\left(\bar{R}_{f}, \bar{\tau}, \bar{v}, \bar{\sigma}\right)}=-\frac{\beta \bar{\sigma}^{2}}{2 \gamma} \bar{Y}\left(b^{2}+a c+2 b c\right)=-\frac{\beta \bar{\sigma}^{2}}{2 \gamma} \bar{Y}\left[b^{2}+2 b c+c^{2}-c^{2}+a c\right]$

$=-\frac{\beta \bar{\sigma}^{2}}{2 \gamma} \bar{Y}\left[(b+c)^{2}+c(a-c)\right]<0 \quad \because a>c>0$

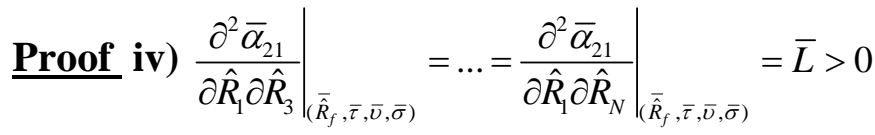


From equation (13),

$$
\begin{aligned}
& \frac{\partial^{2} \bar{\alpha}_{21}}{\partial \hat{R}_{1} \partial \hat{R}_{m}}=\frac{\beta}{\gamma} \bar{Y} \frac{\partial\left(\Omega^{-1}\right)_{(2,1)}}{\partial \hat{R}_{m}}\left(1+\hat{R}_{1}\right)+\frac{\beta}{\gamma} \bar{Y} \sum_{k=1}^{N} \frac{\partial^{2}\left(\Omega^{-1}\right)_{(2, k)}}{\partial \hat{R}_{1} \partial \hat{R}_{m}} E\left[\hat{R}_{k}-\hat{R}_{f}+\frac{1}{2}\left(\hat{R}_{k}^{2}-\hat{R}_{f}^{2}\right)\right]+\frac{\beta}{\gamma} \bar{Y} \frac{\partial\left(\Omega^{-1}\right)_{(2, m)}}{\partial \hat{R}_{1}}\left(1+\hat{R}_{m}\right) \\
& \text { for } \mathrm{m}=1, \ldots, \mathrm{N}
\end{aligned}
$$

a) For $m=3$,

$$
\left.\frac{\partial^{2} \bar{\alpha}_{21}}{\partial \hat{R}_{1} \partial \hat{R}_{3}}\right|_{\left(\bar{R}_{f}, \bar{\tau}, \bar{v}, \bar{\sigma}\right)}=\left.\frac{\beta}{\gamma} Y_{1} \sum_{k=1}^{N} \frac{\partial^{2}\left(\Omega_{1}^{-1}\right)_{(2, k)}}{\partial \hat{R}_{1} \partial \hat{R}_{3}} E\left[\hat{R}_{k}-\hat{R}_{f}+\frac{1}{2}\left(\hat{R}_{k}^{2}-\hat{R}_{f}^{2}\right)\right]\right|_{\left(\bar{R}_{f}, \bar{\tau}, \bar{v}, \bar{\sigma}\right)}
$$

$\left.\frac{\partial \Omega_{1}}{\partial \hat{R}_{3}}\right|_{\left(\hat{R}_{f}, \bar{\tau}, \bar{v}, \bar{\sigma}\right)}=\left(\begin{array}{ccccc}0 & 0 & 0 & \cdots & 0 \\ 0 & 0 & 0 & \cdots & 0 \\ 0 & 0 & 0 & & 0 \\ \vdots & \vdots & & \ddots & \vdots \\ 0 & 0 & & \cdots & 0\end{array}\right)$

Based on the differentiation rule of inverse matrix,

$\left.\frac{\partial^{2} \Omega_{1}^{-1}}{\partial \hat{R}_{1} \partial \hat{R}_{3}}\right|_{\left(\hat{R}_{f}, \bar{\tau}, \bar{\nu}, \bar{\sigma}\right)}=-\left.\Omega_{1}^{-1} \frac{\partial^{2} \Omega_{1}}{\partial \hat{R}_{1} \partial \hat{R}_{3}} \Omega_{1}^{-1}\right|_{\left(\overline{\hat{R}}_{f}, \bar{\tau}, \bar{\nu}, \bar{\sigma}\right)}$ where $\left.\frac{\partial^{2} \Omega_{1}}{\partial \hat{R}_{1} \partial \hat{R}_{3}}\right|_{\left(\overline{\hat{R}}_{f}, \bar{\tau}, \bar{v}, \bar{\sigma}\right)}=\left(\begin{array}{ccccc}0 & 0 & 1 & 0 & 0 \\ 0 & 0 & 0 & \cdots & \vdots \\ 1 & 0 & \ddots & \\ 0 & \vdots & & & \\ 0 & 0 & \cdots & & 0\end{array}\right)$,

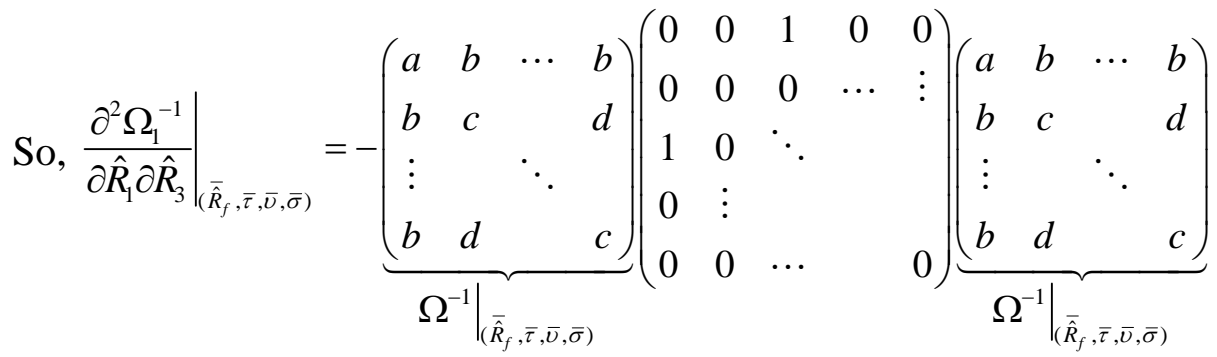

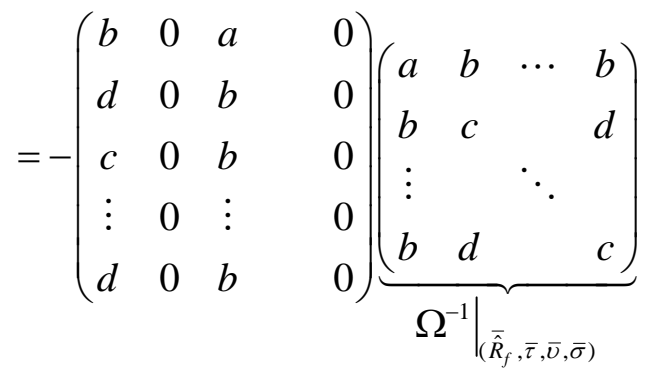

Hence,

$$
\left.\frac{\partial^{2} \bar{\alpha}_{21}}{\partial \hat{R}_{1} \partial \hat{R}_{3}}\right|_{\left.\right|_{\left(\hat{R}_{f}, \bar{\tau}, \bar{v}, \bar{\sigma}\right)}}=\left.\frac{\beta}{\gamma} \bar{Y} \sum_{k=1}^{N} \frac{\partial^{2}\left(\Omega_{1}^{-1}\right)_{(2, k)}}{\partial \hat{R}_{1} \partial \hat{R}_{3}} E\left[\hat{R}_{k}-\hat{R}_{f}+\frac{1}{2}\left(\hat{R}_{k}^{2}-\hat{R}_{f}^{2}\right)\right]\right|_{\left(\overline{\hat{R}}_{f}, \bar{\tau}, \bar{v}, \bar{\sigma}\right)}=-\frac{\beta \bar{\sigma}^{2}}{2 \gamma} \bar{Y}\left(a d+b^{2}+b c+b d\right)
$$


where $\left.\frac{\partial^{2}\left(\Omega^{-1}\right)_{(2,1)}}{\partial \hat{R}_{1} \partial \hat{R}_{3}}\right|_{\left(\bar{R}_{f}, \overline{,}, \overline{,}, \bar{\sigma}\right)}=-a d-b^{2},\left.\frac{\partial^{2}\left(\Omega^{-1}\right)_{(2,3)}}{\partial \hat{R}_{1} \partial \hat{R}_{3}}\right|_{\left.\bar{R}_{R}, \bar{T}, \overline{,}, \bar{\sigma}\right)}=-b d-b c$ $E\left[\hat{R}_{k}-\hat{R}_{f}+\frac{1}{2}\left(\hat{R}_{k}^{2}-\hat{R}_{f}^{2}\right)\right]=\frac{\bar{\sigma}^{2}}{2}$ for $\mathrm{k}=1,3$ and otherwise zero.

b) For m=4, $\left.\frac{\partial^{2} \bar{\alpha}_{21}}{\partial \hat{R}_{1} \partial \hat{R}_{4}}\right|_{\left.\bar{R}_{f}, \bar{\tau}, \bar{\nu}, \bar{\sigma}\right)}=\left.\frac{\beta}{\gamma} Y_{1} \sum_{k=1}^{N} \frac{\partial^{2}\left(\Omega_{1}^{-1}\right)_{(2, k)}}{\partial \hat{R}_{1} \partial \hat{R}_{4}} E\left[\hat{R}_{k}-\hat{R}_{f}+\frac{1}{2}\left(\hat{R}_{k}^{2}-\hat{R}_{f}^{2}\right)\right]\right|_{\left(\bar{R}_{f}, \bar{\tau}, \bar{\nu}, \bar{\sigma}\right)}$ where $\left.\frac{\partial^{2} \Omega_{1}^{-1}}{\partial \hat{R}_{1} \partial \hat{R}_{4}}\right|_{\left.\right|_{\left(\bar{R}_{f}, \bar{\tau}, \bar{\sigma}, \bar{\sigma}\right)}}=-\left.\Omega_{1}^{-1} \frac{\partial^{2} \Omega_{1}}{\partial \hat{R}_{1} \partial \hat{R}_{4}} \Omega_{1}^{-1}\right|_{\left(\bar{R}_{f}, \bar{\tau}, \bar{v}, \bar{\sigma}\right)}$

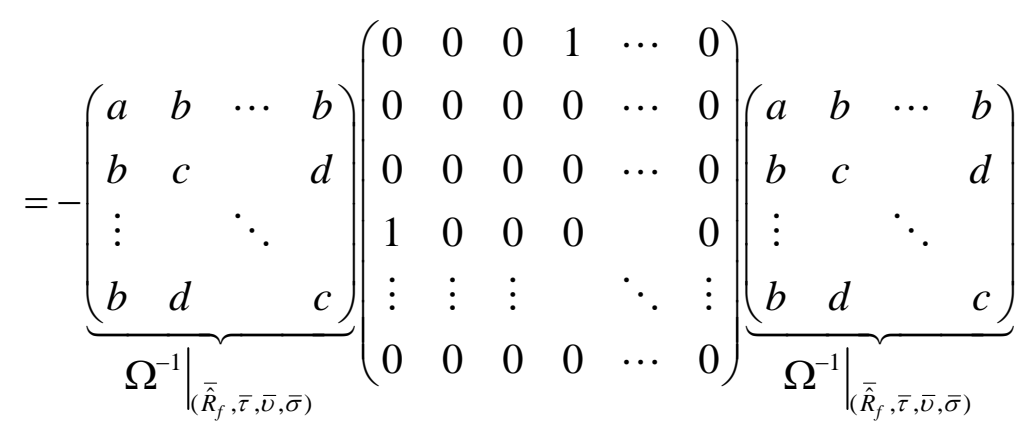

\section{Hence,}

$$
\begin{aligned}
& \left.\frac{\partial^{2} \bar{\alpha}_{21}}{\partial \hat{R}_{1} \partial \hat{R}_{4}}\right|_{\left.\overline{\hat{R}}_{f}, \bar{\tau}, \bar{\nu}, \bar{\sigma}\right)}=\left.\frac{\beta}{\gamma} \bar{Y} \sum_{k=1}^{N} \frac{\partial^{2}\left(\Omega_{1}^{-1}\right)_{(2, k)}}{\partial \hat{R}_{1} \partial \hat{R}_{4}} E\left[\hat{R}_{k}-\hat{R}_{f}+\frac{1}{2}\left(\hat{R}_{k}^{2}-\hat{R}_{f}^{2}\right)\right]\right|_{\overline{\hat{R}}_{\left.\hat{R}_{f}, \bar{\tau}, \bar{\nu}, \bar{\sigma}\right)}}=-\frac{\beta \bar{\sigma}^{2}}{2 \gamma} \bar{Y}\left(a d+b^{2}+b c+b d\right) \\
& \text { where }\left.\frac{\partial^{2}\left(\Omega^{-1}\right)_{(2,1)}}{\partial \hat{R}_{1} \partial \hat{R}_{4}}\right|_{\left.\bar{R}_{f}, \bar{\tau}, \overline{,}, \bar{\sigma}\right)}=-a d-b^{2},\left.\frac{\partial^{2}\left(\Omega^{-1}\right)_{(2,4)}}{\partial \hat{R}_{1} \partial \hat{R}_{4}}\right|_{\bar{R}_{\hat{R}, \overline{,}, \bar{\nu}, \bar{\sigma})}}=-b d-b c \\
& E\left[\hat{R}_{k}-\hat{R}_{f}+\frac{1}{2}\left(\hat{R}_{k}^{2}-\hat{R}_{f}^{2}\right)\right]=\frac{\bar{\sigma}^{2}}{2} \text { for } \mathrm{k}=1,4 \text { and otherwise zero. }
\end{aligned}
$$

Furthermore, for $\mathrm{m}=\mathrm{N}$

$$
\begin{aligned}
& \left.\frac{\partial^{2} \bar{\alpha}_{21}}{\partial \hat{R}_{1} \partial \hat{R}_{m}}\right|_{\left(\hat{R}_{f}, \bar{\tau}, \bar{v}, \bar{\sigma}\right)}=\left.\frac{\beta}{\gamma} \bar{Y} \sum_{k=1}^{N} \frac{\partial^{2}\left(\Omega_{1}^{-1}\right)_{(2, k)}}{\partial \hat{R}_{1} \partial \hat{R}_{m}} E\left[\hat{R}_{k}-\hat{R}_{f}+\frac{1}{2}\left(\hat{R}_{k}^{2}-\hat{R}_{f}^{2}\right)\right]\right|_{\left(\bar{R}_{R}, \bar{\tau}, \bar{v}, \bar{\sigma}\right)}=-\frac{\beta \bar{\sigma}^{2}}{2 \gamma} \bar{Y}\left(a d+b^{2}+b c+b d\right) \\
& \text { where }\left.\frac{\partial^{2}\left(\Omega_{1}^{-1}\right)_{(2,1)}}{\partial \hat{R}_{1} \partial \hat{R}_{N}}\right|_{\left(\bar{R}_{f}, \bar{\tau}, \bar{v}, \bar{\sigma}\right)}=-a d-b^{2},\left.\frac{\partial^{2}\left(\Omega_{1}^{-1}\right)_{(2, N)}}{\partial \hat{R}_{1} \partial \hat{R}_{N}}\right|_{\left(\bar{R}_{f}, \bar{\tau}, \bar{v}, \bar{\sigma}\right)}=-b d-b c
\end{aligned}
$$




$$
E\left[\hat{R}_{k}-\hat{R}_{f}+\frac{1}{2}\left(\hat{R}_{k}^{2}-\hat{R}_{f}^{2}\right)\right]=\frac{\bar{\sigma}^{2}}{2} \text { for } \mathrm{k}=1, \mathrm{~N} \text { and otherwise zero. }
$$

$$
\begin{aligned}
& \text { The sign of }\left.\frac{\partial^{2} \bar{\alpha}_{21}}{\partial \hat{R}_{1} \partial \hat{R}_{3}}\right|_{\left(\hat{R}_{f}, \bar{\tau}, \bar{v}, \bar{\sigma}\right)}=\ldots=\left.\frac{\partial^{2} \bar{\alpha}_{21}}{\partial \hat{R}_{1} \partial \hat{R}_{N}}\right|_{\left(\bar{R}_{f}, \bar{\tau}, \bar{v}, \bar{\sigma}\right)}=\bar{L} \geq 0 \\
& \left.\frac{\partial^{2} \bar{\alpha}_{21}}{\partial \hat{R}_{1} \partial \hat{R}_{m}}\right|_{\left(\hat{R}_{f}, \bar{\tau}, \bar{v}, \bar{\sigma}\right)}=-\frac{\beta \bar{\sigma}^{2}}{2 \gamma} \bar{Y}\left(a d+b^{2}+b c+b d\right)=-\frac{\beta \bar{\sigma}^{2}}{2 \gamma} \bar{Y}\left[\left(a d+b^{2}+b(c+d)\right]\right.
\end{aligned}
$$

The value of each component, $a, b, c, d$, in the inverse covariance matrix is a function of $\bar{\tau}$ which is ranged from 1 to an infinity.

a) When $\bar{\tau}=1, c=a, d=b,\left.\frac{\partial^{2} \bar{\alpha}_{21}}{\partial \hat{R}_{1} \partial \hat{R}_{m}}\right|_{\left(\bar{R}_{f}, \bar{\tau}, \bar{v}, \bar{\sigma}\right)}=-\frac{\beta \bar{\sigma}^{2}}{\gamma} \bar{Y}(b(a+b)) \geq 0 \quad \because b \leq 0$ and $(a+b)>0$ The leading principal minor of the inverse matrix (when $\bar{\tau}=1)$ is positive $\left(a^{2}-b^{2}>0\right)$ due to the property of positive definite matrix, and $a>0 \Rightarrow a+b>0$

b) When $\bar{\tau} \rightarrow \infty, b(\bar{\tau}), \mathrm{c}(\bar{\tau}), d(\bar{\tau}) \rightarrow 0$ except for $a(\bar{\tau})$ based on the inverse matrix calculation, $\left.\frac{\partial^{2} \bar{\alpha}_{21}}{\partial \hat{R}_{1} \partial \hat{R}_{m}}\right|_{\left(\bar{R}_{f}, \bar{\tau}, \bar{v}, \bar{\sigma}\right), \bar{\tau} \rightarrow \infty}=0$

Hence, the sign of $\left.\frac{\partial^{2} \bar{\alpha}_{21}}{\partial \hat{R}_{1} \partial \hat{R}_{m}}\right|_{\left(\bar{R}_{f}, \bar{\tau}, \bar{v}, \bar{\sigma}\right), \bar{\tau} \rightarrow \infty}$ mainly depends on the term $-\frac{\beta \bar{\sigma}^{2}}{2 \gamma} \bar{Y} \cdot \operatorname{ad}(>0)$ as $\bar{\tau}$ becomes bigger.

Therefore, $\left.\frac{\partial^{2} \bar{\alpha}_{21}}{\partial \hat{R}_{1} \partial \hat{R}_{3}}\right|_{\left(\bar{R}_{f}, \bar{\tau}, \bar{v}, \bar{\sigma}\right)}=\ldots=\left.\frac{\partial^{2} \bar{\alpha}_{21}}{\partial \hat{R}_{1} \partial \hat{R}_{N}}\right|_{\left(\bar{R}_{f}, \bar{\tau}, \bar{v}, \bar{\sigma}\right)}=\bar{L} \geq 0$

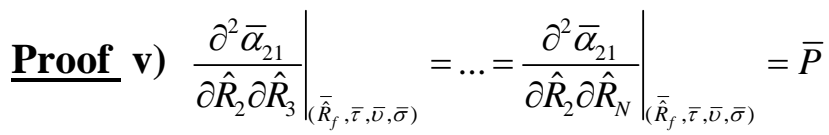

From equation (13),

$$
\frac{\partial^{2} \bar{\alpha}_{21}}{\partial \hat{R}_{2} \partial \hat{R}_{m}}=\frac{\beta}{\gamma} Y_{1} \frac{\partial\left(\Omega_{1}^{-1}\right)_{(2,2)}}{\partial \hat{R}_{m}}\left(1+\hat{R}_{2}\right)+\frac{\beta}{\gamma} Y_{1} \sum_{k=1}^{N} \frac{\partial^{2}\left(\Omega_{1}^{-1}\right)_{(2, k)}}{\partial \hat{R}_{2} \partial \hat{R}_{m}} E\left[\hat{R}_{k}-\hat{R}_{f}+\frac{1}{2}\left(\hat{R}_{k}^{2}-\hat{R}_{f}^{2}\right)\right]+\frac{\beta}{\gamma} Y_{1} \frac{\partial\left(\Omega_{1}^{-1}\right)_{(2, m)}}{\partial \hat{R}_{2}}\left(1+\hat{R}_{m}\right)
$$




$$
\begin{aligned}
& \left.\frac{\partial^{2} \bar{\alpha}_{21}}{\partial \hat{R}_{2} \partial \hat{R}_{m}}\right|_{\left.\bar{R}_{\hat{R},}, \overline{\bar{\tau}}, \overline{\bar{v}}, \bar{\sigma}\right)}=\left.\frac{\beta}{\gamma} Y_{1} \sum_{k=1}^{N} \frac{\partial^{2}\left(\Omega_{1}^{-1}\right)_{(2, k)}}{\partial \hat{R}_{2} \partial \hat{R}_{m}} E\left[\hat{R}_{k}-\hat{R}_{f}+\frac{1}{2}\left(\hat{R}_{k}^{2}-\hat{R}_{f}^{2}\right)\right]\right|_{\left(\bar{R}_{f}, \overline{\bar{\tau}}, \overline{\bar{v}}, \bar{\sigma}\right)} \\
& \text { because }\left.\frac{\partial \Omega_{1}}{\partial \hat{R}_{m}}\right|_{\left(\overline{\hat{R}}_{f}, \overline{\bar{\tau}}, \overline{\bar{v}}, \bar{\sigma}\right)}=\left(\begin{array}{ccccc}
0 & 0 & 0 & \cdots & 0 \\
0 & 0 & 0 & \cdots & 0 \\
0 & 0 & 0 & & 0 \\
\vdots & \vdots & & \ddots & \vdots \\
0 & 0 & \cdots & 0
\end{array}\right)
\end{aligned}
$$

So,

a) For m=3, $\left.\frac{\partial^{2} \bar{\alpha}_{21}}{\partial \hat{R}_{2} \partial \hat{R}_{3}}\right|_{\left(\overline{\hat{R}}_{f}, \bar{\tau}, \bar{v}, \bar{\sigma}\right)}=\left.\frac{\beta}{\gamma} Y_{1} \sum_{k=1}^{N} \frac{\partial^{2}\left(\Omega_{1}^{-1}\right)_{(2, k)}}{\partial \hat{R}_{2} \partial \hat{R}_{3}} E\left[\hat{R}_{k}-\hat{R}_{f}+\frac{1}{2}\left(\hat{R}_{k}^{2}-\hat{R}_{f}^{2}\right)\right]\right|_{\left(\bar{R}_{f}, \bar{\tau}, \bar{v}, \bar{\sigma}\right)}$

where $\left.\frac{\partial^{2} \Omega_{1}^{-1}}{\partial \hat{R}_{2} \partial \hat{R}_{3}}\right|_{\left.\right|_{\left.\bar{R}_{f}, \bar{\tau}, \bar{\nu}, \bar{\sigma}\right)}}=-\left.\Omega_{1}^{-1} \frac{\partial^{2} \Omega_{1}}{\partial \hat{R}_{2} \partial \hat{R}_{3}} \Omega_{1}^{-1}\right|_{\left(\bar{R}_{f}, \bar{\tau}, \bar{\nu}, \bar{\sigma}\right)}$

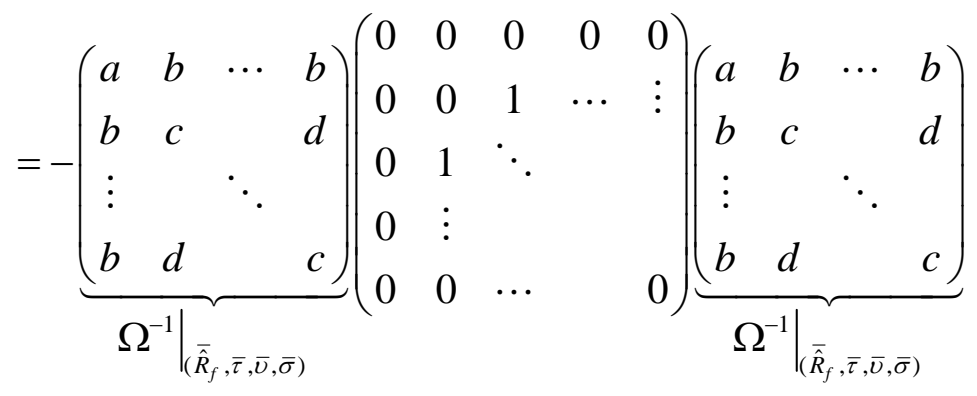

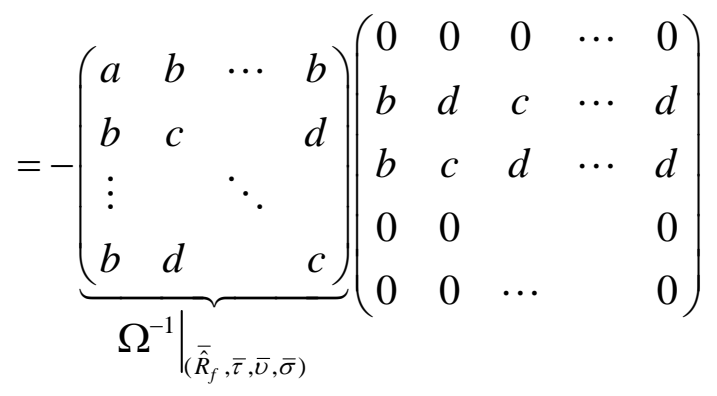

$\left.\frac{\partial^{2} \bar{\alpha}_{21}}{\partial \hat{R}_{2} \partial \hat{R}_{3}}\right|_{\hat{\hat{R}}_{\hat{R}, \bar{\tau}, \bar{v}, \bar{\sigma})}}=\frac{\beta}{\gamma} Y_{1} \sum_{k=1}^{N} \frac{\partial^{2}\left(\Omega_{1}^{-1}\right)_{(2, k)}}{\partial \hat{R}_{2} \partial \hat{R}_{3}} E\left[\hat{R}_{k}-\hat{R}_{f}+\left.\frac{1}{2}\left(\hat{R}_{k}^{2}-\hat{R}_{f}^{2}\right)\right|_{\left.\right|_{\left.\bar{R}_{f}, \bar{\tau}, \bar{\nu}, \bar{\sigma}\right)}}=-\frac{\beta \bar{\sigma}^{2}}{2 \gamma} \bar{Y}(c+d)(b+c+d)\right.$

where $\left.\frac{\partial^{2}\left(\Omega^{-1}\right)_{(2,1)}}{\partial \hat{R}_{2} \partial \hat{R}_{3}}\right|_{\left(\bar{R}_{f}, \bar{\tau}, \bar{\nu}, \bar{\sigma}\right)}=-b c-b d,\left.\frac{\partial^{2}\left(\Omega^{-1}\right)_{(2,2)}}{\partial \hat{R}_{2} \partial \hat{R}_{3}}\right|_{\left(\bar{R}_{f}, \bar{\tau}, \bar{\sigma}, \bar{\sigma}\right)}=-2 c d,\left.\frac{\partial^{2}\left(\Omega^{-1}\right)_{(2,3)}}{\partial \hat{R}_{2} \partial \hat{R}_{3}}\right|_{\left(\hat{R}_{f}, \bar{T}, \bar{v}, \bar{\sigma}\right)}=-c^{2}-d^{2}$ $E\left[\hat{R}_{k}-\hat{R}_{f}+\frac{1}{2}\left(\hat{R}_{k}^{2}-\hat{R}_{f}^{2}\right)\right]=\frac{\bar{\sigma}^{2}}{2}$ for $\mathrm{k}=1,2,3$ and otherwise zero. 
b) For $\mathrm{m}=4,\left.\frac{\partial^{2} \bar{\alpha}_{21}}{\partial \hat{R}_{2} \partial \hat{R}_{4}}\right|_{\left.\overline{\hat{R}}_{f}, \bar{\tau}, \bar{\nu}, \bar{\sigma}\right)}=\left.\frac{\beta}{\gamma} Y_{1} \sum_{k=1}^{N} \frac{\partial^{2}\left(\Omega_{1}^{-1}\right)_{(2, k)}}{\partial \hat{R}_{2} \partial \hat{R}_{4}} E\left[\hat{R}_{k}-\hat{R}_{f}+\frac{1}{2}\left(\hat{R}_{k}^{2}-\hat{R}_{f}^{2}\right)\right]\right|_{\left(\bar{R}_{f}, \bar{\tau}, \bar{v}, \bar{\sigma}\right)}$

where $\left.\frac{\partial^{2} \Omega_{1}^{-1}}{\partial \hat{R}_{2} \partial \hat{R}_{4}}\right|_{\left(\bar{R}_{f}, \bar{\tau}, \bar{v}, \bar{\sigma}\right)}=-\left.\Omega_{1}^{-1} \frac{\partial^{2} \Omega_{1}}{\partial \hat{R}_{2} \partial \hat{R}_{4}} \Omega_{1}^{-1}\right|_{\left(\bar{R}_{f}, \bar{\tau}, \bar{v}, \bar{\sigma}\right)}$

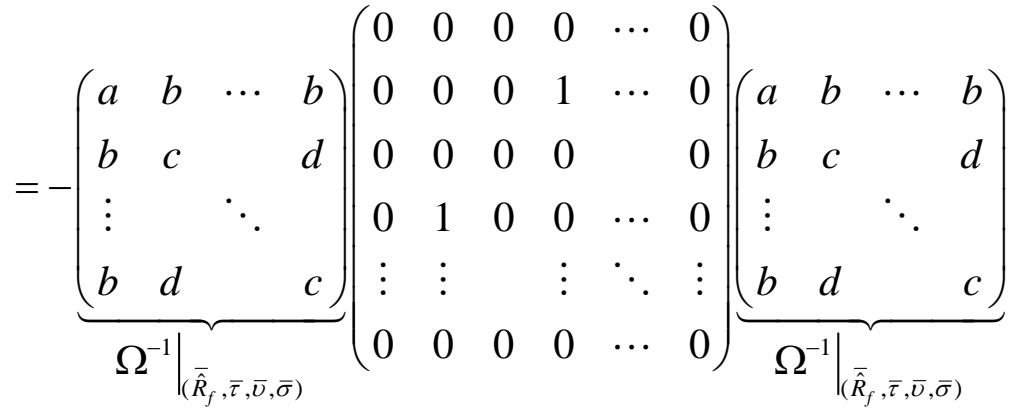

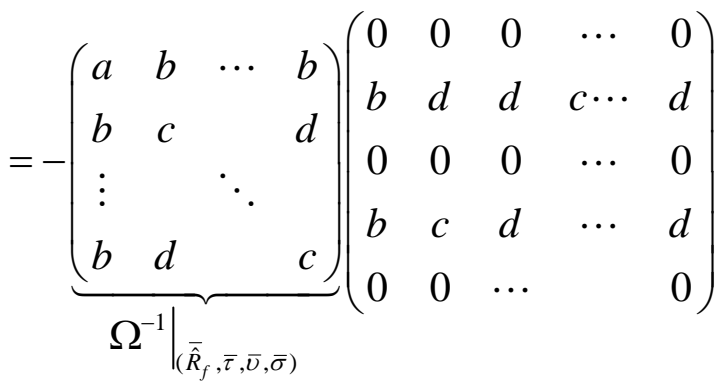

\section{Hence,}

$\left.\frac{\partial^{2} \bar{\alpha}_{21}}{\partial \hat{R}_{2} \partial \hat{R}_{4}}\right|_{\left(\bar{R}_{f}, \bar{\tau}, \bar{v}, \bar{\sigma}\right)}=\left.\frac{\beta}{\gamma} Y_{1} \sum_{k=1}^{N} \frac{\partial^{2}\left(\Omega_{1}^{-1}\right)_{(2, k)}}{\partial \hat{R}_{2} \partial \hat{R}_{4}} E\left[\hat{R}_{k}-\hat{R}_{f}+\frac{1}{2}\left(\hat{R}_{k}^{2}-\hat{R}_{f}^{2}\right)\right]\right|_{\left.\overline{\hat{R}}_{f}, \overline{\bar{t}}, \bar{\nu}, \bar{\sigma}\right)}=-\frac{\beta \bar{\sigma}^{2}}{2 \gamma} \bar{Y}(c+d)(b+c+d)$

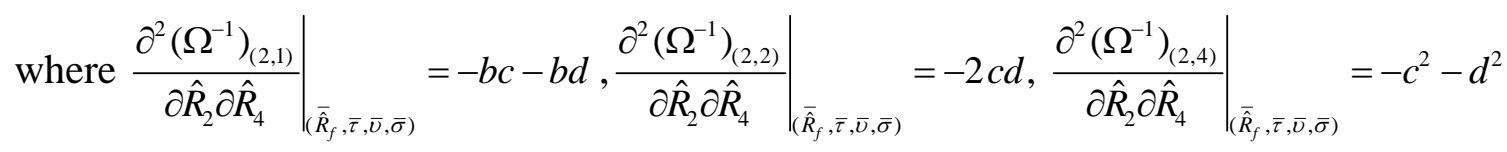

$E\left[\hat{R}_{k}-\hat{R}_{f}+\frac{1}{2}\left(\hat{R}_{k}^{2}-\hat{R}_{f}^{2}\right)\right]=\frac{\bar{\sigma}^{2}}{2}$ for $\mathrm{k}=1,2,4$ and otherwise zero.

Furthermore,

$$
\begin{aligned}
& \left.\frac{\partial^{2} \bar{\alpha}_{21}}{\partial \hat{R}_{2} \partial \hat{R}_{m}}\right|_{\left(\bar{R}_{f}, \bar{\tau}, \bar{v}, \bar{\sigma}\right)}=\left.\frac{\beta}{\gamma} Y_{1} \sum_{k=1}^{N} \frac{\partial^{2}\left(\Omega_{1}^{-1}\right)_{(2, k)}}{\partial \hat{R}_{2} \partial \hat{R}_{m}} E\left[\hat{R}_{k}-\hat{R}_{f}+\frac{1}{2}\left(\hat{R}_{k}^{2}-\hat{R}_{f}^{2}\right)\right]\right|_{\left.\overline{\hat{R}}_{f}, \bar{\tau}, \bar{\nu}, \bar{\sigma}\right)}=-\frac{\beta \bar{\sigma}^{2}}{2 \gamma} \bar{Y}(c+d)(b+c+d)
\end{aligned}
$$

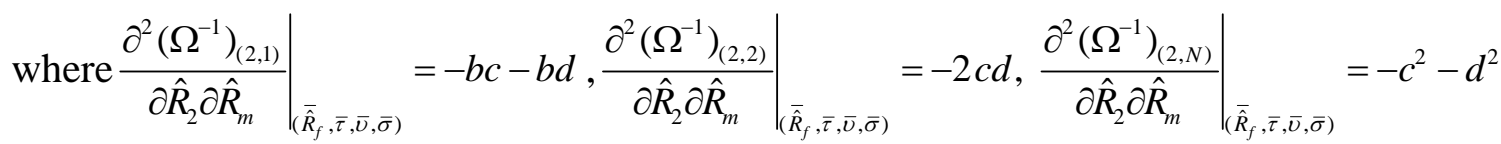




$$
E\left[\hat{R}_{k}-\hat{R}_{f}+\frac{1}{2}\left(\hat{R}_{k}^{2}-\hat{R}_{f}^{2}\right)\right]=\frac{\bar{\sigma}^{2}}{2} \text { for } \mathrm{k}=1,2, \mathrm{~m} \text { and otherwise zero. }
$$

Therefore, $\left.\frac{\partial^{2} \bar{\alpha}_{21}}{\partial \hat{R}_{2} \partial \hat{R}_{3}}\right|_{\left(\bar{R}_{f}, \bar{\tau}, \bar{v}, \bar{\sigma}\right)}=\ldots=\left.\frac{\partial^{2} \bar{\alpha}_{21}}{\partial \hat{R}_{2} \partial \hat{R}_{N}}\right|_{\left(\bar{R}_{f}, \bar{\tau}, \bar{v}, \bar{\sigma}\right)}=\bar{P}$

$$
\begin{aligned}
& \text { The sign of }\left.\frac{\partial^{2} \bar{\alpha}_{21}}{\partial \hat{R}_{2} \partial \hat{R}_{m}}\right|_{\left(\bar{R}_{f}, \bar{\tau}, \bar{v}, \bar{\sigma}\right)}=\bar{P}>0 \text { if } b+c+d<0 \\
& \left.\frac{\partial^{2} \bar{\alpha}_{21}}{\partial \hat{R}_{2} \partial \hat{R}_{m}}\right|_{\left(\overline{\hat{R}}_{f}, \bar{\tau}, \bar{v}, \bar{\sigma}\right)}=-\frac{\beta \bar{\sigma}^{2}}{2 \gamma} \bar{Y} \cdot(c+d)(b+c+d)>0 \quad \text { if } \quad b+c+d<0 \\
& \because\left(c^{2}-d^{2}\right)>0 \text { and } c>0 \Rightarrow c+d>0
\end{aligned}
$$

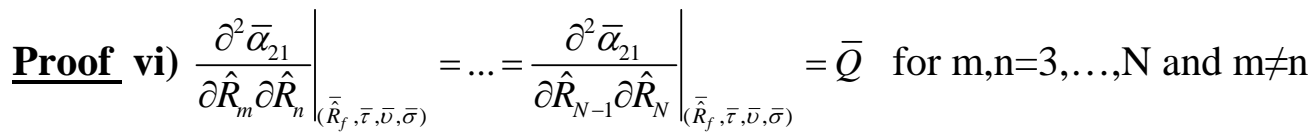

From equation (13),

$$
\frac{\partial^{2} \bar{\alpha}_{21}}{\partial \hat{R}_{m} \partial \hat{R}_{n}}=\frac{\beta}{\gamma} Y_{1} \frac{\partial\left(\Omega_{1}^{-1}\right)_{(2, \mathrm{n})}}{\partial \hat{R}_{m}}\left(1+\hat{R}_{n}\right)+\frac{\beta}{\gamma} Y_{1} \sum_{k=1}^{N} \frac{\partial^{2}\left(\Omega_{1}^{-1}\right)_{(2, k)}}{\partial \hat{R}_{m} \partial \hat{R}_{n}} E\left[\hat{R}_{k}-\hat{R}_{f}+\frac{1}{2}\left(\hat{R}_{k}^{2}-\hat{R}_{f}^{2}\right)\right]+\frac{\beta}{\gamma} Y_{1} \frac{\partial\left(\Omega_{1}^{-1}\right)_{(2, m)}}{\partial \hat{R}_{n}}\left(1+\hat{R}_{m}\right)
$$

for $m, n=3, \ldots, N$ and $m \neq n$

a) For $m=3$ and $n=4$,

$$
\left.\frac{\partial^{2} \bar{\alpha}_{21}}{\partial \hat{R}_{3} \partial \hat{R}_{4}}\right|_{\left(\bar{R}_{f}, \bar{\tau}, \bar{v}, \bar{\sigma}\right)}=\left.\frac{\beta}{\gamma} Y_{1} \sum_{k=1}^{N} \frac{\partial^{2}\left(\Omega_{1}^{-1}\right)_{(2, k)}}{\partial \hat{R}_{3} \partial \hat{R}_{4}} E\left[\hat{R}_{k}-\hat{R}_{f}+\frac{1}{2}\left(\hat{R}_{k}^{2}-\hat{R}_{f}^{2}\right)\right]\right|_{\left(\overline{\hat{R}}_{f}, \bar{\tau}, \bar{v}, \bar{\sigma}\right)}
$$

because $\left.\frac{\partial \Omega_{1}}{\partial \hat{R}_{m}}\right|_{\left(\overline{\hat{R}}_{f}, \bar{\tau}, \bar{v}, \bar{\sigma}\right)}=\left(\begin{array}{ccccc}0 & 0 & 0 & \cdots & 0 \\ 0 & 0 & 0 & \cdots & 0 \\ 0 & 0 & 0 & & 0 \\ \vdots & \vdots & & \ddots & \vdots \\ 0 & 0 & & \cdots & 0\end{array}\right)$

Based on the differentiation rule of inverse matrix, 


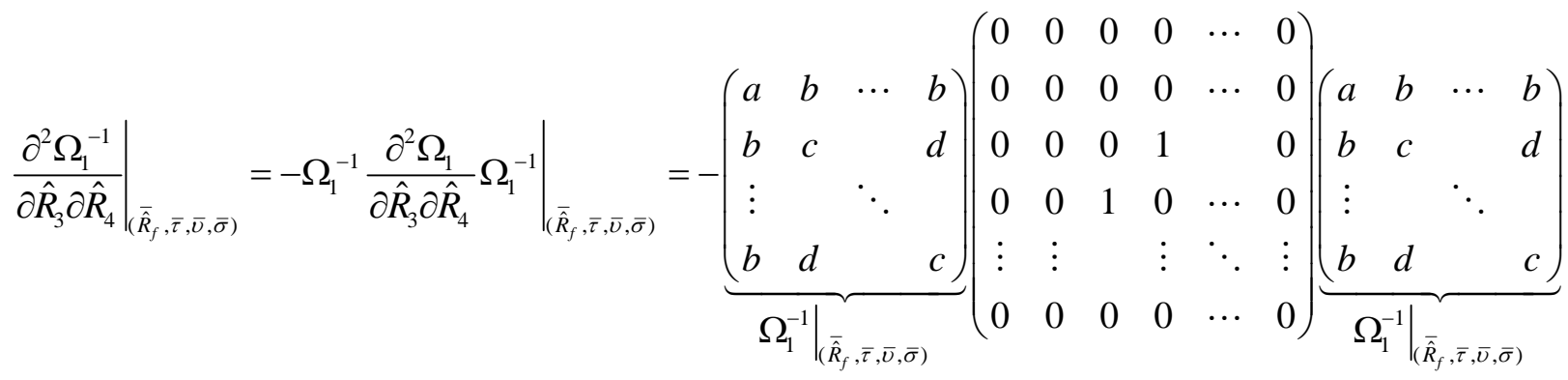

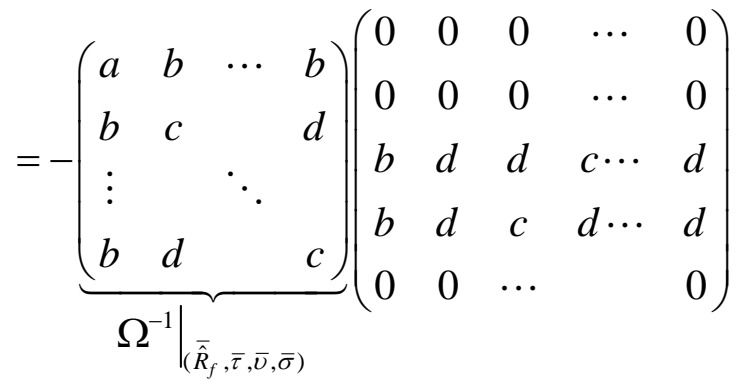

Hence,

$$
\begin{aligned}
& \left.\frac{\partial^{2} \bar{\alpha}_{21}}{\partial \hat{R}_{3} \partial \hat{R}_{4}}\right|_{\left.\bar{R}_{f}, \bar{\tau}, \bar{v}, \bar{\sigma}\right)}=\left.\frac{\beta}{\gamma} Y_{1} \sum_{k=1}^{N} \frac{\partial^{2}\left(\Omega_{1}^{-1}\right)_{(2, k)}}{\partial \hat{R}_{3} \partial \hat{R}_{4}} E\left[\hat{R}_{k}-\hat{R}_{f}+\frac{1}{2}\left(\hat{R}_{k}^{2}-\hat{R}_{f}^{2}\right)\right]\right|_{\left.\overline{\hat{R}}_{f}, \bar{\tau}, \bar{v}, \bar{\sigma}\right)}=-\frac{\beta \bar{\sigma}^{2}}{\gamma} \bar{Y} \cdot d(b+c+d) \\
& \text { where }\left.\frac{\partial^{2}\left(\Omega^{-1}\right)_{(2,1)}}{\partial \hat{R}_{3} \partial \hat{R}_{4}}\right|_{\left(\bar{R}_{f}, \bar{\tau}, \bar{v}, \bar{\sigma}\right)}=-2 b d ;\left.\frac{\partial^{2}\left(\Omega^{-1}\right)_{(2,3)}}{\partial \hat{R}_{3} \partial \hat{R}_{4}}\right|_{\left(\bar{R}_{f}, \bar{\tau}, \bar{v}, \bar{\sigma}\right)}=\left.\frac{\partial^{2}\left(\Omega^{-1}\right)_{(2,4)}}{\partial \hat{R}_{3} \partial \hat{R}_{4}}\right|_{\left(\bar{R}_{f}, \bar{\tau}, \bar{v}, \bar{\sigma}\right)}=-d^{2}-c d \\
& E\left[\hat{R}_{k}-\hat{R}_{f}+\frac{1}{2}\left(\hat{R}_{k}^{2}-\hat{R}_{f}^{2}\right)\right]=\frac{\bar{\sigma}^{2}}{2} \text { for } \mathrm{k}=1,3,4 \text { and otherwise zero. }
\end{aligned}
$$

b) For $m=4$ and $n=5$,

$$
\begin{aligned}
& \left.\frac{\partial^{2} \bar{\alpha}_{21}}{\partial \hat{R}_{4} \partial \hat{R}_{5}}\right|_{\left(\bar{R}_{f}, \bar{\tau}, \bar{v}, \bar{\sigma}\right)}=\left.\frac{\beta}{\gamma} \sum_{k=1}^{N} \frac{\partial^{2}\left(\Omega_{1}^{-1}\right)_{(2, k)}}{\partial \hat{R}_{4} \partial \hat{R}_{5}} E\left[\hat{R}_{k}-\hat{R}_{f}+\frac{1}{2}\left(\hat{R}_{k}^{2}-\hat{R}_{f}^{2}\right)\right]\right|_{\left(\hat{R}_{f}, \bar{\tau}, \bar{v}, \bar{\sigma}\right)} \\
& \text { because }\left.\frac{\partial \Omega_{1}}{\partial \hat{R}_{m}}\right|_{\left(\bar{R}_{f}, \bar{\tau}, \bar{v}, \bar{\sigma}\right)}=\left(\begin{array}{ccccc}
0 & 0 & 0 & \cdots & 0 \\
0 & 0 & 0 & \cdots & 0 \\
0 & 0 & 0 & & 0 \\
\vdots & \vdots & & \ddots & \vdots \\
0 & 0 & & \cdots & 0
\end{array}\right)
\end{aligned}
$$

Based on the differentiation rule of inverse matrix, 


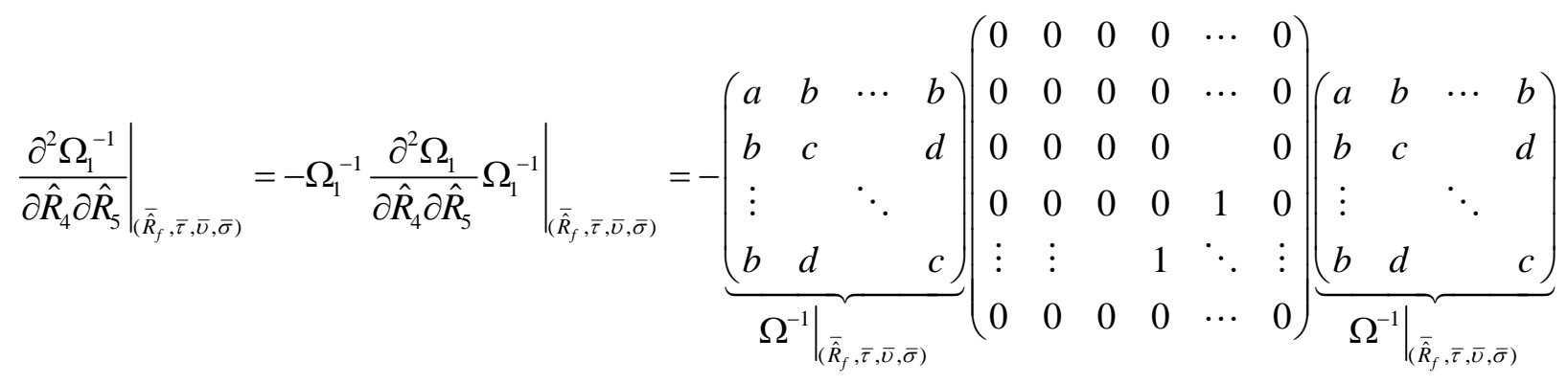

Hence

$$
\begin{aligned}
& \left.\frac{\partial^{2} \bar{\alpha}_{21}}{\partial \hat{R}_{4} \partial \hat{R}_{5}}\right|_{\left(\bar{R}_{f}, \bar{\tau}, \bar{v}, \bar{\sigma}\right)}=\left.\frac{\beta}{\gamma} Y_{1} \sum_{k=1}^{N} \frac{\partial^{2}\left(\Omega_{1}^{-1}\right)_{(2, k)}}{\partial \hat{R}_{4} \partial \hat{R}_{5}} E\left[\hat{R}_{k}-\hat{R}_{f}+\frac{1}{2}\left(\hat{R}_{k}^{2}-\hat{R}_{f}^{2}\right)\right]\right|_{\left(\hat{R}_{f}, \bar{\tau}, \bar{v}, \bar{\sigma}\right)}=-\frac{\beta \bar{\sigma}^{2}}{\gamma} \bar{Y} \cdot d(b+c+d) \\
& \text { where }\left.\frac{\partial^{2}\left(\Omega^{-1}\right)_{(2,1)}}{\partial \hat{R}_{4} \partial \hat{R}_{5}}\right|_{\left(\bar{R}_{f}, \bar{\tau}, \bar{v}, \bar{\sigma}\right)}=-2 b d,\left.\frac{\partial^{2}\left(\Omega_{1}^{-1}\right)_{(2,4)}}{\partial \hat{R}_{4} \partial \hat{R}_{5}}\right|_{\left(\hat{R}_{f}, \bar{\tau}, \bar{v}, \bar{\sigma}\right)}=\left.\frac{\partial^{2}\left(\Omega_{1}^{-1}\right)_{(2,5)}}{\partial \hat{R}_{4} \partial \hat{R}_{5}}\right|_{\left(\overline{\hat{R}}_{f}, \bar{\tau}, \bar{v}, \bar{\sigma}\right)}=-d^{2}-c d \\
& \qquad E\left[\hat{R}_{k}-\hat{R}_{f}+\frac{1}{2}\left(\hat{R}_{k}^{2}-\hat{R}_{f}^{2}\right)\right]=\frac{\bar{\sigma}^{2}}{2} \text { for } \mathrm{k}=1,4,5 \text { and otherwise zero. }
\end{aligned}
$$

So, we conjecture the cases for $m, n=3, \ldots, N$ and $m \neq n$

$$
\begin{aligned}
& \left.\frac{\partial^{2} \bar{\alpha}_{21}}{\partial \hat{R}_{m} \partial \hat{R}_{n}}\right|_{\left(\bar{R}_{f}, \bar{\tau}, \bar{v}, \bar{\sigma}\right)}=\left.\frac{\beta}{\gamma} Y_{1} \sum_{k=1}^{N} \frac{\partial^{2}\left(\Omega_{1}^{-1}\right)_{(2, k)}}{\partial \hat{R}_{m} \partial \hat{R}_{n}} E\left[\hat{R}_{k}-\hat{R}_{f}+\frac{1}{2}\left(\hat{R}_{k}^{2}-\hat{R}_{f}^{2}\right)\right]\right|_{\left(\bar{R}_{f}, \bar{\tau}, \bar{v}, \bar{\sigma}\right)}=-\frac{\beta \bar{\sigma}^{2}}{\gamma} \bar{Y} \cdot d(b+c+d) \\
& \text { where }\left.\frac{\partial^{2}\left(\Omega^{-1}\right)_{(2,1)}}{\partial \hat{R}_{m} \partial \hat{R}_{n}}\right|_{\left(\bar{R}_{f}, \bar{\tau}, \bar{v}, \bar{\sigma}\right)}=-2 b d,\left.\frac{\partial^{2}\left(\Omega_{1}^{-1}\right)_{(2, m)}}{\partial \hat{R}_{m} \partial \hat{R}_{n}}\right|_{\left(\hat{R}_{f}, \bar{\tau}, \bar{v}, \bar{\sigma}\right)}=\left.\frac{\partial^{2}\left(\Omega_{1}^{-1}\right)_{(2, \mathrm{n})}}{\partial \hat{R}_{m} \partial \hat{R}_{n}}\right|_{\left(\hat{R}_{f}, \bar{\tau}, \bar{v}, \bar{\sigma}\right)}=-d^{2}-c d \\
& E\left[\hat{R}_{k}-\hat{R}_{f}+\frac{1}{2}\left(\hat{R}_{k}^{2}-\hat{R}_{f}^{2}\right)\right]=\frac{\bar{\sigma}^{2}}{2} \text { for } \mathrm{k}=1, \mathrm{~m}, \mathrm{n} \text { and otherwise zero. }
\end{aligned}
$$

Therefore, $\left.\frac{\partial^{2} \bar{\alpha}_{21}}{\partial \hat{R}_{m} \partial \hat{R}_{n}}\right|_{\left(\bar{R}_{f}, \bar{\tau}, \bar{\nu}, \bar{\sigma}\right)}=\ldots=\left.\frac{\partial^{2} \bar{\alpha}_{21}}{\partial \hat{R}_{N-1} \partial \hat{R}_{N}}\right|_{\left(\bar{R}_{f}, \bar{\tau}, \bar{\nu}, \bar{\sigma}\right)}=\bar{Q}$ for $\mathrm{m}, \mathrm{n}=3, \ldots, \mathrm{N}$ and $\mathrm{m} \neq \mathrm{n}$.

(Q.E.D)

$$
\begin{gathered}
\text { The sign of }\left.\frac{\partial^{2} \bar{\alpha}_{21}}{\partial \hat{R}_{m} \partial \hat{R}_{n}}\right|_{\left(\hat{R}_{f}, \bar{\tau}, \bar{v}, \bar{\sigma}\right)}=\bar{Q} \leq 0 \text { if } b+c+d<0 \\
\begin{array}{c}
\left.\frac{\partial^{2} \bar{\alpha}_{21}}{\partial \hat{R}_{2} \partial \hat{R}_{m}}\right|_{\left(\bar{R}_{f}, \bar{\tau}, \bar{v}, \bar{\sigma}\right)} \quad=-\frac{\beta \bar{\sigma}^{2}}{\gamma} \bar{Y} \cdot d(b+c+d) \leq 0 \text { if } b+c+d<0 \\
\because d \leq 0
\end{array}
\end{gathered}
$$




\section{F. List of Countries}

Source country (64)

Argentina*, Australia*, Austria, Bahamas, Bahrain, Barbados, Belgium*, Bermuda, Brazil*, Bulgaria, Canada*, Chile*, Colombia*, Costa Rica, Cyprus, Czech Republic*, Denmark*, Egypt, Estonia, Finland*, France*, Germany*, Greece*, Hong Kong*, Hungary*, Iceland*, India*, Indonesia*, Ireland*, Israel*, Italy*, Japan*, Kazakhstan, Korea, Rep. of*, Kuwait, Lebanon, Luxembourg, Macao (China), Malaysia*, Malta, Mauritius, Mexico*, Netherlands*, New Zealand*, Norway*, Pakistan, Panama, Philippines*, Poland*, Portugal*, Russia, Singapore, Slovakia*, South Africa*, Spain*, Sweden*, Switzerland*, Thailand*, Turkey*, Ukraine, United Kingdom*, United States*, Uruguay, Venezuela

Destination county (141) : 77 world countries +64 Source countries

64 Source countries, Albania, Algeria, Angola, Armenia, Bangladesh*, Belarus, Belize, Benin, Bolivia, Bosnia, Botswana, Brunei, Burkina Faso, Burundi, Cambodia, Cameroon, Cape Verde, Central African Rep., China*, Congo Rep., Democratic Rep. of Congo, Cote d'Ivoire, Croatia*, Cuba, Dominica, Dominican Republic, Ecuador, El Salvador, Eritrea, Fiji, Gabon, Georgia, Ghana, Guatemala, Guinea, Guinea-Bissau, Honduras, Iran, Jamaica, Jordan, Kenya*, Latvia, Liberia, Libya, Lithuania*, Madagascar, Malawi, Maldives, Mali, Morocco*, Mozambique, Nicaragua, Niger, Oman, Papua New Guinea, Paraguay, Peru, Qatar, Romania*, Saudi Arabia*, Senegal, Seychelles, Slovenia, Sri Lanka*, St.Vincent \& Grenadines, Sudan, Swaziland, Tanzania, Togo, Tunisia, Trinidad \& Tobago, Uganda, Ukraine, UAE, Vietnam, Zambia, Zimbabwe

Note: * represents 49 countries that equity return correlation data are available 


\section{G. Summary statistics and Correlation among main variables}

i) Summary statistics

\begin{tabular}{|c|c|c|c|c|c|}
\hline & Obs. & Mean & S.D. & Min. & Max. \\
\hline $\ln \left(\right.$ equity holdings $\mathrm{s}_{\mathrm{ij}}$ ) & 1064 & 12.308 & 3.161 & 6.876 & 20.297 \\
\hline$E Q C O V_{i j}$ & 1064 & 0.022 & 0.025 & -0.111 & 0.174 \\
\hline $\operatorname{Var}_{i}$ & 1064 & 0.086 & 0.181 & 0.001 & 1.315 \\
\hline $\operatorname{Var}_{j}$ & 1064 & 0.191 & 0.406 & 0.001 & 1.887 \\
\hline Multilateral Effects $\left(M T_{i j}\right)$ & 1064 & 0.712 & 0.395 & 0.013 & 1.651 \\
\hline Destination Effects $\left(D T_{i}\right)$ & 1064 & 0.627 & 4.047 & 0 & 2.427 \\
\hline $\begin{array}{l}\text { Stock market capitalization } \\
\text { (log) (source*host/ world) }\end{array}$ & 1064 & 14.944 & 2.126 & 7.814 & 21.266 \\
\hline $\begin{array}{l}\text { Equity Market Liberalization } \\
\text { (Bekaert et al. 2005) }\end{array}$ & 1064 & 0.897 & 0.305 & 0 & 1 \\
\hline $\begin{array}{l}\text { Capital Account Openness } \\
\text { (Chinn and Ito, 2006) }\end{array}$ & 1064 & 13.958 & 6.137 & 0.707 & 19.854 \\
\hline $\begin{array}{l}\text { Capital Account Openness } \\
\text { (Quinn 1997) }\end{array}$ & 753 & 0.740 & 0.253 & 0.141 & 1 \\
\hline Border & 1064 & 0.055 & 0.227 & 0 & 1 \\
\hline (log) Distance & 1064 & 7.871 & 1.034 & 4.765 & 9.393 \\
\hline Common Language & 1064 & 0.135 & 0.342 & 0 & 1 \\
\hline Colony & 1064 & 0.033 & 0.178 & 0 & 1 \\
\hline Common colonizer & 1064 & 0.008 & 0.086 & 0 & 1 \\
\hline Currency Union & 1064 & 0.075 & 0.264 & 0 & 1 \\
\hline Longitude difference & 1064 & 65.606 & 57.160 & 0 & 271 \\
\hline OECD & 1064 & 0.539 & 0.499 & 0 & 1 \\
\hline Common Legal Origin & 1064 & 0.295 & 0.456 & 0 & 1 \\
\hline Tax treaty & 1064 & 0.662 & 0.473 & 0 & 1 \\
\hline (log) Bilateral trade/sum of GDP & 1064 & -6.291 & 1.381 & -12.164 & -2.262 \\
\hline
\end{tabular}

ii) Correlation among key variables 


\begin{tabular}{lcccccccc}
\hline & $\ln \left(\mathrm{eq}_{\mathrm{ij}}\right)$ & $E$ & $\operatorname{Var}_{\mathrm{i}}$ & $\mathrm{Var}_{\mathrm{j}}$ & $\mathrm{MT}_{\mathrm{ij}}$ & $\mathrm{DT}_{\mathrm{ij}}$ & $\begin{array}{c}\text { Stock mkt } \\
\text { Cap }\end{array}$ & $\mathrm{EQ} \mathrm{LIB}$ \\
\hline $\ln \left(\mathrm{eq}_{\mathrm{ij}}\right)$ & 1.000 & & & & & & & \\
EQCOV $_{i j}$ & -0.110 & 1.000 & & & & & & \\
$\operatorname{Var}_{\mathrm{i}}$ & -0.238 & 0.343 & 1.000 & & & & & \\
$\operatorname{Var}_{\mathrm{j}}$ & -0.086 & 0.308 & -0.025 & 1.000 & & & & \\
$\mathrm{MT}_{\mathrm{ij}}$ & 0.114 & 0.310 & 0.200 & -0.010 & 1.000 & & & \\
$\mathrm{DT}_{\mathrm{ij}}$ & 0.071 & 0.490 & -0.024 & 0.471 & -0.096 & 1.000 & & \\
Stock mkt cap & 0.637 & -0.096 & -0.104 & -0.103 & 0.082 & 0.059 & 1.000 & \\
EQ & 0.318 & 0.110 & -0.010 & 0.029 & 0.068 & 0.231 & 0.374 & 1.000 \\
Liberalization & & & & & & & & \\
\hline
\end{tabular}

